ISSN: $1688-9266$

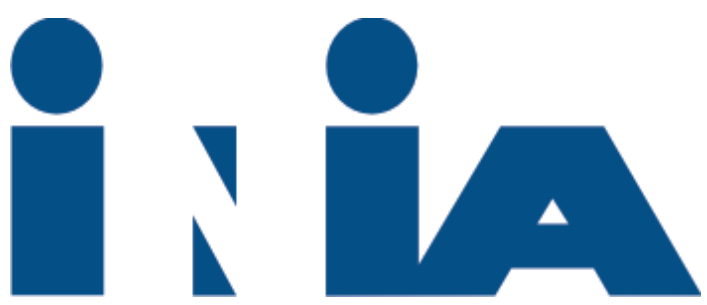

INSTITUTO NACIONAL DE
INVESTIGACIÓN
AGROPECUARIA

URUGUAY
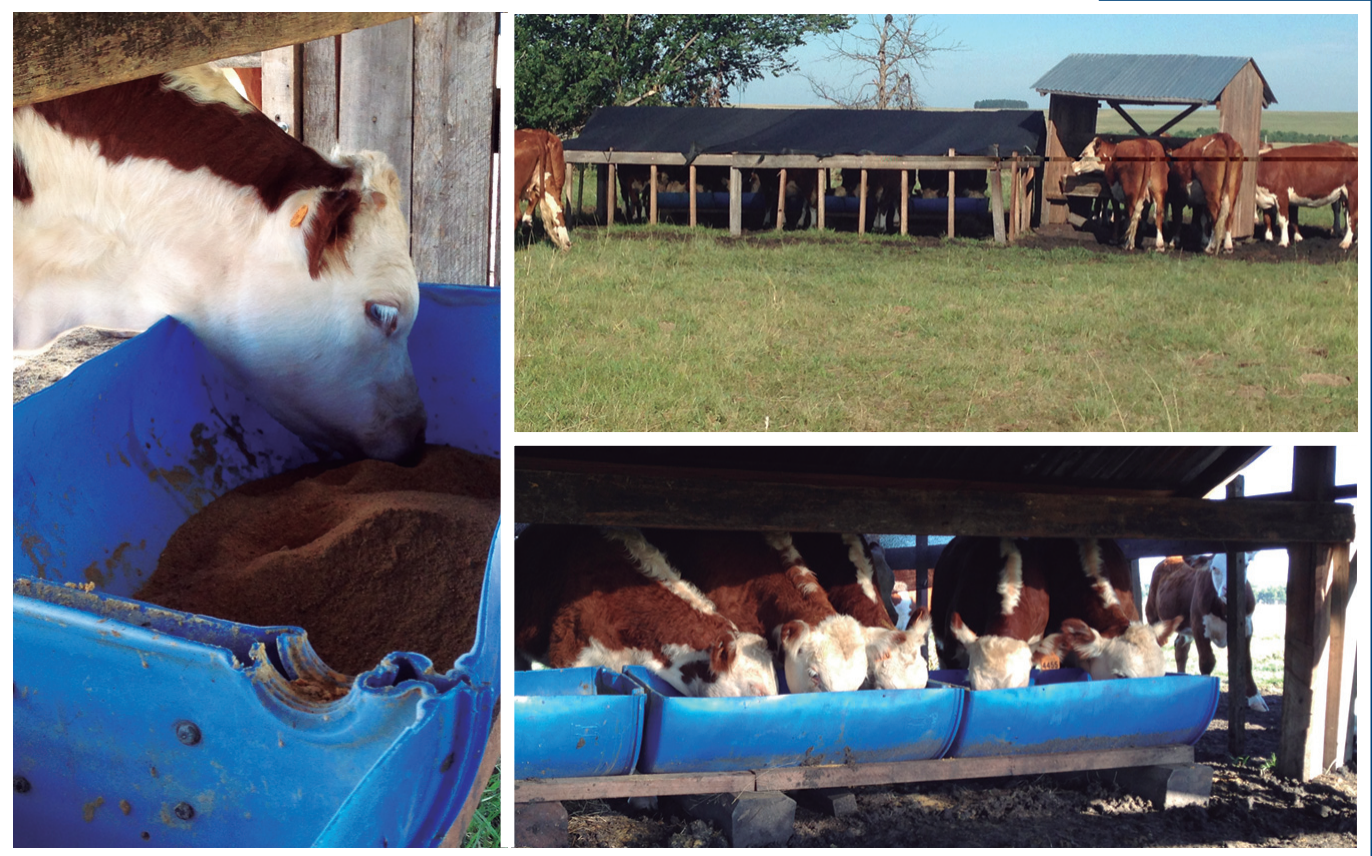

CREEP FEEDING:

TECNOLOGÍA

PARAAUMENTAR

EL PESO AL

DESTETE

Noviembre, 2017

SERIE TÉCNICA

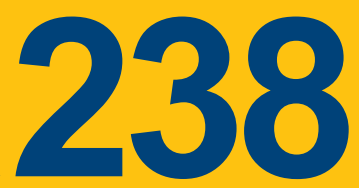

INIA 


\title{
CREEP FEEDING: TECNOLOGÍA PARA AUMENTAR EL PESO AL DESTETE
}

\author{
Editores: Carolina Viñoles Gil* \\ Juan Pablo Álvarez**
}

* Med. Vet. Ph.D. Polo Agroforestal, Casa de la Universidad de Cerro Largo, UDELAR.

carolina.vinoles@poloagroforestal.edu.uy

** Estudiante Facultad de Veterinaria. Programa Investigación Carne y Lana, INIA Tacuarembó. 
Título: CREEP FEEDING: TECNOLOGÍA PARA AUMENTAR EL PESO AL DESTETE

\section{Editores: Carolina Viñoles Gil}

\section{Juan Pablo Alvarez}

Serie Técnica $N^{\circ} 238$

(C) 2017, INIA

ISBN 978-9974-38-389-0

Editado por la Unidad de Comunicación y Transferencia de Tecnología del INIA Andes 1365, Piso 12. Montevideo - Uruguay

http://www.inia.uy

Quedan reservados todos los derechos de la presente edición. Esta publicación no se podrá reproducir total o parcialmente sin expreso consentimiento del INIA. 


\section{I nstituto Nacional de I nvestigación Agropecuaria}

\section{I ntegración de la Junta Directiva}

D.M.T.V., Ph.D. J osé Luis Repetto - Presidente

Ing. Agr., MSc., PhD. Álvaro Roel - Vicepresidente

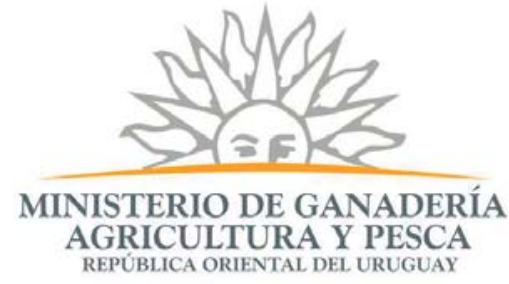

Ing. Agr. M.Sc. Diego Payssé Salgado

Ing. Agr. J orge Peñagaricano
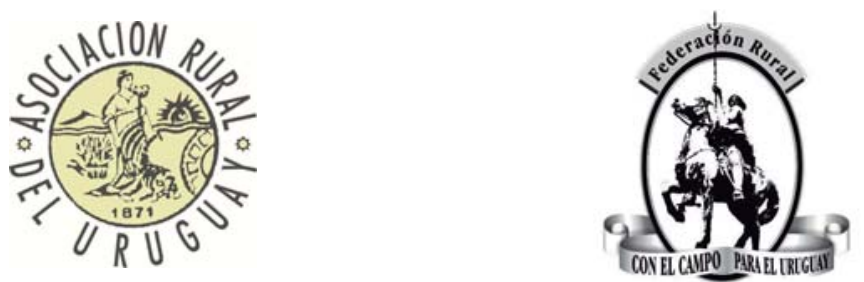

Ing. Agr. Pablo Gorriti

Ing. Agr. Alberto Bozzo
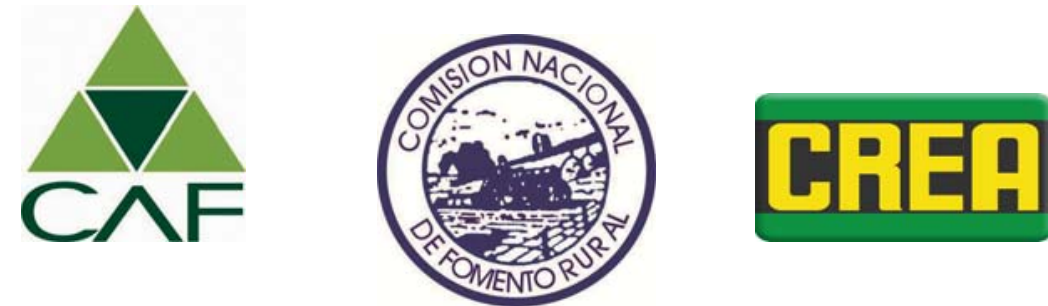



\section{CONTENIDO}

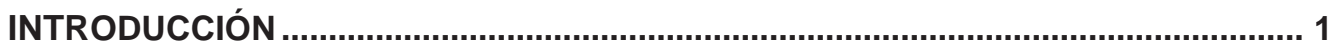

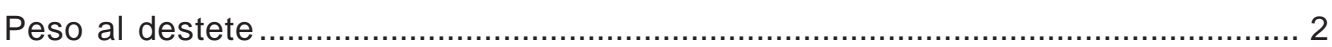

Alimentación preferencial del ternero .................................................................... 2

Efectos de la alimentación preferencial del ternero .............................................. 4

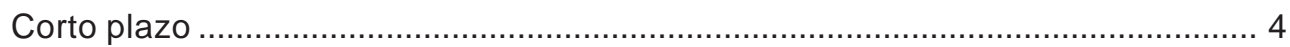

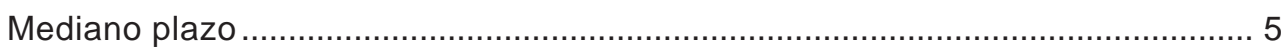

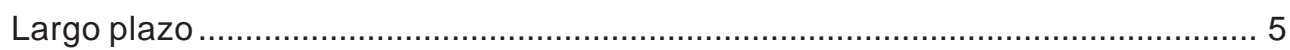

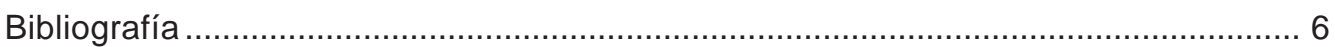

EFECTO DE LA DOTACIÓN Y LA ALIMENTACIÓN DIFERENCIAL DE LOS TERNEROS SOBRE SU TASA DE CRECIMIENTO Y EL DESEMPEÑO

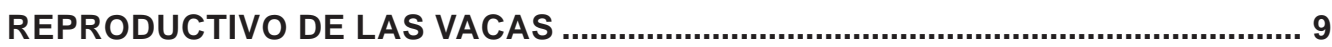

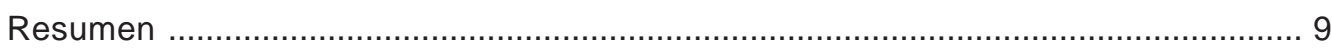

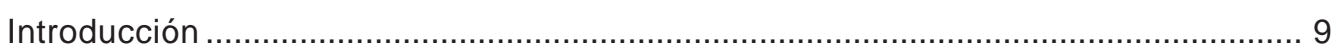

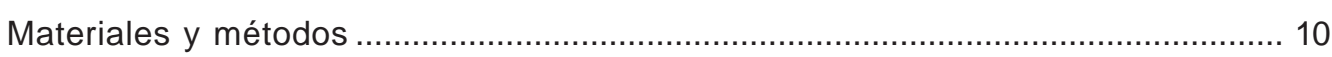

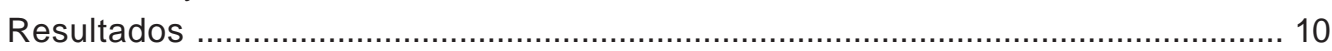

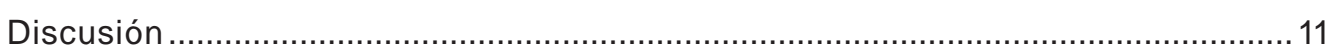

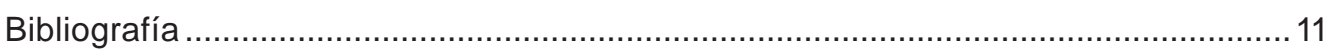

EFECTO DE LA CARGA Y LA SUPLEMENTACIÓN DE LAS TERNERAS SOBRE SU TASA DE CRECIMIENTO Y LA PERFORMANCE REPRODUCTIVA

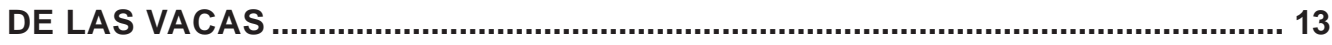

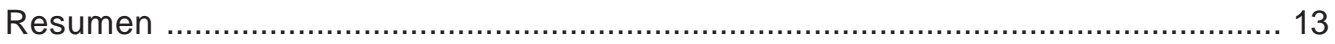

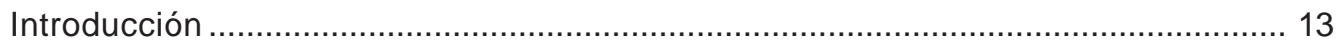

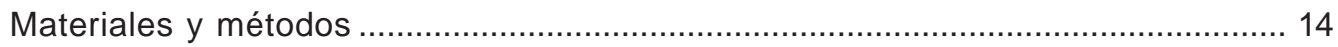

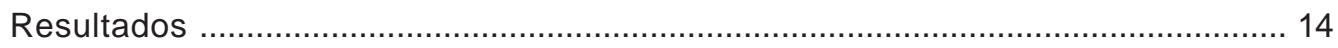

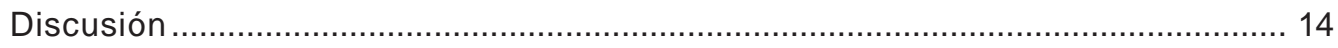

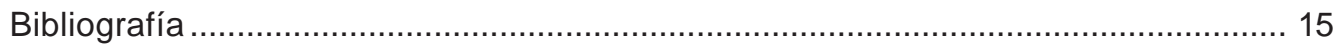

EFECTO DEL CREEP FEEDING Y EL DESTETE TEMPORARIO SOBRE LA PERFORMANCE REPRODUCTIVA DE VACAS HEREFORD PRIMÍPARAS Y LA TASA DE CRECIMIENTO DE LOS TERNEROS ........................................... 17

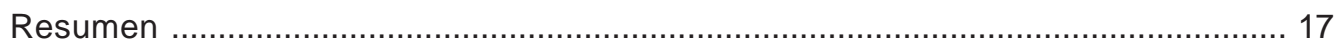

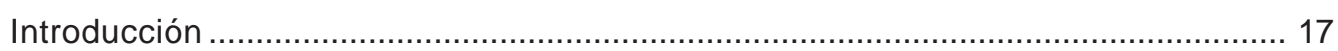

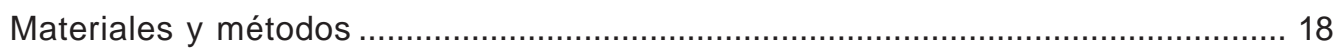

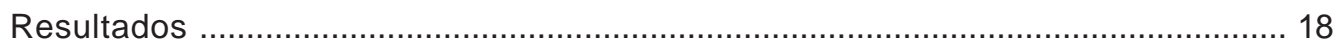

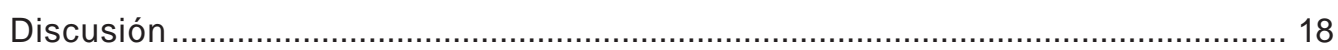

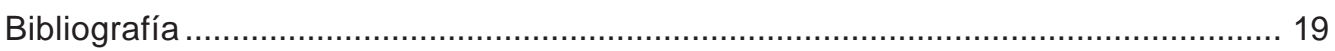

EFECTO DEL CREEP FEEDING Y EL DESTETE TEMPORARIO SOBRE EL DESARROLLO DE LOS TERNEROS Y LA EFICIENCIA REPRODUCTIVA DE

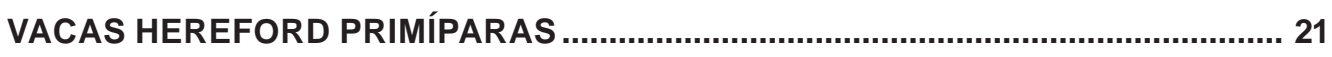

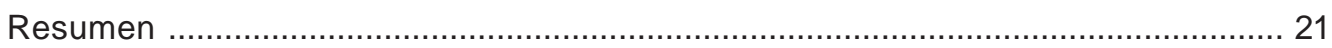

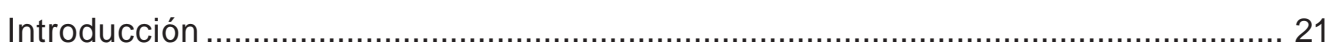

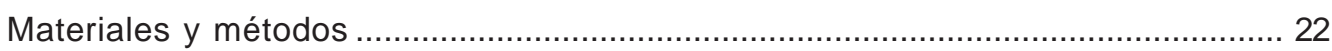




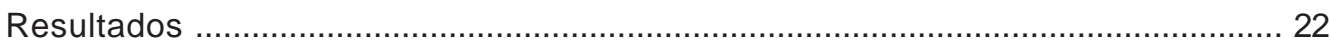

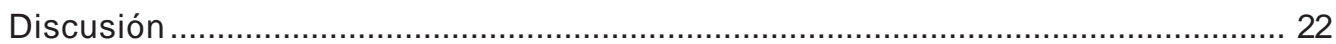

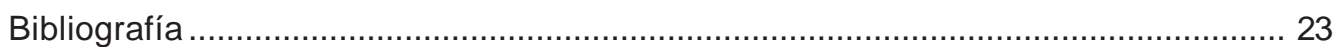

EFECTO DEL CREEP FEEDING CON AFRECHILLO DE ARROZ Y EL DESTETE TEMPORARIO SOBRE EL CRECIMIENTO DE LOS TERNEROS Y LA EFICIENCIA REPRODUCTIVA DE VACAS HEREFORD ............................. 25

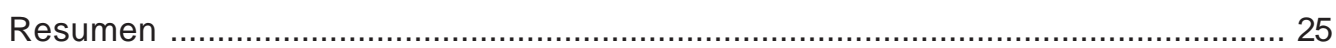

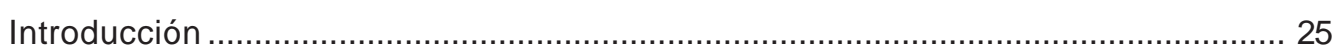

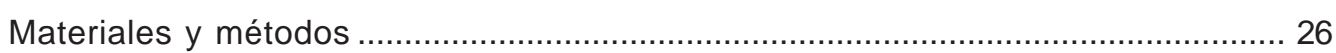

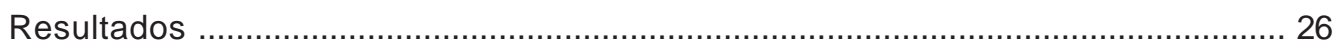

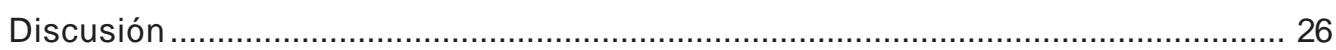

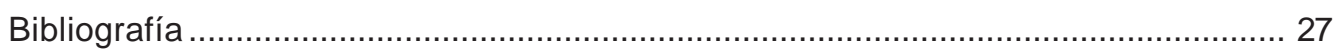

EFECTO DEL CREEP FEEDING CON AFRECHILLO DE ARROZ Y UNA SAL COMERCIAL Y EL DESTETE TEMPORARIO SOBRE PARÁMETROS PRODUCTIVOS DE LOS TERNEROS Y LA EFICIENCIA REPRODUCTIVA

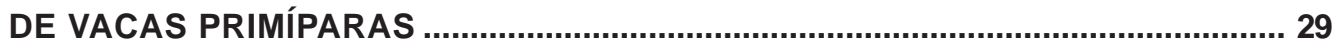

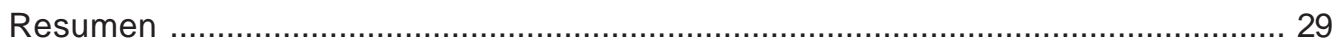

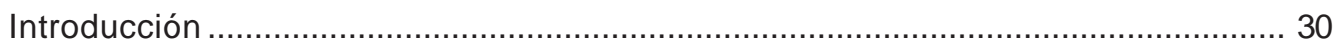

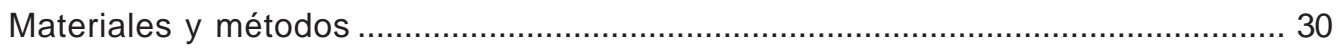

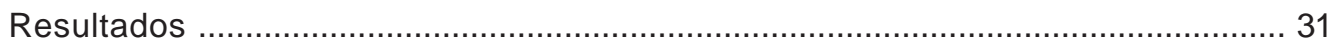

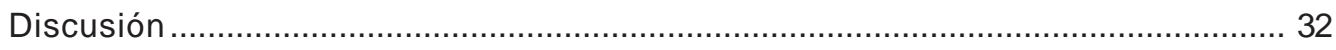

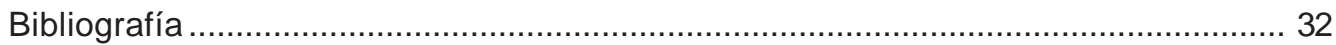

EFECTO DEL CREEP FEEDING CON DDGS Y EL DESTETE TEMPORARIO SOBRE EL DESARROLLO DE LOS TERNEROS Y LA EFICIENCIA REPRODUCTIVA DE VACAS HEREFORD ........................................................ 33

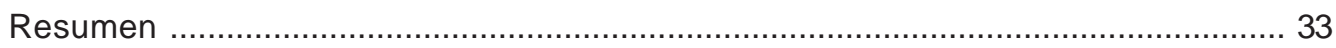

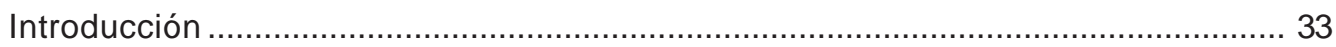

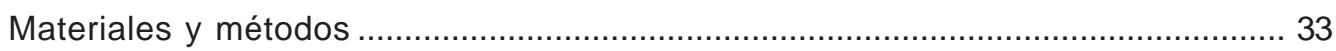

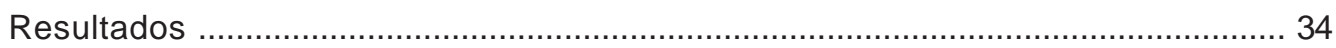

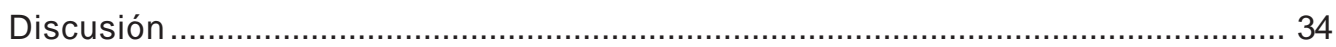

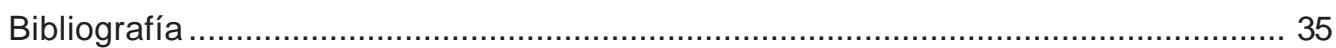

EFECTO DE MEDIANO PLAZO DE DIFERENTES SISTEMAS DE MANEJO SOBRE EL CRECIMIENTO, PARÁMETROS ENDÓCRINOS Y PUBERTAD EN TERNERAS HEREFORD PASTOREANDO CAMPO NATURAL ........................ 37

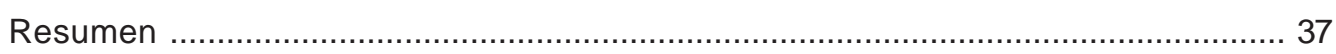

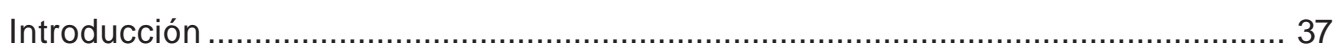

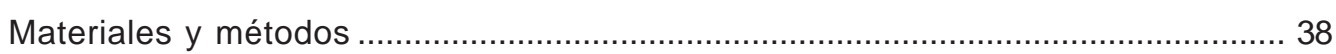

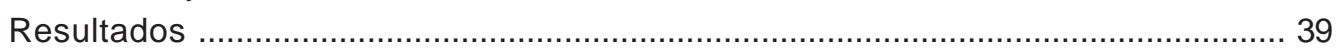

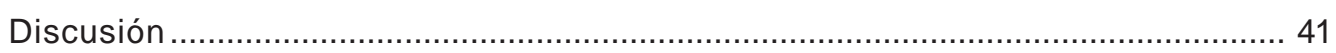

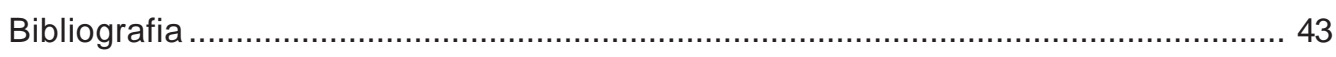


EFECTO DE MEDIANO PLAZO DE LA NUTRICIÓN SOBRE PARÁMETROS ENDÓCRINOS Y LA EXPRESIÓN DE GENES DEL EJE SOMATOTRÓFICO EN ENDOMETRIO E HÍGADO EN VAQUILLONAS HEREFORD ...................................45

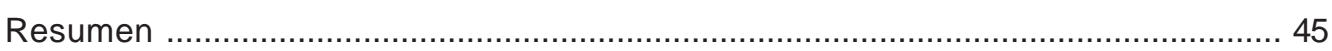

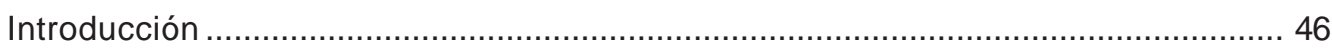

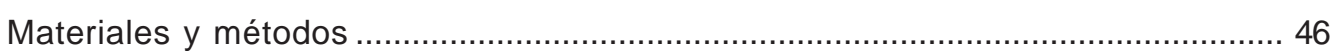

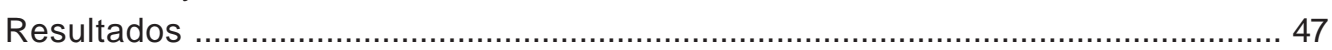

Concentraciones plasmáticas de hormonas .........................................................4 47

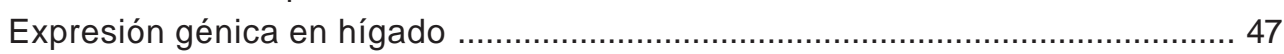

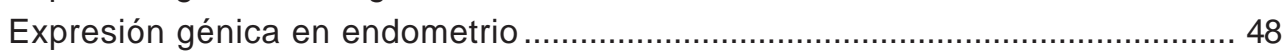

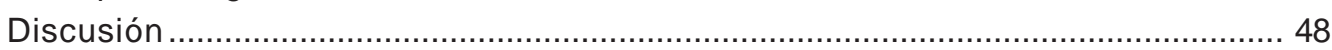

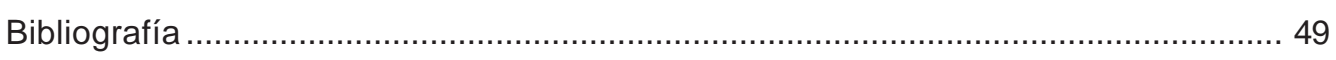

IMPACTO DE LARGO PLAZO DE DISTINTOS SISTEMAS DE MANEJO

APLICADOS A TEMPRANA EDAD SOBRE LAS DIMENSIONES DE LOS

TERNEROS Y LA PRODUCCIÓN DE LECHE EN LA PRIMERA LACTANCIA

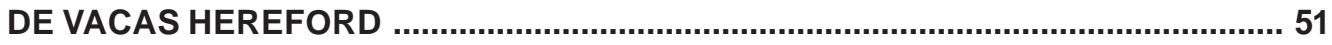

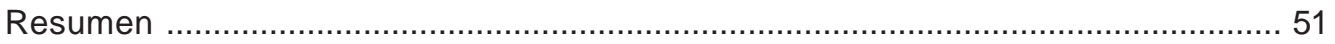

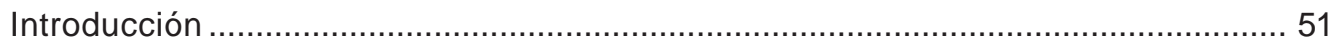

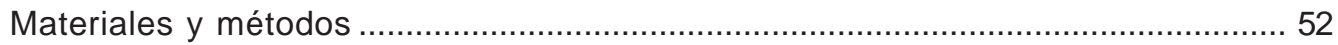

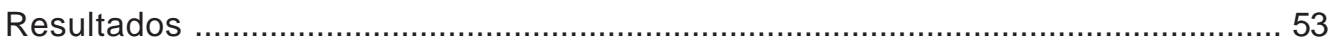

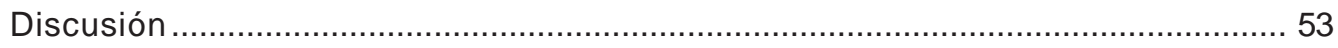

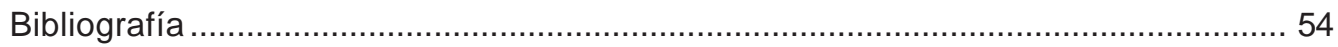

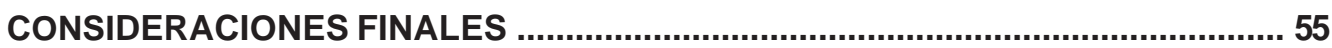

RECOMENDACIONES PRÁCTICAS PARA LA APLICACIÓN DE LA TÉCNICA

DE CREEP FEEDING

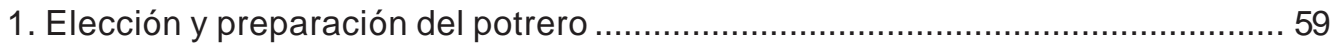

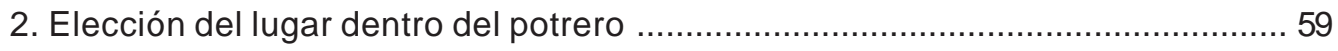

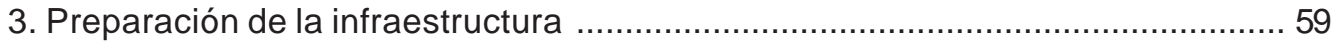

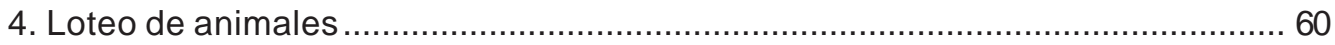

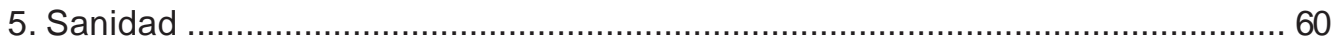

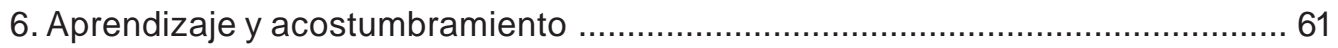

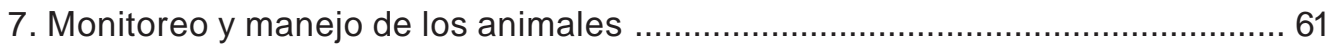

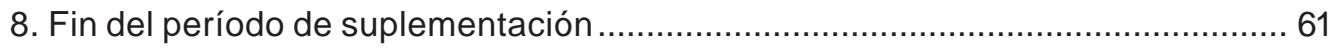





\section{PRÓLOGO}

Esta publicación sistematiza, analiza y concluye sobre la información científica y tecnológica generada por el equipo de producción animal y pasturas de INIA en el marco del proyecto de investigación «Mejora de la productividad y valorización de productos y procesos generados en los sistemas ganaderos del Basalto y Areniscas del Uruguay», desarrollado en el marco del Plan Estratégico Institucional 2011-2015. En este proyecto, el componente relacionado a los aspectos reproductivos (estudios de factores que afectan la eficiencia reproductiva y la edad de entore, entre otros) y temáticas asociadas (ej. influencia de corto y largo plazo sobre el crecimiento del ternero de la aplicación de tecnologías sobre la unidad vaca-ternero) dio origen a la presente publicación técnica titulada «Creep feeding: tecnología para aumentar el peso al destete».

Este proyecto se realizó en el marco de un modelo de articulación en red con otros actores del sistema público y privado de investigación, destacando la formación académica de estudiantes de grado y posgrado con la UdelaR (Facultades de Veterinaria y Agronomía), donde se abordaron en profundidad las relaciones causa-efecto que nos permiten explicar con mayor precisión y exactitud los resultados obtenidos de acuerdo a las hipótesis planteadas. Esta estrategia permitió generar una importante producción científica a nivel de revistas arbitradas e indexadas. Las implicancias de los efectos de la alimentación preferencial de los terneros al pie de las vacas de cría de diferentes edades, permitieron alimentar modelos de simulación sobre las implicancias productivas y económicas de esta tecnología a nivel de los sistemas de cría en un proceso de intensificación variable. Esta línea de trabajo experimental permitió obtener la mayor base de información científica y tecnológica generada en el país y en la región sobre la tecnología de «creep feeding» a nivel de los rodeos de cría, con diferentes focos: i) estudio sobre la eficiencia reproductiva de las vacas de cría adultas y vaquillonas, ii) el impacto en el ternero, iii) la evaluación del entore de 13 a 15 meses, iv) comparar esta tecnología con otras técnicas más conocidas del control del amamantamiento, y v) evaluar las interacciones de esta tecnología en el corto, mediano y largo plazo sobre madres e hijos involucrando los diversos aspectos mencionados.

La publicación está desarrollada sobre la base de la información generada en 10 experimentos. En la introducción se analizan los antecedes y justificación de esta línea de trabajo de investigación, seguidamente se documentan los resúmenes, materiales y métodos, resultados, discusión y conclusiones y finalmente se desarrollan recomendaciones prácticas. Nueve de los diez trabajos experimentales fueron ejecutados en la Unidad Experimental «Glencoe», ubicada en la región de Basalto, perteneciente a INIA Tacuarembó. EI restante experimento fue realizado en un predio comercial en el departamento de Cerro Largo.

Los autores realizan un amplio análisis y recomendaciones para una correcta aplicación de la tecnología de «creep feeding» a nivel de terneros y diferentes categorías de edades de vacas de cría y vaquillonas que pastorean campo natural o campo natural mejorado, y los efectos posteriores de corto, mediano y largo plazo en la vida productiva de los animales que reciben una alimentación diferencial al pie de sus madres. Esta información constituye un aporte de INIA para mejorar la productividad y competitividad de los sistemas 
criadores o de ciclo completo, con especial énfasis en la región norte del Uruguay, pero con proyección nacional. Esperamos que estas contribuciones sean de beneficio a productores y técnicos asesores, así como su uso a nivel del sistema educativo por parte de docentes y estudiantes.

Finalmente, queremos expresar un especial agradecimiento a todos los estudiantes, productores, técnicos, y personal de apoyo e investigadores de INIA por su participación comprometida para cumplir con los objetivos establecidos en esta propuesta tecnológica.

Ing. Agr. PhD. Fabio Montossi

Responsable del Proyecto de Investigación «Mejora de la productividad y valorización de productos y procesos generados en los sistemas ganaderos del Basalto y Areniscas del Uruguay» 


\section{INTRODUCCIÓN}

En Uruguay el sector agropecuario es fundamental para el crecimiento de la economía y el desarrollo social del país. Si se consideran las exportaciones como uno de los indicadores para demostrar la trascendencia del sector sobre la economía nacional, aproximadamente el $74 \%$ del total de las exportaciones proviene de lo que genera la agroindustria nacional (DIEA, 2016). Por lo tanto el desarrollo futuro de este sector hace a la prosperidad y bienestar de la población (Montossi, 2008). La cría es uno de los procesos más complejos y desafiantes de los sistemas de producción ganaderos. Es común hacer referencia a la baja eficiencia física y económica de la cría, lo cual ha llevado a su paulatino desplazamiento por rubros más competitivos a zonas marginales en cuanto a calidad y tipo de suelo (Pigurina, 2000). Sin embargo, es importante destacar que la ganadería de carne está transitando un periodo de precios y relaciones flaco/gordo notoriamente superiores a las históricas, lo que permite valorizar la producción y lograr una mejor rentabilidad en predios criadores.
En este contexto es importante brindar herramientas para que los productores puedan elevar la productividad y de esa forma mejorar el ingreso económico de sus sistemas (Viñoles et al., 2012). Los factores que determinan el ingreso de los sistemas criadores son la carga animal, la preñez y el peso de los terneros al destete (Figura 1).

Por lo tanto, un sistema criador debe apostar a aumentar la cantidad de kilos de terneros producidos por unidad de superficie, en un rodeo de cría manejado a una carga adecuada para ese sistema y con un buen manejo reproductivo (De Nava, 2011). Dentro de las herramientas generadas por la investigación nacional, el manejo del campo natural es uno de los aspectos más relevantes. Considerando que es el sustento nutricional de la cría vacuna, el manejo adecuado de este recurso es clave para cubrir los altos requerimientos de mantenimiento y producción de vacas en pastoreo (Short et al., 1990). Una adecuada asignación de forraje durante el ciclo reproductivo, para alcanzar una condición corporal compatible con un alto porcentaje de preñez durante el entore es

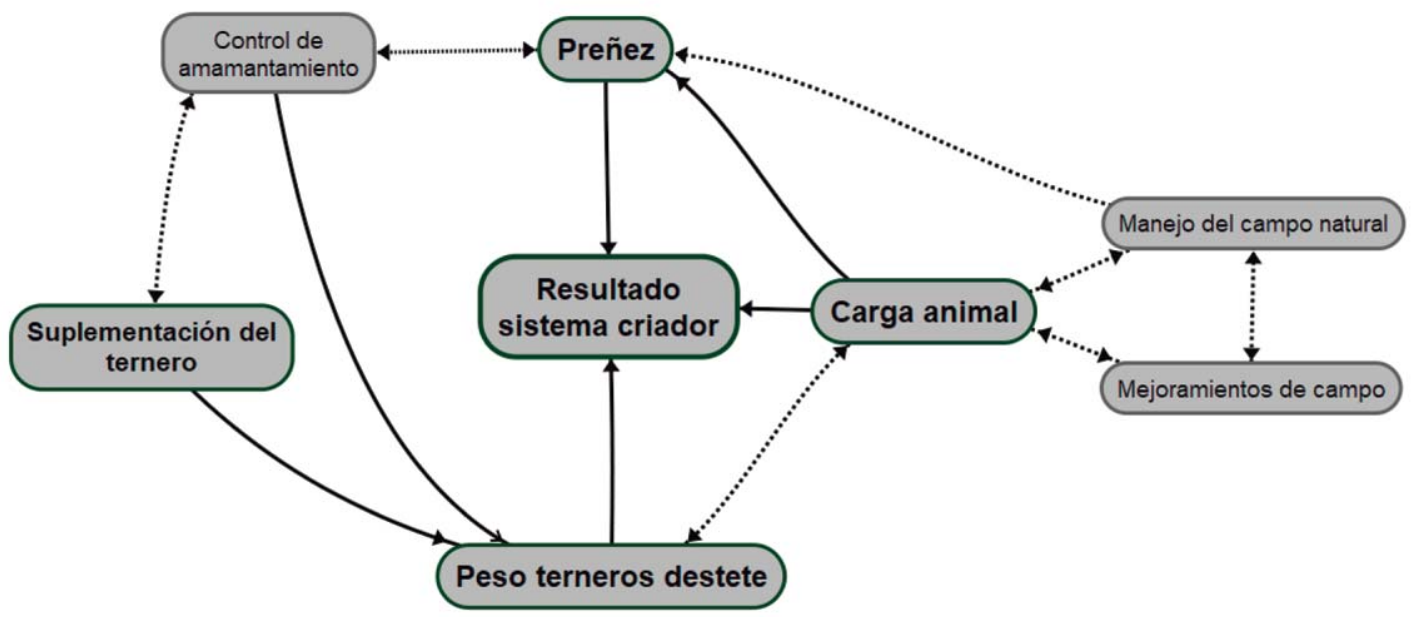

Figura 1. Factores que afectan el resultado de un sistema criador (carga animal, peso de los terneros al destete y preñez) y su interacción con otras variables del sistema. 
una estrategia fundamental (Soca y Orcasberro, 1992). Vacas en adecuada condición corporal al parto [4 adultas; 4,5 primera cría; (escala 1-8; Vizcarra et al., 1986)] pueden prescindir de la aplicación de medidas de manejo correctivas para lograr altos índices de preñez, pudiéndonos concentrar en lograr un alto porcentaje de preñeces tempranas. Las medidas correctivas incluyen el manejo del amamantamiento (destete temporario y precoz) separadas o asociadas a la suplementación de las vacas (Soca et al,. 2014).

El destete temporario es una herramienta que ha sido ampliamente adoptada por los productores, y consiste en la aplicación de una tabilla nasal a terneros mayores de 60 días de vida y que pesen $70 \mathrm{~kg}$ (Quintans et al, . 2009). Se ha descrito que la respuesta es mayor en vacas adultas con una condición corporal > a 3,5 unidades, y en vacas de primera cría una condición $>4$ (Quintans et al., 2004). Vacas que se encuentran en anestro superficial (presencia de folículos ováricos > a $8 \mathrm{~mm}$ ) son la que mejor responden a ésta medida de manejo (Quintans et al., 2006). Por lo tanto, lo ideal es definir en qué par vaca-ternero se debe aplicar ésta medida de manejo, lo que se logra a través del monitoreo de la actividad ovárica o monitoreo del entore. Esta actividad consiste en realizar una ecografía para evaluar el tracto reproductivo de las vacas al mes de comenzado el entore e identificar individualmente a las vacas preñadas, ciclando, en anestro superficial y en anestro profundo (De Nava, 2011). La medida recomendada para terneros hijos de vacas en anestro profundo (folículos ováricos < $8 \mathrm{~mm}$ ) es el destete precoz, lo que permitirá que las vacas recuperen condición corporal y comience a ciclar antes de retirar los toros. En vacas en anestro superficial el destete temporario es una alternativa que permite acortar el anestro posparto. Es importante destacar que el destete temporario disminuye las tasas de ganancia de peso de los terneros, y se refleja en pesos 7 a 18 kg más bajo al destete definitivo (Nava Silva et al., 1994; Quintans y Vázquez, 2002; Quintans y Jiménez de Aréchaga, 2006; Quintans et al., 2009, 2010, 2013). Por lo tanto, esta herramienta sola- mente mejora una de las variables que afecta los ingresos del sistema criador.

\section{Peso al destete}

El número de terneros destetados y su peso, determinan el ingreso más relevante de muchos sistemas criadores, que pueden además vender vacas para invernada, vacas gordas o excedentes de vaquillonas (Soares de Lima y Montossi, 2014). El destete es además el inicio de la recría de las futuras vacas del rodeo, período improductivo que debe ser lo más corto posible. La disminución en la edad al primer parto a 2 años, elimina la categoría vaquillonas de 1-2 años, pasando de ternera a vaca preñada, lo que aumenta el área para el rodeo de cría y redunda en un mayor ingreso económico (Soares de Lima y Montossi, 2012). El peso al destete es un factor determinante de la duración de la recría, ya que con pesos al destete mayores a $200 \mathrm{~kg}$ y un alto plano nutricional pos-destete se puede realizar el entore a los 13-15 meses. En nuestras condiciones de producción, el peso al destete es una de las mayores limitantes, por lo que la búsqueda de alternativas para aumentar este indicador es muy relevante para mejorar la eficiencia física y económica de los sistemas criadores.

\section{Alimentación preferencial del ternero}

Esta herramienta tiene el objetivo de elevar los pesos al destete, permitiendo la alimentación de los terneros con pasturas (creep grazing) o concentrados (creep feeding, CF) a la cual las madres no tienen acceso. El principio de esta técnica se basa en que los terneros de tres meses de edad requieren de un plano nutricional mayor al ofrecido por la leche materna (Figura 2; Eversole, 2001). En nuestras condiciones de producción, esta edad coincide con el verano, momento en que generalmente se asocia con una baja disponibilidad y/o calidad del forraje, lo que impide que los terneros expresen su potencial genético de crecimiento (Pigurina, 2000). Se ha sugerido que las mejores respuestas a la alimentación prefe- 


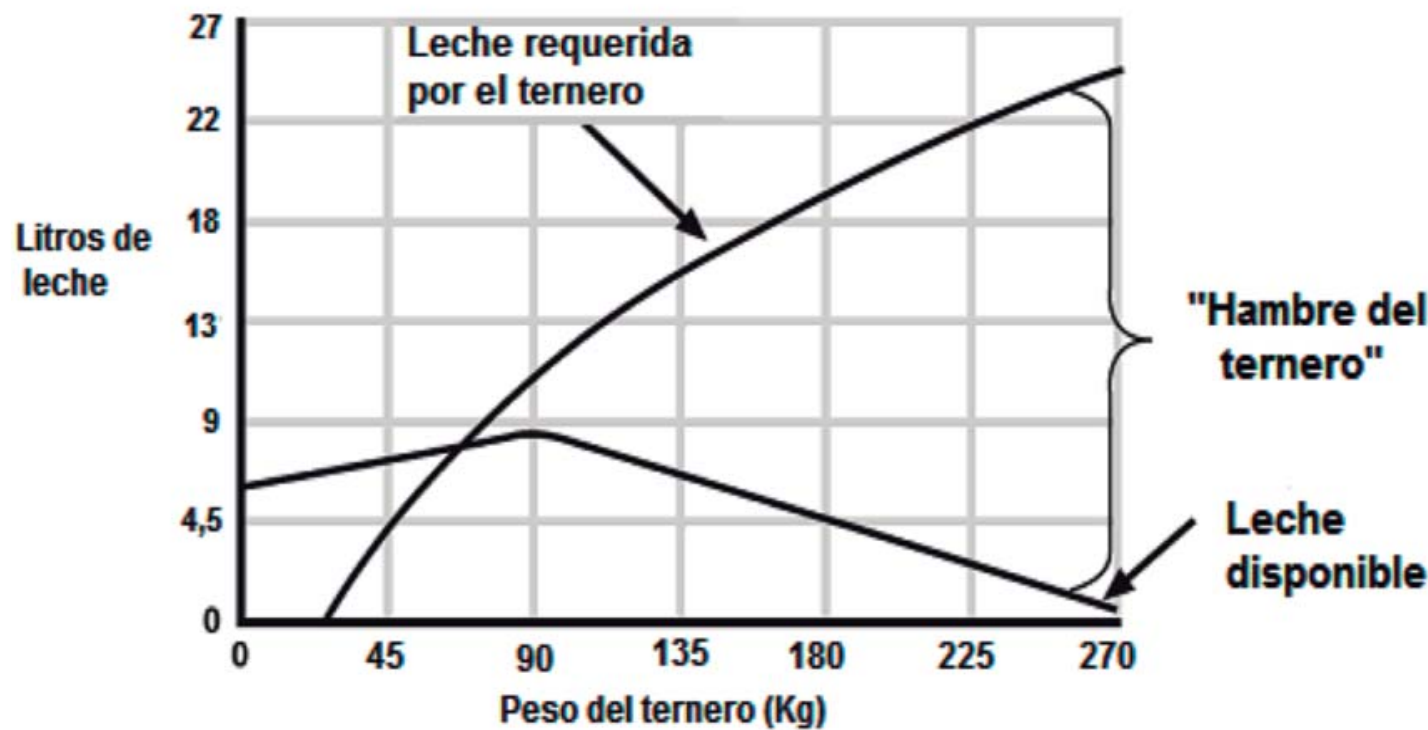

Figura 2. Evolución del peso de los terneros y de la producción de leche de las vacas, y en qué medida esta cubre los requerimientos de mantenimiento y crecimiento de los mismos. Desde el nacimiento y hasta los $70 \mathrm{~kg}$ de peso vivo, la leche cubre los requerimientos de los terneros, pero a partir de allí, la producción de leche cae y aumentan los requerimientos del ternero, por lo que comienza un período de «hambre del ternero» que debe ser cubierto por otro tipo de nutrientes si el objetivo es mantener altas tasas de ganancia de peso y altos pesos al destete (modificado de Eversole, 2001).

rencial ocurren cuando el forraje es demasiado maduro (baja calidad) para ser utilizado eficientemente por ésta categoría, hay baja disponibilidad debido a una sequía o sobrepastoreo y hay baja producción de leche (por ejemplo vaquillonas) (Scaglia, 2004).

La implementación del CF no requiere de instalaciones sofisticadas (Figura 3). Las mismas deben permitir el libre acceso de los terneros a los comederos y mediante la instalación de un escamoteador impedir el paso de sus madres. Se recomienda que tenga una altura de travesaños de 0,80 m (0,7-1,0 $\mathrm{m})$ para que los terneros pasen por debajo y un ancho $(0,4-0,5 \mathrm{~m})$ que permita el ingreso de los animales hasta el destete (Lusby y Gill, 1999). La estructura debe ser firme para que las vacas y los toros no puedan derrumbarla. Se debe evitar el uso de alambres eléctricos o cualquier recurso que genere un recuerdo negativo del ingreso al área de suplementación. Antes de armar el sitio de suplementación, es fundamental conocer los hábitos del ganado en ese potrero, la presencia de sombra y agua, en una área de suelo firme y de fácil acceso para la administración diaria del concentrado (Carreras, 2012).
Un aspecto fundamental es que los terneros aprendan a comer y hayan probado el suplemento antes de iniciar la suplementación (por ejemplo administrando un puñado en la boca de cada ternero). Las alternativas para el aprendizaje sea efectivo son: a) suplementar a algunos terneros junto a sus madres (elegir vacas en baja condición corporal y cola de parición); b) utilizar terneros o categorías de sobreaño que ya sepan comer, o c) encerrar a los terneros por la mañana durante 3 a 4 horas en el área de suplementación durante el período de acostumbramiento. El acostumbramiento dura entre 7 y 10 días y la cantidad de concentrado se aumenta $0,2 \%$ en forma diaria, hasta alcanzar el $1 \%$ del peso vivo de los terneros. Es importante repuntar diariamente a vacas y terneros al área de suplementación durante éste período de acostumbramiento. Se sugiere administrar sal a las vacas alrededor del área de suplementación, para que lleven a sus terneros y permanezcan en el área mientras sus crías se alimentan.

El suplemento debe aportar los nutrientes necesarios para cubrir los requerimientos de los terneros en energía, proteína y 


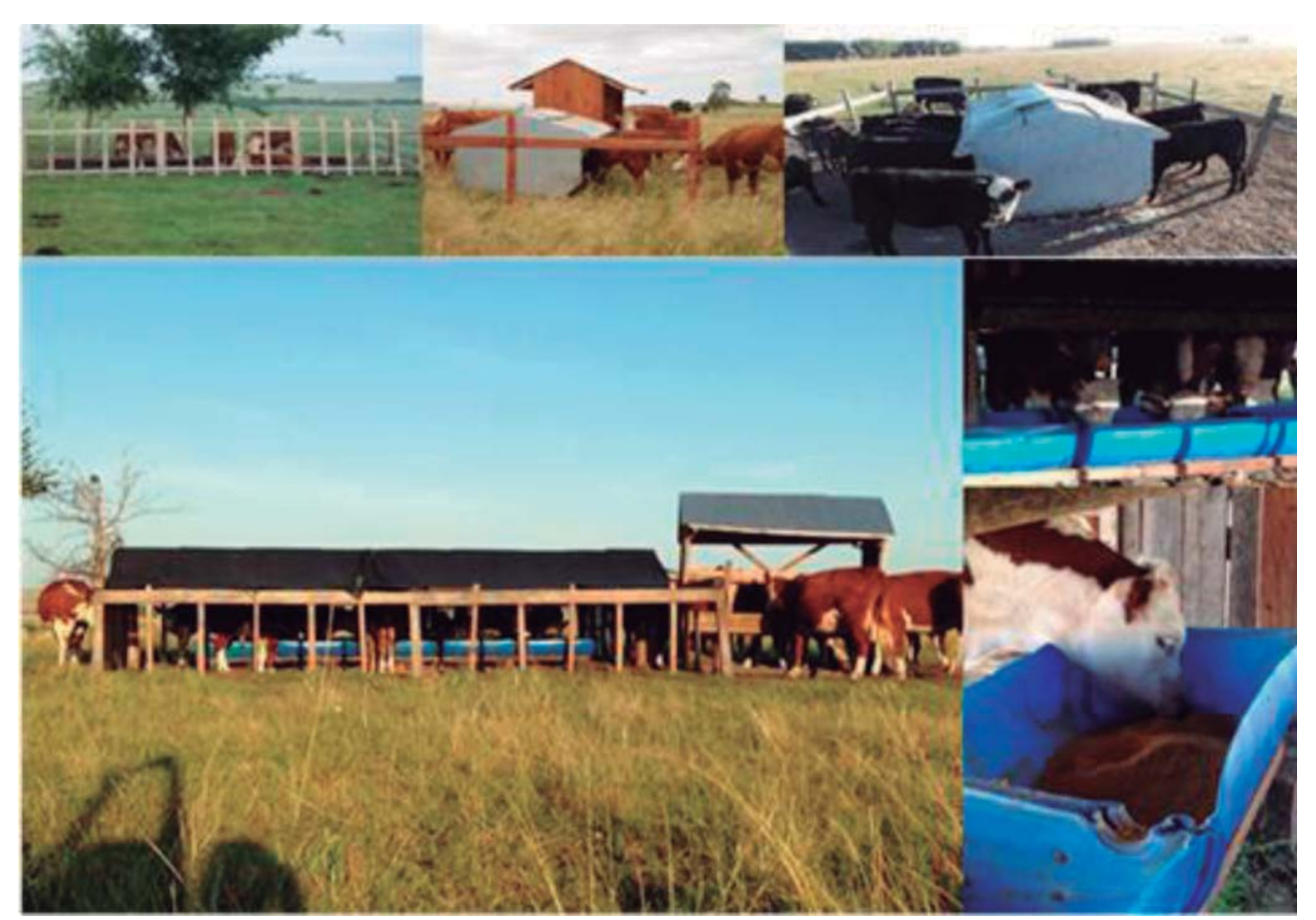

Figura 3. Imágenes ilustrativas de área de suplementación exclusiva del ternero o creep feeding.

minerales. Se considera necesario que contenga un mínimo de $70 \%$ de NDT, un tenor de 15 a $19 \%$ de proteína digestible o alrededor de 18 a $22 \%$ de proteína bruta, sin nitrógeno no proteico, más el agregado de los minerales que se considere necesario para dicho campo. Es fundamental que sea una ración de alta palatabilidad, para inducir al ternero a consumirla desde edad temprana (Bavera y Peñafort, 2006).

La cantidad de ración consumida por los terneros varía de acuerdo a la edad del ternero, la cantidad de leche que la madre produce, la cantidad de forraje disponible y la palatabilidad de la ración. Debe contemplarse que el ternero prefiere primero la leche, luego una ración palatable y finalmente la pastura y por esto ante una buena disponibilidad de leche y pastura, la ración se transforma en el sustituto de esta última. En general, la eficiencia de conversión (kg de suplemento consumido por cada kg extra de peso vivo) utilizando suplementos en base a granos oscila entre 4:1 y 26:1 (Scaglia, 2004).

Un aspecto fundamental para definir la viabilidad de la aplicación de esta técnica es el análisis basado en coeficientes técnicos, de los incrementos en performance animal e ingresos económicos factibles de alcanzar, considerando los costos de su aplicación (Scaglia, 2004). En este sentido, el precio del ternero, el precio de la ración, la eficiencia de conversión, la mano de obra disponible y el destino del ternero destetado son algunos aspectos a tener en cuenta (Scaglia, 2004).

\section{Efectos de la alimentación preferencial del ternero}

\section{Corto plazo}

La información generada demuestra que la respuesta al CF puede ser variable, dependiendo de factores como peso inicial del ternero, tipo de suplemento, nivel de consumo, curva de producción láctea de las vacas y la brecha entre cantidad y calidad de la pastura y los requerimientos del ternero (Carreras, 2012). Se han observado resultados favorables, asociados a un aumento del peso al destete de los terneros suplementados que 
superan en 21 a $60 \mathrm{~kg}$ a los testigos (Pacola et al., 1977; Simeone et al., 2015). El uso del creep feeding asociado al destete temporario, podría permitir aumentar la ganancia de peso de los terneros durante el período que se aplica la tablilla nasal. Para que el efecto positivo ocurra, lo terneros deberían estar acostumbrados a consumir el suplemento al momento de aplicar la técnica. Sin embargo, no existen antecedentes en el Uruguay sobre el uso combinado de ambas estrategias de manejo.

También se han reportado efectos positivos del CF sobre el desempeño productivo y reproductivo de las vacas (Pacola et al., 1989; Nogueira et al.. 2006; Carreras. 2012), constatándose ganancias de peso a partir de los 3 meses de lactancia, con diferencias entre 20 y 40 kilogramos a favor de las madres de terneros que fueron suplementados. Estas mayores ganancias fueron atribuidas a una disminución en el consumo de forraje por parte de los terneros y por consiguiente, un aumento en la disponibilidad de forraje para las vacas (Carreras, 2012). Sin embargo, en nuestro país no se encontraron diferencias en peso vivo, ganancia diaria y condición corporal de las vacas (Pigurina et al. 2000). Esto podría explicarse porque la disminución en el consumo de forraje por los terneros no sería suficiente para promover un impacto sobre el balance energético en las vacas (Gelvin et al., 2004), ya que se ha demostrado que el CF no provoca una disminución en la frecuencia de amamantamiento. Los efectos sobre la condición corporal, el peso vivo y la preñez de las vacas son controvertidos, por lo que se requieren más estudios para definir si ocurren o no cambios positivos.

\section{Mediano plazo}

Se ha demostrado que animales que recibieron CF y se les mantiene en un plano nutricional pos-destete que permita ganancias de alrededor de 500 gramos diarios hasta la terminación, mantienen la diferencia de peso comparados con los que no fueron sometidos a CF (Pacola et al., 1977). En forma similar, se han reportado mayores pesos vivos de las vaquillonas suplementadas al pie de la madre hasta los 1,5 años de edad (Holloway y Totusek, 1973). Esta ventaja de la suplementación diferencial de la ternera podría asociarse con una menor edad a la pubertad ya que la precocidad en llegar a la pubertad está determinada por las ganancias pre-destete (Gasser et al., 2006; Wiltbank et al., 1966). Sin dudas, si existiera este efecto de mediano plazo, el impacto sobre la recría seria aún más favorable en sistemas que realizan el entore temprano (13-15 meses). Esto permitiría el ingreso a la recría de terneras más pesadas, lo que se asocia con un menor esfuerzo en términos de ganancia diaria para alcanzar el peso de entore (55-60 \% peso adulto) (Viñoles, 2016). Además esto permitiría que las vaquillonas lleguen a la temporada de servicios ciclando regularmente y cuantos más ciclos estrales previos, mayor será la probabilidad de concepción al primer servicio (Snelling et al., 2012). Sin embargo, no existen publicaciones que estudien el impacto de la suplementación a edades tempranas sobre la edad a la pubertad, y menos aún sobre los perfiles de hormonas metabólicas y expresión de genes miembros de eje somatotrófico en hígado y útero, que estimulan el crecimiento y tienen un efecto positivo en la fertilidad al primer servicio.

\section{Largo plazo}

Un aspecto relevante de la administración de altos planos nutricionales a edades tempranas es que tienen efectos de largo plazo en la progenie. Se ha descrito que los hijos de vacas que reciben $\mathrm{CF}$ cuando son terneras, son más pesados que las que no son suplementadas (Holloway y Totusek, 1973). Este efecto podría tener consecuencias negativas en la facilidad de parto de las vacas, particularmente si el primer parto ocurre a los 2 años de edad. Sin lugar a dudas éste es un aspecto que preocupa mucho a los productores, porque la recuperación de esa vaca y preñez en su segundo entore es más rápida si el parto ocurre sin complicaciones. Un aspecto negativo de los altos planos nutricionales a edades tempranas es que ganancias mayores a $0,8 \mathrm{~kg} / \mathrm{d}$ durante el período de crecimiento alométrico de la glán- 
dula mamaria, se asocian con su engrasamiento y una menor producción de leche (Zanton y Hienrich, 2005). Esto redunda en un menor peso de los terneros al destete (5$6 \mathrm{~kg}$ menos) comparado con vacas que tienen menores tasas de ganancia en este período (Holloway y Totusek, 1973). Sin embargo, existe escasa información respecto a los efectos de largo plazo de la nutrición a edades tempanas en la performance de esa vaca en el rodeo de cría.

En la secuencia de experimentos que se presentará a continuación (2007-2016), buscamos llenar los vacíos de información existentes en ésta temática en sus efectos de corto, mediano y largo plazo. Nuestra hipótesis de trabajo fue que el creep feeeding aumentaría el peso al destete de los terneros nacidos en primavera, y que adelantaría la pubertad y preñez al primer servicio de terneras suplementadas al pie de la madre, pero que aumentaría el tamaño de su progenie y reduciría su peso al destete. Los efectos positivos en la eficiencia reproductiva de las vaquillonas, estaría asociados con un aumento en las concentraciones de hormonas metabólicas y el funcionamiento del eje somatotrófico. En el transcurso de esta década, fuimos modificando el tipo de suplemento, para mejorar el margen de ganancia económica para el productor, y utilizando vacas cada vez más jóvenes (primer parto con dos años) y alimentadas con una asignación de forraje que no fuera limitante para alcanzar la condición corporal objetivo al segundo entore. Se estudió además la asociación del creep feeding con el destete temporario, como herramienta para aumentar las ganancias de peso de los terneros durante ese período.

\section{BIBLIOGRAFIA}

Bavera GA, Peñafort CH (2006) Alimentación diferenciada del ternero al pie de la madre. Sitio Argentino de Producción Animal.

Carreras H (2012) Suplementación del rodeo de cría (Creep Feeding). Sitio Argentino de Producción Animal 1-4.
DIEA (2016) Anuario estadístico agropecuario. Ministerio de Agricultura Ganadería y Pesca.

Eversole D. (2001) Creep Feeding Beef Calves. Virginia Cooperative Extension 400-003.

Gasser CL et al. (2006) Effect of timing of feeding a high-concentrate diet on growth and attainment of puberty in earlyweaned heifers. Journal of Animal Science 84:3118-3122.

Gelvin AA et al. (2004) performance by nursing calves grazing native range in western North Dakota The online version of this article, along with updated information and services, is located on the World Wide Web at/ : Effect of field pea-based creep feed on intake, digestibil. Journal of Animal Science 3589-3599.

Lusby KS, Gill DR (1999) Beef Cattle Handbook. Oklahoma State University $\mathrm{BCH}-5476$.

Montossi F (2008) SEMINARIO DE ACTUALIZACION TÉCNICA: Cría Vacuna. Montossi, F.

De Nava G (2011) Reproducción en los rodeos de cría pastoriles: el enfoque de un veterinario de campo. In: XXXIX Jornadas uruguayas de Buiatría.

Nava Silva GT de et al. (1994) The effects of restricted suckling and prepartum nutritional level on reproductive performance of primiparous crossbred beef cows. Proceedings of the New Zealand Society of Animal Production 54:307310.

Nogueira E et al. (2006) Efeito do creep feeding sobre o desempenho de bezerros e a eficiência reprodutiva de primíparas Nelore, em pastejo. Arquivo Brasileiro de Medicina Veterinária e Zootecnia 58:607 $-613$.

Pacola L et al. (1989) Suplementaçao de bezerros em cocho provativo. Boletim de Indústria Animal 46:167 - 175.

Pacola L, Do Nascimento J, Moreira H (1977) Alimentação suplementar de bezerros zebus: influência sobre a idade dos machos ao abate e das fêmeas à primeira cobrição. Boletim de Indústria Animal 34:177 - 201.

Pigurina G et al. (2000) Efecto de la alimentación diferencial del ternero sobre el peso al destete y la performance reproductiva de sus madres. INIA Serie Actividades de Difusión 239:31-33. 
Pigurina G (2000) Situación de la cría en el Uruguay. INIA Serie Técnica 108.

Quintans G et al. (2013) Destete temporario con tablilla nasal 14 días y suplementación durante el mismo período en vacas multiparas: resultados preliminares. seminario de actualizacion técnica: Cría Vacuna 208:197-205.

Quintans G et al. (2010) Effect of body condition and suckling restriction with and without presence of the calf on cow and calf performance. Animal production science $\mathrm{VO}$ - 50, no. 10 .

Quintans G et al. (2006) Effect of the use of temporary weaning depending on the ovarian activity during mating period on pregnancy rate in beef cows. Revista Argentina de Producción Animal 26:rf 24rf 24.

Quintans G, Jiménez de Aréchaga C (2006) Efecto del destete temporario sobre la fertilidad de vacas primíparas Braford y la ganancia de peso de los terneros. (Poster). In: 29० Congreso Argentino de Producción Animal, Mar del Plata, Argentina.

Quintans G, Vázquez Al (2002) Effect of premature weaning and suckling restriction with nose plates on the reproductive performance of primiparous cows under range conditions. In: Sixth International Symposiumin Domestic Ruminants, Crieff, Scotland. p. A65 (Abstr.).

Quintans G, Vázquez Al, Weigel KA (2009) Effect of suckling restriction with nose plates and premature weaning on postpartum anestrous interval in primiparous cows under range conditions. Animal Reproduction Science 116:10-18.

Quintans G, Viñoles C, Sinclair KD (2004) Follicular growth and ovulation in postpartum beef cows following calf removal and $\mathrm{GnRH}$ treatment. Animal reproduction science 80:5-14.

Scaglia G (2004) Alimentación preferencial del ternero. Boletín divulgación 83. INIA Treinta y Tres.

Short RE et al. (1990) Physiological Mechanisms Controlling Anestrus and
Infertiliy in Postpartum Beff Cattle. Journal of Animal Science 68:799-816.

Simeone A et al. (2015) Aumentando el producto bruto en Sistemas criadores: Vías de mejora del peso de los terneros a los seis mesos. Revista U.P.I.C.

Snelling WM et al. (2012) Physiology and Endocrinology Symposium: How single nucleotide polymorphism chips will advance our knowledge of factors controlling puberty and aid in selecting replacement beef females. Journal of animal science 90:1152-1165.

Soares de Lima J, Montossi F (2012) La cría vacuna en la nueva realidad ganadera: análisis y propuestas de INIA. Revista INIA 31:6-10.

Soares de Lima J, Montossi F (2014) LOS SISTEMAS DE CRÍA VACUNA SOBRE BASALTO/: Ante todo, sistemas de producción de carne. Serie técnica 217 INIA.

Soca P et al. (2014) Metabolic and endocrine profiles of primiparous beef cows grazing native grassland . 2 . Effects of body condition score at calving, type of suckling restriction and flushing on plasmatic and productive parameters. 862-868.

Soca P, Orcasberro R (1992) Propuesta de Manejo del Rodeo de Cría en base a estado corporal, altura del pasto y aplicación del destete temporario. In: Evaluación Física y Económica de Alternativas Tecnológicas en Predios Ganaderos. Estación Experimental M.A. Cassinoni. Facultad de Agronomía.

Viñoles C et al. (2012) Alternativas para aumentar la eficiencia de los sistemas de cría. Revista INIA Uruguay 29:5-8.

Viñoles C (2016) Desafíos del entore de 14 meses. Revista INIA Uruguay.

Vizcarra JA, Ibañez W, Orcasberro R (1986) Repetibilidad y reproductibilidad de dos escalas para estimar la condición corporal de vacas Hereford. Investigaciones Agronómicas 7:45-47.

Wiltbank JN et al. (1966) Effects of Heterosis on Age and Weight at Puberty in Beef Heifers. Animal Science 25:744-751. 



\title{
EFECTO DE LA DOTACIÓN Y LA ALIMENTACIÓN DIFERENCIAL DE LOS TERNEROS SOBRE SU TASA DE CRECIMIENTO YEL DESEMPEÑO REPRODUCTIVO DE LAS VACAS
}

A. Michelena ${ }^{1}$, A. Martin¹, V. Echenique ${ }^{1}$, C Viñoles $^{2}$

\begin{abstract}
RESUMEN
El objetivo de este estudio fue evaluar el impacto de la carga animal y la alimentación diferencial de los terneros o creep feeding (CF) sobre su tasa de crecimiento y la eficiencia reproductiva de las madres. Sesenta piezas de cría Hereford fueron asignadas a un diseño que estudió el efecto de la carga y el creep ( $n=15 / g r u p o): 1)$ Carga baja $(1,1 \mathrm{UG} / \mathrm{ha}) ; 2)$ Carga baja con CF; 3) Carga alta (1,7 UG/ha); 4) Carga alta con CF. Los animales pastorearon en forma continua en campo natural reservado (Ornitophus pinnatus) con una disponibilidad de $2100 \mathrm{~kg} \mathrm{MS} / \mathrm{ha}$. Los terneros recibieron una ración comercial con 21\% de proteína cruda. Se realizó detección de celo diario, peso y condición corporal cada 14 días, comportamiento en pastoreo y producción de leche cada 3 semanas. Los terneros del grupo carga baja con $C F$ tuvieron mayores pesos al destete $(P<0,01)$. El consumo de ración disminuyó las horas destinadas a pastoreo pero no el consumo de leche. Las vacas de los grupos CF aumentaron de peso y produjeron más leche, por lo que no mejoró su eficiencia reproductiva. Las vacas de carga alta no vieron deprimida su performance reproductiva a pesar de que perdieron peso. Concluimos que el CF tuvo un impacto positivo en peso al destete sin afectar el desempeño reproductivo de las madres.
\end{abstract}

\section{INTRODUCCIÓN}

La reducción en el área de cría vacuna hace necesario buscar alternativas que permitan aumentar la carga sin afectar la eficiencia de los sistemas. Una alternativa es la alimentación diferencial del ternero al pie de su madre o creep feeding (CF) (Scaglia, 2004). En condiciones nutricionales restrictivas esta alternativa permite aumentar el peso de los terneros al destete y mejorar la condición corporal de las vacas (Scaglia, 2004). La recuperación de la condición corporal de la vaca depende de que el ternero se independice del consumo de leche (Nunes Motta de Souza et al., 2007) y además deje más forraje disponible para la vaca (Nogueira et al., 2006). Sin embargo, no se ha evaluado si ese menor consumo se asocia con una menor producción de leche. Además, el efecto de esa mejora en la condición corporal sobre la eficiencia reproductiva de las vacas es contradictorio. Otra alternativa nutricional lo constituyen los campos cerrados para permitir la implantación y semillazón de mejoramientos de campo natural, dado que el acumulo de forraje permitirá que el sistema soporte mayores cargas. La hipótesis de

${ }^{1}$ Estudiantes de tesis de Facultad de Veterinaria.

2 INIA, Instituto Nacional de Investigación Agropecuaria. 
este trabajo fue que la alimentación diferencial de los terneros permite una adecuada tasa de ganancia aún en situaciones de alta carga, y al reducir la frecuencia de amamantamiento posibilita una recuperación más rápida del peso vivo y la condición corporal de las vacas lo que redunda en un reinicio más temprano de la actividad cíclica. El objetivo de este estudio fue evaluar el impacto de la carga animal y la alimentación diferencial de los terneros sobre su tasa de crecimiento y la eficiencia reproductiva de las madres.

\section{MATERIALES Y MÉTODOS}

El experimento fue realizado en la Unidad Experimental «Glencoe» INIA Tacuarembó del 18/12/2007 al 25/03/2008. Se utilizaron 60 vacas Hereford (edad: 4-6 años; peso vivo: $418 \pm 0,1$ kg (1,1 UG); condición corporal: $4 \pm 0,1$ unidades (escala 1-8)) y sus ter-

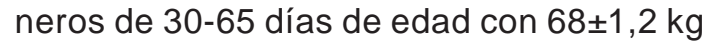
de peso al inicio del experimento. Las piezas de cría fueron asignadas a un diseño experimental que estudió dos factores: carga y CF, dando lugar a 4 grupos ( $n=15 /$ grupo): 1) Carga baja (1,1 UG/ha); 2) Carga baja con CF; 3) Carga alta (1,7 UG/ha); 4) Carga alta con CF. Los animales pastorearon en campo natural reservado (primer año de Ornitophus pinnatus cerrado al inicio de primavera), en pastoreo continuo. La asignación de forraje fue de $3 \mathrm{~kg} \mathrm{MS} / \mathrm{kg}$ peso vivo para las vacas en carga alta, y de $4 \mathrm{~kg} \mathrm{MS} / \mathrm{kg}$ peso vivo para las vacas en carga baja. El área experimental (50 ha) fue dividida en 4 parcelas, 2 de 15 ha y 2 de 10 ha. La disponibilidad de materia seca al inicio fue de 2100 $\mathrm{kg} \mathrm{MS/ha} \mathrm{(10} \mathrm{cm} \mathrm{altura).} \mathrm{A} \mathrm{los} \mathrm{terneros} \mathrm{se}$ les ofreció sin restricción (rechazo > 15\%) una ración comercial con $21 \%$ de proteína cruda (Ternero Premium, Colonia El Ombú, Río Negro, Uruguay), comenzando al 1\% del peso vivo. Para enseñar a comer a los terneros, las vacas recibieron el suplemento al 1\% del peso vivo en las primeras dos semanas del experimento. Se utilizaron escamoteadores, para permitir el ingreso de los terneros al área de suplementación. Se suministraron bloques de sal mineral a todos los gru- pos (Bloque fosfórico, Laboratorio Cibeles, Montevideo, Uruguay). La detección de celo y servicio se realizó dos veces al día con un toro. Cada 14 días se registró el peso vivo de terneros y vacas y se evaluó la condición corporal de las vacas. El comportamiento de los animales en pastoreo fue evaluado durante las horas luz a intervalos de 3 semanas. El consumo de leche se evaluó cada 4 semanas por el método peso-amamantamiento-peso. Los resultados se analizaron mediante análisis de varianza y estudio de frecuencias utilizando el paquete estadístico de SAS. Los valores fueron considerados significativos si $\mathrm{P}<0,05$.

\section{RESULTADOS}

El peso de los terneros al destete y la ganancia diaria estuvieron afectados por el CF y la carga (Alta: $144 \pm 3 \mathrm{~kg}$ y $0,8 \pm 0,02 \mathrm{~kg} / \mathrm{d}$; Alta con CF: $169 \pm 7 \mathrm{~kg}$ y $1,1 \pm 0,05 \mathrm{~kg} / \mathrm{d}$; Baja: $150 \pm 3 \mathrm{~kg}$ y $0,9 \pm 0,02 \mathrm{~kg} / \mathrm{d}$; Baja con CF: $185 \pm 4$ $\mathrm{kg}$ y $1,2 \pm 0,03 \mathrm{~kg} / \mathrm{d}$, respectivamente; $\mathrm{P}<0,001)$. Los terneros de CF pastorearon menos tiempo $(4,5 \pm 0,1$ horas $)$ que los terneros sin CF $(7,4 \pm 0,1$ horas $)$ y los de carga alta más tiempo $(6,5 \pm 0,1$ horas) que los de carga baja $(5,4 \pm 0,1$ horas; $P<0,001)$. El tiempo dedicado al amamantamiento fue similar entre grupos $(0,55 \pm 0,06$ horas; $P<0,05)$. La evolución del peso vivo de las vacas estuvo afectada por la carga y el CF. La vacas de los grupos CF, tuvieron un aumento transitorio de peso vivo en las 2 primeras semanas del experimento $(423 \pm 7,5 \mathrm{~kg}$ y $441 \pm 7,5 \mathrm{~kg}$; $\mathrm{P}<0,05)$. Las vacas de la carga baja mantuvieron peso hasta la semana $8(424 \pm 7,5 \mathrm{~kg})$, mientras que las de carga alta perdieron peso de la semana 2 a la semana $4(434 \pm 7,5 \mathrm{~kg}$ a $419 \pm 7,5 \mathrm{~kg} ; \mathrm{P}<0,05)$. El peso vivo se recuperó en todos los grupos a partir de la semana 10. La evolución de la condición corporal no estuvo afectada por la interacción entre CF y carga $(P<0,05)$, pero disminuyó gradualmente desde la semana 1 a la $8(4,1 \pm 0,06$ y $3,5 \pm 0,06)$ recuperándose en la semana 10 $(3,9 \pm 0,06 ; P<0,001)$. Las vacas de cargas altas $(8,9 \pm 0,1$ horas) pastorearon por más tiempo que las de las cargas bajas $(8,1 \pm 0,1$ horas; $P<0,01)$. La producción de leche fue 
mayor para las vacas de CF $(5,1 \pm 0,2$ lts $)$ que en las vacas sin CF $(3,8 \pm 0,2$ Its; $P<0,001)$. El número de vacas en celo (Baja: 9/15; Baja con CF: 12/15; Alta: 9/15; Alta con CF: 11/15) y preñadas (Baja: 9/15; Baja con CF: 11/15; Alta: 9/15; Alta con CF: 11/15) fue similar entre grupos.

\section{DISCUSIÓN}

La alimentación diferencial de los terneros permitió una mayor tasa de ganancia, asociándose con una sustitución del pasto por el suplemento, pero no por la leche materna. A pesar de que el tiempo de amamantamiento fue similar entre grupos, la mayor producción de leche de las vacas cuyos terneros recibieron CF puede haber afectado la tasa de ganancia de peso (Rovira, 1996). La alimentación diferencial de las vacas para enseñar a comer a los terneros aumentó el peso vivo, pero al aumentar la producción de leche no se vio reflejado en una mayor performance reproductiva. Las vacas de carga alta tuvieron que dedicar más tiempo al pastoreo para poder mantener la condición corporal al mismo nivel que las de carga baja. La pérdida transitoria de peso en las vacas de carga alta no se vio reflejada en una menor eficiencia reproductiva, probablemente porque la asignación de forraje entre grupos de carga alta y baja fue similar. Concluimos que la alimentación diferencial de los terneros tiene un impacto directo sobre la tasa de ganancia y el peso al destete, pero al no favorecer una recuperación de la condición corporal de las vacas no se expresa en una mayor eficiencia reproductiva.

\section{BIBLIOGRAFÍA}

Nogueira E et al. (2006) Efeito do creep feeding sobre o desempenho de bezerros e a eficiência reprodutiva de primíparas Nelore, em pastejo. Arquivo Brasileiro de Medicina Veterinária e Zootecnia 58:607 $-613$.

Nunes Motta de Souza A, Piva Lobato JF, Neumann M (2007) Efeitos do livre acesso de 5,1 vs 3.8 bezerros ao creepfeeding sobre os desempenhos produtivo e reprodutivo de vacas primíparas. Revista Brasileira de Zootecnia 36:1894-1901.

Rovira J (1996) Manejo nutritivo de los rodeos de cría en pastoreo. Buenos Aires. Hemisferio Sur.

Scaglia G (2004) Alimentación preferencial del ternero. Boletín divulgación 83. INIA Treinta y Tres. 



\title{
EFECTO DE LA CARGA Y LA SUPLEMENTACIÓN DE LAS TERNERAS SOBRE SUTASA DE CRECIMIENTO Y LA PERFORMANCE REPRODUCTIVA DE LAS VACAS
}

\author{
C. Betancurt ${ }^{1}$, I. Quagliotti ${ }^{1}$, H. Rosano ${ }^{1}$, P. Cuadro ${ }^{2}$, C. Viñoles ${ }^{2}$
}

\begin{abstract}
RESUMEN
Para evaluar el impacto de la carga animal y la alimentación diferencial por medio de creep feeding (CF) de las terneras sobre su tasa de crecimiento y la eficiencia reproductiva de las madres, se utilizaron 36 piezas de cría Hereford. Se formaron 4 grupos ( $n=9 / g r u p o$ ): 1) Carga baja ( 0,7 UG/ha); 2) Carga baja con CF; 3) Carga alta (1,1 UG/ha); 4) Carga alta con CF. El suplemento aumentó la tasa de ganancia y el peso de las terneras $(P<0,001)$. Las terneras de carga alta con CF dedicaron más horas al amamantamiento y el pastoreo $(P<0,05)$. Terneras mantenidas en carga baja tuvieron una mayor tasa de ganancia de peso que las terneras en carga alta $(P<0,05)$. La carga afectó la evolución de peso vivo y condición corporal de las vacas, promoviendo un reinicio de la ciclicidad y preñez más temprana en vacas mantenidas en carga baja $(P<0,05)$. En conclusión la alimentación preferencial y la carga baja aumentaron la ganancia de peso de las terneras, pero solo la carga afectó la eficiencia reproductiva de las madres.
\end{abstract}

\section{INTRODUCCIÓN}

La eficiencia de los sistemas criadores puede ser cuantificada como los $\mathrm{kg}$ de ternero destetado por unidad de superficie de pastoreo, indicador que incluye el porcentaje de destete, el peso al destete y la carga (Simeone y Beretta, 2002). La mayor pérdida del potencial para producir terneros ocurre porque las vacas tienen un período de anestro posparto prolongado, por lo que no quedan preñadas durante el entore. La duración del anestro pos-parto está determinada por la nutrición y el amamantamiento (Short et al., 1990).

En sistemas pastoriles, la nutrición está determinada por un adecuado ajuste entre la oferta de forraje y los requerimientos de las vacas. En el Basalto, la producción y crecimiento de pasturas en la época de entore (verano) es variable, afectando la recuperación de la condición corporal de las vacas y la tasa de crecimiento de los terneros (Berreta y Bemhaja, 1998).

El efecto de la alimentación preferencial de los terneros o creep feeding (CF) sobre su tasa de ganancia es consistente (Eversole, 2001; Michelena et al., 2008). Sin embargo, los resultados sobre la evolución del peso, condición corporal y tasa de preñez de las vacas son contradictorios (Prichard et al., 1989). A pesar de que se especula con que terneros suplementados disminuirían el consumo de leche, no existen resul-

${ }^{1}$ Estudiantes de tesis de Facultad de Veterinaria,

2 INIA, Instituto Nacional de Investigación Agropecuaria. 
tados claros al respecto. Por lo tanto, nos planteamos la hipótesis de que la suplementación de terneras al pie de la madre permite una adecuada tasa de ganancia aún en situaciones de alta carga, y una reducción en la frecuencia del amamantamiento lo que redundaría en un reinicio más temprano de la actividad ovárica de las madres. El objetivo de este estudio fue evaluar el impacto de la carga y la suplementación de terneras al pie de la madre sobre su tasa de crecimiento y el reinicio de la actividad ovárica en vacas.

\section{MATERIALES Y MÉTODOS}

El experimento fue realizado en la Unidad Experimental «Glencoe» INIA Tacuarembó del 17/12/2008 al 24/03/2009. Se utilizaron 36 vacas Hereford (edad: 4-6 años; peso vivo: $456 \pm 40 \mathrm{~kg}(1,3 \cup \mathrm{UG})$; condición corporal: 4,3 $\pm 0,5$ unidades (escala 1-8)). Las terneras (56 \pm 2 días) pesaron $73 \pm 12 \mathrm{~kg}$ al inicio del experimento (22/12/08). El diseño experimental dio origen a 4 grupos ( $n=9 / g r u p o)$ : 1) Carga baja (0,7 UG/ha); 2) Carga baja con CF; 3) Carga alta (1,1 UG/ha); 4) Carga alta con CF. Los animales pastorearon campo natural en pastoreo continuo, la disponibilidad al inicio fue de $1084 \mathrm{~kg} \mathrm{MS} / \mathrm{ha}$. La asignación de forraje fue de $3 \mathrm{~kg}$ MS/ $\mathrm{kg}$ peso vivo a las vacas en carga alta y de $7 \mathrm{~kg} \mathrm{MS/}$ $\mathrm{kg}$ peso vivo a las vacas en carga baja. A las terneras se les ofreció al $1 \%$ de su peso vivo una ración con 18 \% de proteína cruda. El entore duró 60 días. Cada 14 días se registró el peso vivo de terneras y vacas y la condición corporal de las vacas. Semanalmente se determinó la presencia de cuerpos lúteos; indicativo de ciclicidad. El comportamiento de los animales fue evaluado cada 4 semanas durante 4 horas en la mañana y 4 horas en la tarde, registrando las actividades (pastoreo, suplementación, amamantamiento) cada 5 minutos. El consumo de leche se evaluó cada 4 semanas por el método peso-amamantamiento-peso. Los resultados se analizaron mediante análisis de varianza y estudio de frecuencias utilizando el paquete estadístico de SAS. Los valores fueron considerados significativos si $\mathrm{P}<0,05$.

\section{RESULTADOS}

Las vacas carga alta tenían una asignación de forraje de $450 \mathrm{~kg}$ MS/ha disponible al mes de iniciado el experimento . Dado que todas las vacas perdieron peso y condición corporal durante la seca, fue necesaria la suplementación con fardos (300 kg: 2 fardos/ semana en la carga baja y 1,5 fardos/semana en la carga alta). A los 80 días de iniciado

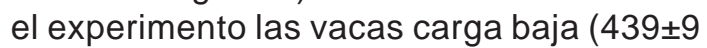
kg) pesaban $53 \mathrm{~kg}$ más y tenían 0,9 puntos más de condición corporal ( $4 \pm 0,1$ unidades) que las carga alta $(386 \pm 11 \mathrm{~kg} ; 3 \pm 0,2$ unidades; $\mathrm{P}<0,001)$. A los 21 días de iniciado el experimento, más vacas carga baja (12/18) estaban ciclando, respecto a las de carga alta $(6 / 18 ; P<0,05)$. A los 41 días de iniciado el experimento, más vacas carga baja estaban preñadas (6/18), respecto a las de carga alta $(1 / 18 ; P<0,05)$. Al final del entore, la cantidad de vacas preñadas fue similar (carga baja: 17/18; carga alta: 13/18).

Las ganancias de peso fueron mayores en la terneras con $C F(0,77 \pm 0,02 \mathrm{~kg} /$ día) que en las sin CF $(0,59 \pm 0,02 \mathrm{~kg} /$ día; $P<0,001)$. A los 80 días de comenzado el experimento, las terneras CF (carga baja con CF: $136 \pm 6,1$ kg y carga alta con CF: $134 \pm 4,8$ ) eran más pesadas que las sin CF (carga baja: $118 \pm 4,3$ kg y carga alta: $121 \pm 6,2 \mathrm{~kg} ; \mathrm{P}<0,001)$. Las terneras de carga baja tuvieron mayores ganancias $(0,71 \pm 0,02 \mathrm{~kg} /$ día) que las de carga alta $(0,65 \pm 0,02 \mathrm{~kg} / \mathrm{día} ; \mathrm{P}<0,05)$. Las terneras con CF pastorearon menos tiempo $(4,08 \pm 0,1$ horas) que las terneras sin CF $(5,63 \pm 0,1$ horas; $P<0,001)$. Las terneras carga alta sin CF mamaron más tiempo $(0,37 \pm 0,05$ horas) y consumieron más leche $(4,1 \pm 0,3 \mathrm{~kg})$ que los demás grupos (carga baja sin CF: $0,27 \pm 0,05$ horas y $3,0 \pm 0,3 \mathrm{~kg}$; carga baja con CF: $0,28 \pm 0,05$ horas y $3,5 \pm 0,3$ kg; carga alta con CF: 0,23 $\pm 0,05$ horas y $3,3 \pm 0,3 \mathrm{~kg} ; \mathrm{P}<0,05)$.

\section{DISCUSIÓN}

La suplementación preferencial de terneras al pie de la madre permitió una adecuada tasa de ganancia en situaciones de alta carga, y redujo el consumo de leche de las 
terneras pero no afectó el reinicio de la ciclicidad en las vacas.

El CF permitió aumentar las ganancias y el peso de las terneras. Estos resultados coinciden con los obtenidos anteriormente, reafirmando que esta herramienta permite obtener terneros más pesados al destete (Michelena et al., 2008). La mayor ganancia de peso de las terneras que recibieron CF estuvo asociada a un menor tiempo de pastoreo. La evolución de peso y condición corporal de las vacas no estuvo afectada por la suplementación de las terneras, por lo que no se modificó la duración del anestro posparto. La carga baja favoreció una mayor tasa de ganancia de las terneras, pero no estuvo asociada al consumo de leche. Sin embargo, las terneras de carga alta sin CF mamaron más tiempo y consumieron más leche que las de carga baja para mantener tasas de ganancia de peso más bajas. La dotación tuvo un efecto importante en la evolución del peso vivo y la condición corporal de las vacas (Short et al., 1990). Las vacas de carga baja, comenzaron a ciclar y se preñaron una semana antes que las vacas de carga alta.

Concluimos que el CF aumenta la tasa de ganancia de peso y reduce el consumo de leche solamente en carga alta. La carga baja aumenta la ganancia de peso de las terneras y acelera el reinicio de la ciclicidad de las vacas.

\section{BIBLIOGRAFÍA}

Berreta EJ, Bemhaja M (1998) Seminario de actualización en tecnologías para basalto. Serie técnica 102 INIA.

Eversole D. (2001) Creep Feeding Beef Calves. Virginia Cooperative Extension 400-003.

Michelena A et al. (2008) Efecto de la dotación y la alimentación diferencial sobre la tasa de crecimiento de los terneros y el desempeño reproductivo de las vacas. In: XXXVI Jornadas Uruguayas de Buiatría. pp. 237 - 238.

Prichard DL et al. (1989) Effects of creep feeding, zeranol implants and breed type on beef production: I. Calf and cow performance. Journal of animal science 67:609-616.

Short RE et al. (1990) Physiological Mechanisms Controlling Anestrus and Infertiliy in Postpartum Beff Cattle. Journal of Animal Science 68:799-816.

Simeone A, Beretta V (2002) Destete precoz en ganado de carne. Editor. Agropecuaria Hemisferio Sur S. R. L. 



\title{
EFECTO DEL CREEP FEEDING Y EL DESTETE TEMPORARIO SOBRE LA PERFORMANCE REPRODUCTIVA DE VACAS HEREFORD PRIMÍPARAS Y LA TASA DE CRECIMIENTO DE LOS TERNEROS
}

\begin{abstract}
RESUMEN
Se utilizaron 68 vacas Hereford de primera cría en un diseño factorial 2x2 que evaluó el efecto del creep feeding (CF) y el destete temporario (DT), formándose 4 grupos: 1 ) +CF-DT $(n=16) ; 2)+C F+D T(n=17) ; 3) \operatorname{Sin} C F(-C F+D T, n=17)$ y 4) $-C F$ y sin DT (-CF-DT, $n=18)$. La condición corporal de las vacas $+C F+D T(5,2 \pm 0,1$ unidades; $P<0,001)$ fue superior a la de los otros grupos (5,0 0,1 unidades). El DT adelantó el momento de la concepción (-CF+DT= $62 \pm 3 \mathrm{~d} ; \mathrm{P}<0,01)$ comparado con los otros grupos ( $-C F-D T=51 \pm 2 \mathrm{~d} ;+C F+D T=52 \pm 3 \mathrm{~d}$ y + CF$D T=54 \pm 3 \mathrm{~d})$. Los terneros del grupo $+C F-D T(201 \pm 6 \mathrm{~kg} ; P<0,001)$ fueron más pesados que los de los otros grupos (-CF-DT $=180 \pm 7 \mathrm{~kg} ;-C F+D T=177 \pm 4 \mathrm{~kg} ;+C F+D T=184 \pm 8 \mathrm{~kg}$ ). La tasa de ganancia de peso fue mayor en el grupo + CF-DT $(0,891 \pm 0,1 \mathrm{~kg} / \mathrm{d} ; \mathrm{P}<0,001)$ que en los otros grupos (-CF-DT=0,681 $\pm 0,1 \mathrm{~kg} / \mathrm{d}$; $-\mathrm{CF}+\mathrm{DT}=0,689 \pm 0,1 \mathrm{~kg} / \mathrm{d}$; $+C F+D T=0,697 \pm 0,1 \mathrm{~kg} / \mathrm{d}$ ). Concluimos que el CF tiene un impacto positivo en el crecimiento de los terneros pero elimina el impacto positivo del DT sobre el momento de la concepción de las vacas.
\end{abstract}

\section{INTRODUCCIÓN}

El creep feeding (CF) permite a los terneros lograr tasas de ganancia $>1 \mathrm{~kg}$ durante el verano, y pesos de destete $180 \mathrm{~kg}, 20-30$ $\mathrm{kg}$ mayores que los terneros no suplementados, con eficiencias de conversión de 45:1 (Michelena et al., 2008, Betancurt et al., 2009). Sin embargo, la suplementación del ternero no tiene un impacto positivo en la eficiencia reproductiva de las vacas adultas, a pesar de que disminuye el tiempo dedicado al amamantamiento en situaciones de alta carga (Michelena et al., 2008, Betancurt et al., 2009). El destete temporario (DT) con tablillas nasales durante 14 días corta el ama- mantamiento, y permite una recuperación de los niveles de hormonas metabólicas, que favorecen el desarrollo folicular y la ovulación (Quintans et al., 2010). Para que sea efectiva, la tablilla debe aplicarse a vacas con condición corporal > 3,5 unidades, y el resultado es variable en vacas de primera cría. Durante el período de aplicación de la tablilla nasal, los terneros tienen tasas de ganancia de peso muy leves, que muchas veces no se recuperan al momento del destete definitivo. Una alternativa para mejorar las tasas de ganancia de los terneros podría ser combinar el DT con el CF. El objetivo de este trabajo fue evaluar el impacto de la alimentación diferencial de los terneros y el control

${ }^{1}$ INIA, Instituto Nacional de Investigación Agropecuaria 
de amamantamiento sobre la tasa de crecimiento de los terneros y la preñez de las vacas al segundo entore.

\section{MATERIALES Y MÉTODOS}

El experimento se llevó a cabo en la Unidad Experimental Glencoe, en el período 23 de Noviembre de 2011 al 8 de Marzo de 2012 (106 días de duración). Se utilizaron 68 vacas Hereford primíparas (501 $\pm 7 \mathrm{~kg}$ de peso vivo y 5,2 $\pm 0,1$ unidades de CC; escala 1-8 unidades), de 2 y 3 años de edad y sus terneros $(115 \pm 3,2 \mathrm{~kg})$ con $73 \pm 2$ días pos-parto, en un diseño factorial que evaluó dos factores: 1) la alimentación diferencial de los terneros o CF; 2) el destete temporario (DT) de 14 días de duración, formándose 4 grupos: 1) +CF-DT $(n=16) ; 2)+C F+D T(n=17) ; 3) \sin$ CF (-CF+DT, n=17) y 4) -CF y sin DT (-CFDT, $n=18)$. Las vacas pastorearon campo natural con una disponibilidad promedio de $2098 \mathrm{~kg}$ MS, una altura de $10 \mathrm{~cm}$ y una asignación de forraje de $4 \mathrm{~kg} \mathrm{MS} / \mathrm{kg}$ peso vivo. La carga promedio durante el período experimental fue de 1,3 UG/ha. Los terneros del grupo CF fueron sometidos a un período de acostumbramiento de 8 días, previo a la aplicación de las tablillas nasales. Se utilizó una ración comercial de destete precoz (18\% de PC y 3 Mcal de energía/ $\mathrm{kg}$ ) que fue administrada al $1 \%$ del peso vivo. La tablilla nasal se aplicó el día de inicio del entore (Día 0) durante 14 días (Día 14). Se tomaron registros de condición corporal en las vacas, y peso de los terneros cada 14 días. Se realizaron ecografías ováricas al momento de aplicar y retirar la tablilla, y a los días 43, 77 y 98 de comenzado el entore para evaluar la edad embrionaria/fetal. Las variables continuas fueron analizadas utilizando el procedimiento mixto y glm de SAS, ajustando por el peso vivo y la condición corporal iniciales. Las variables categóricas fueron analizadas utilizando el procedimiento genmode de SAS. Los valores fueron considerados significativos si $\mathrm{P}<0,05$.

\section{RESULTADOS}

La condición corporal se mantuvo en niveles $\geq 5$ unidades $(5,2 \pm 0,1$ unidades; $\mathrm{P}<0,001)$ durante todo el período solamente en el grupo +CF+DT respecto a la de los otros grupos $(5,0 \pm 0,1$ unidades). La ciclicidad (100\% al Día 43 de comenzado el entore) y el porcentaje de preñez (97\%) fueron similares entre grupos. Las vacas a cuyos terneros se les aplicó DT tuvieron una mayor edad gestacional al diagnóstico (-CF+DT=62,4 $\pm 2,5$ días; $P<0,01)$, que las vacas cuyos terneros pertenecieron a los grupos -CF-DT $(50,8 \pm 2,4$ días $),+C F+D T$ (51,6 $\pm 2,5$ días) o +CF-DT (53,8 $\pm 2,6$ días). Los terneros del grupo +CF-DT $(201 \pm 6$ kg; $\mathrm{P}<0,001)$ fueron más pesados al destete que los de los grupos -CF-DT $=180 \pm 7 \mathrm{~kg}$, $\mathrm{CF}+\mathrm{DT}=177 \pm 4 \mathrm{~kg}$ y $+\mathrm{CF}+\mathrm{DT}=184 \pm 8 \mathrm{~kg}$. El peso de los terneros de los grupos -CF-DT fue similar al de los del grupo +CF+DT. La tasa de ganancia de peso de los terneros del grupo +CF-DT fue mayor y constante en el tiempo $(0,891 \pm 0,1 \mathrm{~kg} / \mathrm{d}$; $P<0,001)$ comparados con los otros grupos (-CF-DT=0,681 $\pm 0,1 \mathrm{~kg} / \mathrm{d}$; $-C F+D T=0,689 \pm 0,1 \mathrm{~kg} / \mathrm{d}$; +CF+DT=0,697 $\pm 0,1 \mathrm{~kg} /$ d).

\section{DISCUSIÓN}

Los terneros suplementados al pie de la madre a los que no se aplicó DT tuvieron tasas de ganancia de peso mayores y lograron pesos al destete de $201 \mathrm{~kg}$. Estos resultados son consistentes con los obtenidos anteriormente (Michelena et al., 2008, Betancurt et al., 2009), y refuerzan el concepto de que el nivel nutricional en los sistemas criadores del Basalto limita la expresión del potencial genético para crecimiento de los terneros. El uso de la tablilla nasal redujo las tasas de ganancia de peso de los terneros a 0,2-0,4 kg/d, pero el CF permitió que el peso vivo se recuperara hacia el momento de destete. Por lo tanto, la suplementación del ternero durante el período de aplicación de la tablilla nasal permite recuperar los kilos de peso que se pierden por el uso de esta herramienta. La condición corporal de las vacas determinó una excelente performan- 
ce reproductiva. EI DT sin CF tuvo un efecto positivo en adelantar el momento de la preñez, pero su combinación con el CF eliminó ese efecto positivo. La falta de efecto en adelantar la preñez por aplicar el CF en terneros con DT puede estar asociado con el comportamiento de las vacas, que durante el primer mes de CF permanecen rodeando el área de CF. Por lo tanto, el CF favorece al ternero, pero reduce la performance reproductiva que podría ser mejorada con un DT de 14 días de duración. Concluimos que el CF tuvo un impacto positivo en la tasa de ganancia y el peso al destete de los terneros, y la condición corporal de las vacas, pero a pesar de ello, no se reflejó asociado con el DT, en un adelanto en el momento de la preñez.

\section{BIBLIOGRAFÍA}

Betancurt C, Quagliotti I, Rosano H, Cuadro P \& Viñoles C 2009. XXXVII Jornadas Uruguayas de Buiatría 150-151.

Michelena A, Martín A, Echenique $V$ \& Viñoles C. 2008. XXXVI Jornadas Uruguayas de Buiatría 237-238.

Quintans G, Banchero G, Carriquiry M, LópezMazz C \& Baldi F 2010 Animal Production Science 50 931-938. 



\title{
EFECTO DEL CREEP FEEDING Y EL DESTETE TEMPORARIO SOBRE EL DESARROLLO DE LOS TERNEROS Y LA EFICIENCIA REPRODUCTIVA DE VACAS HEREFORD PRIMÍPARAS
}

\author{
M. Bentancor ${ }^{1}$, A. Bistolfi ${ }^{1}$, L. Zerbino ${ }^{1}$, C. Viñoles $^{2}$
}

\section{RESUMEN}

Se utilizaron 74 vacas Hereford de primera cría en un diseño que evaluó la suplementación del ternero (CF) y el destete temporario (DT). Se formaron 4 grupos, en un diseño factorial, con 2 repeticiones: 1) Sin CF Sin DT (-CF-DT; $n=21)$; 2) sin CF con DT (-CF+DT; $n=16)$; 3) con CF sin DT (+CF-DT; $n=20)$; con CF con DT (+CF+DT; n=17). El DT aumentó la probabilidad de preñez en los primeros 21 días de entore $(0,73 \pm 0,08)$, respecto a los grupos -DT $(0,37 \pm 0,08 ; P<0,05)$. El CF (+CF-DT= 20/20; +CF+DT= 16/17) aumentó la preñez final (-CF-DT: 14/21; -CF+DT=14/16; $P<0,05)$. El CF aumentó la tasa de ganancia de peso de los terneros durante el DT (+CF+DT $=0,454 \pm 0,06 \mathrm{~kg} / \mathrm{d}$ vs $-C F+D T=0,250 \pm 0,06 \mathrm{~kg} / \mathrm{d}$ : $\mathrm{P}<0,01$ ). Los terneros de los grupos con creep feeding (+CF-DT $=190 \pm 2,2 \mathrm{~kg} ;+\mathrm{CF}+\mathrm{DT}=182 \pm 2,3$ $\mathrm{kg}$ ) fueron más pesados al destete que los de los grupos sin creep (-CF-DT $=154 \pm 2,2 \mathrm{~kg}$; $-C F+D T=146 \pm 2,5 \mathrm{~kg} ; \mathrm{P}<0,05)$. Concluimos que el $C F$ tuvo un impacto positivo en la preñez final, la tasa de ganancia y el peso al destete de los terneros, y que el DT aumentó la probabilidad de preñez temprana en vacas de primera cría.

\section{INTRODUCCIÓN}

El creep feeding permite obtener pesos al destete de $180 \mathrm{~kg}$, superando en $20-30 \mathrm{~kg}$ a los terneros no suplementados, mediante tasas de ganancia $>1 \mathrm{~kg}$ durante el verano y con eficiencias de conversión de 4-5:1 (Michelena et al., 2008, Betancurt et al., 2009). Sin embargo, la suplementación del ternero no tiene un impacto positivo en la eficiencia reproductiva de las vacas adultas (Michelena et al., 2008, Betancurt et al., 2009). El destete temporario con tablillas nasales durante 14 días impide el amamantamiento, y permite una recuperación de los niveles de hormonas metabólicas, que favorecen el desarrollo folicular y la ovulación (Quintans et al., 2010). Se ha observado una pobre respuesta al destete con tablilla nasal en vacas de primera cría con baja condición corporal. Para que sea efectiva la tablilla debe aplicarse a terneros hijos de vacas con condición corporal $>4$ unidades. Durante los 14 días de destete temporario, los terneros tienen tasas de ganancia de peso inferiores respecto a los terneros $\sin$ tablilla $(0,46$ vs $1,11 \mathrm{~kg} / \mathrm{día}$ ), que muchas veces no se recuperan al momento del destete definitivo (Jimenez de Aréchaga et al., 2005). Por lo tanto, nos planteamos la hipótesis de que la

${ }^{1}$ Estudiantes de tesis de Facultad de Veterinaria.

2 INIA, Instituto Nacional de Investigación Agropecuaria. 
combinación del creep feeding con el destete temporario, permitiría aumentar la tasa de ganancia de peso de los terneros y mejorar la eficiencia reproductiva de las vacas. El objetivo de este trabajo fue evaluar el impacto de la alimentación diferencial de los terneros y el destete temporario sobre la tasa de crecimiento de los terneros y la preñez de vacas primíparas al segundo entore.

\section{MATERIALES Y MÉTODOS}

El experimento se llevó a cabo en la Unidad Experimental Glencoe, INIA Tacuarembó, desde el 15 de Noviembre de 2012 al 21 de Marzo de 2013. Se utilizaron 74 vacas Hereford primíparas de 2 y 3 años de edad y sus terneros con $75 \pm 2$ días de edad, en un diseño completamente al azar, que evaluó dos factores: Ia alimentación diferencial de los terneros o creep feeding (CF) y el destete temporario (DT). Se formaron 4 grupos, en un diseño factorial, con 2 repeticiones: 1 ) Sin CF Sin DT (-CF-DT; n=21); 2) sin CF con DT (-CF+DT; $n=16) ; 3)$ con CF sin DT (+CFDT; $n=20)$; con CF con DT (+CF+DT; $n=17$ ). El peso vivo (PV) inicial de los terneros fue $79,5 \pm 1,9 \mathrm{~kg}$ y el de las vacas de $418 \pm 1,8 \mathrm{~kg}$ de peso vivo y $4,1 \pm 0,04$ unidades de condición corporal (escala 1-8 unidades). La vacas pastorearon campo natural con una disponibilidad inicial de $2088 \pm 850 \mathrm{~kg} \mathrm{Ms} / \mathrm{ha}$ y una asignación de forraje de $6 \mathrm{~kg}$ MS/kg PV. La carga promedio fue de 1,2 UG/ha. Los terneros del grupo CF fueron sometidos a un período de acostumbramiento de 10 días, previo a la aplicación de las tablillas nasales. El período de suplementación fue de 125 días, la ración comercial fue suministrada al $1 \%$ del PV, con un contenido de energía de $2,73 \mathrm{Mcal}$ EM/kg MS y un contenido de proteína de $18,4 \%$. La tablilla nasal se aplicó el día de inicio del entore (Día 0) durante 14 días. Se tomaron registros de condición corporal, peso de las vacas y terneros, cada 14 días. Se realizaron seis ecografías ováricas a los días -14, 0, 14, 56, 84 y 112 para evaluar la ciclicidad y la edad gestacional. Las variables continuas fueron analizadas utilizando el procedimiento mixto y glm de SAS, ajustando por el peso vivo y la condición corporal inicial. Las variables categóricas fue- ron analizadas utilizando el procedimiento genmode y el test de supervivencia de SAS. Los valores fueron considerados significativos si $\mathrm{P}<0,05$.

\section{RESULTADOS}

El peso vivo y la condición corporal de las vacas no estuvieron afectadas por el CF, el $D T$ ni la interacción entre ambos factores ( $P>$ $0,05)$.

La ocurrencia de la primera ovulación posparto y la proporción de vacas ciclando al final del entore fue similar entre grupos (-CF-DT $=115 \pm 3$ d y 19/21; $-C F+D T=112 \pm 6$ d y $16 / 16 ;+C F-D T=116 \pm 3$ d y $20 / 20 ;+C F+D T=$ $107 \pm 4$ d y 17/17; P>0,05). El DT aumentó la probabilidad de preñez en los primeros 21 días de entore $(0,73 \pm 0,08)$, respecto a los grupos -DT $(0,37 \pm 0,08 ; P<0,05)$, pero no el CF $(+C F=0,57 \pm 0,08$ vs $-C F=0,49 \pm 0,08$; $P>0,05)$. El CF (+CF-DT $=20 / 20 ;+C F+D T=$ $16 / 17)$ tuvo un efecto positivo en la preñez final (-CF-DT=14/21; - CF+DT = 14/16; $P<0,05)$, pero no se observó un efecto del DT. La interacción entre ambos factores tendió a ser significativa $(P=0,09)$. El CF aumentó la tasa de ganancia de peso de los terneros durante el DT (+CF+DT = 0,454 $\pm 0,06$ $\mathrm{kg} / \mathrm{d}$ vs $-C F+D T=0,250 \pm 0,06 \mathrm{~kg} / \mathrm{d} ; \mathrm{P}<0,01)$, y durante todo el período experimental $(+\mathrm{CF}=$ $0,832 \pm 0,02 \mathrm{~kg} / \mathrm{d}$ vs $-\mathrm{CF}=0,530 \pm 0,02 \mathrm{~kg} / \mathrm{d}$; $\mathrm{P}<0,01)$. Los terneros de los grupos con creep, $\quad(+C F-D T=190 \pm 2,2 \quad k g$; $+C F+D T=182 \pm 2,3 \mathrm{~kg}$ ) fueron más pesados al destete que los de los grupos sin creep $(-C F-D T=154 \pm 2,2 \mathrm{~kg} ;-C F+D T=146 \pm 2,5 \mathrm{~kg}$; $\mathrm{P}<0,05)$.

\section{DISCUSIÓN}

La hipótesis de que el creep feeding asociado al destete temporario, permitiría aumentar la tasa de ganancia de peso de los terneros y mejorar la eficiencia reproductiva de las vacas fue aceptada. Los terneros suplementados al pie de la madre a los que no se aplicó DT tuvieron tasas de ganancia de peso mayores y lograron pesos al destete de 190 $\mathrm{kg}$. Estos resultados son consistentes con los obtenidos anteriormente (Michelena et al., 
2008, Betancurt et al., 2009), y refuerzan el concepto de que el nivel nutricional en los sistemas criadores del Basalto limita la expresión del potencial genético para crecimiento de los terneros. El uso de la tablilla nasal redujo las tasas de ganancia de peso de los terneros pero el CF permitió duplicarlas, y superar los $180 \mathrm{~kg}$ de peso al destete. EI DT adelantó el momento de la preñez, lo que puede estar asociado al cese del amamantamiento y a la recuperación de las concentraciones de insulina (Quintans et al., 2010). El efecto positivo del CF sobre la preñez final es un resultado diferente al observado en vacas multíparas, y podría estar asociado al comportamiento maternal de las distintas categorías (Ungerfeld et al., 2011). Concluimos que el CF tuvo un impacto positivo en la tasa de ganancia, el peso al destete de los terneros y la preñez final de las vacas y que el DT aumentó la probabilidad de preñez temprana en vacas de primera cría.

\section{BIBLIOGRAFÍA}

Betancurt C, Quagliotti I, Rosano H, Cuadro P \& Viñoles C 2009. XXXVII Jornadas Uruguayas de Buiatría 150-151.

Jimenez de Aréchaga C, Zarza C, Michelsson J, y Quintans G, (2005). Serie de actividad de difusión $\mathrm{N}^{\circ}$ 403, página 12.

Michelena A, Martín A, Echenique $V$ \& Viñoles C. 2008. XXXVI Jornadas Uruguayas de Buiatría 237-238.

Quintans G, Banchero G, Carriquiry M, LópezMazz C \& Baldi F 2010 Animal Production Science 50 931-938.

Ungerfeld R et al. (2011) Behavioral and physiological changes in early-weaned multiparous and primiparous beef cows. Animal/ : an international journal of animal bioscience 5:1270-5. 



\section{EFECTO DEL CREEP FEEDING CON AFRECHILLO DE ARROZ Y EL DESTETE TEMPORARIO SOBRE EL CRECIMIENTO DE LOS TERNEROS Y LA EFICIENCIA REPRODUCTIVA DE VACAS HEREFORD}

\section{RESUMEN}

Se utilizaron 87 vacas Hereford en un diseño factorial que evaluó la suplementación del ternero (CF) y el destete temporario (DT). El DT adelantó el momento de la concepción de las vacas (-CF-DT $=31 \pm 3 \mathrm{~d}$; $-C F+D T=22 \pm 2 \mathrm{~d} ;+C F-D T=34 \pm 5 \mathrm{~d} ;+C F+D T=24 \pm 2 ; P<0,05)$. El $\mathrm{CF}$ redujo la tasa de ganancia de peso de los terneros durante el período de $\mathrm{DT}$ (+CF+DT= $0,109 \pm 0,05 \mathrm{~kg} / \mathrm{d}$ vs $-C F+D T=0,309 \pm 0,05 \mathrm{~kg} / \mathrm{d} ; \mathrm{P}<0,01)$. Los terneros $+D T$ tuvieron menores ganancias de peso $(0,586 \pm 0,02 \mathrm{~kg} / \mathrm{d})$ durante el experimento respecto a los -DT $(0,834 \pm 0,04$ $\mathrm{kg} / \mathrm{d} ; \mathrm{P}<0,001)$. El CF no afectó el peso al destete de los terneros, pero el DT lo redujo (-CF$\mathrm{DT}=169 \pm 3 \mathrm{~kg} ;-\mathrm{CF}+\mathrm{DT}=155 \pm 2 \mathrm{~kg} ;+\mathrm{CF}-\mathrm{DT}=170 \pm 3 \mathrm{~kg} ;+C F+D T=152 \pm 2 \mathrm{~kg} ; \mathrm{P}<0,001)$. Concluimos que el CF con afrechillo de arroz ad libitum reduce la tasa de ganancia de peso durante el período de DT, y no permite aumentar los pesos al destete, mientras que el DT reduce las tasas de ganancia de peso y el peso al destete de los terneros, pero adelanta el momento de la concepción de las vacas.

\section{INTRODUCCIÓN}

El creep feeding con ración peleteada (18$21 \%$ PC) permite aumentar en forma consistente los pesos al destete (> $180 \mathrm{~kg}$ ) en 20 $40 \mathrm{~kg}$ respecto a terneros no suplementados, con tasas de ganancia $>1 \mathrm{~kg}$ y eficiencias de conversión de 3,2-5:1 (Bentancor et al., 2013; Viñoles et al., 2013). La suplementación del ternero aumenta la preñez final en vacas primíparas, pero no tiene efecto positivo en las multíparas (Bentancor et al., 2013; Viñoles et al., 2013). Se ha observado que vacas prímíparas en buena condición corpo- ral se preñan antes en respuesta al destete temporario (DT) respecto a aquellas cuyos terneros no reciben el tratamiento (Bentancor et al., 2013). Durante los 14 días de DT, los terneros tienen menores tasas de ganancia que los sin DT (0,250 vs 0,558 kg/día), que redundan en pesos más bajos al destete definitivo (Bentancor et al., 2013). Sin embargo, si los terneros aprenden a comer antes de aplicar la tablilla nasal, esas ganancias se duplican $(0,250$ vs $0,454 \mathrm{~kg} / \mathrm{día})$. El uso de sub-productos de menor costo que las raciones, podría aumentar el beneficio económico del creep feeding, pero no existe

${ }^{1}$ INIA, Instituto Nacional de Investigación Agropecuaria 
información al respecto. Por lo tanto, nos planteamos la hipótesis de que el creep feeding con afrechillo de arroz asociado al destete temporario, permitiría aumentar la tasa de ganancia de peso de los terneros y mejorar la eficiencia reproductiva de las vacas. El objetivo de este trabajo fue evaluar el impacto de la alimentación diferencial de los terneros con afrechillo de arroz y el destete temporario sobre la tasa de crecimiento de los terneros y la preñez de vacas Hereford.

\section{MATERIALES Y MÉTODOS}

El experimento se llevó a cabo en la Unidad Experimental Glencoe, INIA Tacuarembó, desde el 15 de Diciembre de 2014 al 23 de Marzo de 2015. Se utilizaron 87 vacas Hereford de 1-3 partos y sus terneros con $104 \pm 2,5$ días de edad, en un diseño factorial que evaluó: la alimentación diferencial de los terneros o creep feeding (CF) y el DT. Se formaron 4 grupos con 2 repeticiones: 1) Sin CF Sin DT (-CF-DT; n=23); 2) sin CF con DT (-CF+DT; $n=26) ; 3$ ) con CF sin DT (+CF-DT; $n=10)$; con CF con DT (+CF+DT; $n=28)$. El peso vivo (PV) inicial de los terneros fue $92,0 \pm 3,5 \mathrm{~kg}$ y el de las vacas de $475 \pm 5,7 \mathrm{~kg}$ y 4,8 $\pm 0,1$ unidades de condición corporal (escala 1-8 unidades). La vacas pastorearon campo natural con una disponibilidad inicial de $2593 \pm 173 \mathrm{~kg}$ Ms/ha y una asignación de forraje de $11 \mathrm{~kg} \mathrm{MS} / \mathrm{kg}$ PV. La carga promedio fue de 0,8 UG/ha. El período de suplementación fue de 98 días, comenzando el día en que se aplicó el DT y el suplemento fue afrechillo de arroz administrado ad libitum en comederos de autoconsumo, con un contenido de energía de 2,85 Mcal EM/kg MS y un contenido de proteína de 15,6\%. EI DT se aplicó el día de inicio del entore (Día 0) durante 14 días. Se tomaron registros de condición corporal, PV de las vacas y terneros, cada 14 días. Se realizaron ecografías para evaluar la edad gestacional. Las variables continuas fueron analizadas utilizando el procedimiento mixto y glm de SAS, ajustando por el PV y la condición corporal inicial. El momento de la concepción se analizó mediante el test de supervivencia de Minitab. Los valores fueron considerados significativos si $\mathrm{P}<0,05$.

\section{RESULTADOS}

Las vacas cuyos terneros recibieron CF fueron más pesadas $(483 \pm 2,9 \mathrm{~kg})$ respecto a las que sus terneros no recibieron CF $(473 \pm 2,2 \mathrm{~kg} ; \mathrm{P}<0,01)$, pero no se observó efecto del DT ni de la interacción CF*DT $(P>0,05)$. La condición corporal de las vacas no estuvo afectada por el CF, el DT ni la interacción entre los factores $(P>0,05)$.

EI DT adelantó el momento de la concepción de las vacas (-CF-DT $=31 \pm 3 \mathrm{~d}$; $-\mathrm{CF}+\mathrm{DT}=$ $22 \pm 2 \mathrm{~d}$; +CF-DT $=34 \pm 5 \mathrm{~d}$; +CF+DT $=24 \pm 2 \mathrm{~d}$; $\mathrm{P}<0,05)$. La proporción de vacas preñadas al final del entore fue similar entre grupos (-CF-DT: 22/23; -CF+DT=25/26; +CF-DT= 8/10; +CF+DT= 26/28; $P<0,05)$. El CF tuvo un efecto negativo en la tasa de ganancia de peso de los terneros durante el período de DT $(+C F+D T=0,109 \pm 0,05 \mathrm{~kg} / \mathrm{d}$ vs $\mathrm{CF}+\mathrm{DT}=0,309 \pm 0,05 \mathrm{~kg} / \mathrm{d} ; \mathrm{P}<0,01)$. Los terneros +DT tuvieron menores ganancias de peso $(0,586 \pm 0,02 \mathrm{~kg} / \mathrm{d})$ durante todo el período experimental respecto a los -DT $(0,834 \pm 0,04 \mathrm{~kg} / \mathrm{d} ; \mathrm{P}<0,001)$. El CF no afectó el peso al destete de los terneros, pero el DT lo redujo (-CF-DT: $169 \pm 3 \mathrm{~kg}$; $-\mathrm{CF}+\mathrm{DT}=$ $155 \pm 2 \mathrm{~kg}$; +CF-DT= 170 $\pm 3 \mathrm{~kg}$; +CF+DT= $152 \pm 2 \mathrm{~kg} ; \mathrm{P}<0,001)$.

\section{DISCUSIÓN}

La hipótesis de que el creep feeding con afrechillo de arroz asociado al destete temporario, permitiría aumentar la tasa de ganancia de peso de los terneros y mejorar la eficiencia reproductiva de las vacas no fue aceptada. Los terneros suplementados al pie de la madre a los que se aplicó DT tuvieron tasas de ganancia de peso menores que los no suplementados durante el período de DT, sin observarse diferencias al momento del destete. Estos resultados difieren de los obtenidos anteriormente con ración peleteada de 18 \% PC (Bentancor et al. , 2013), probablemente por la presencia de factores antinutricionales (Park et al., 2013) en el afrechillo de arroz administrado ad libitum. El DT redujo las tasas de ganancia en $0,248 \mathrm{~g} / \mathrm{d}$ y el $\mathrm{PV}$ al destete de los terneros en 15,5 kg, que en ningún caso se superaron los 170 
kg. El DT adelantó el momento de la preñez de las vacas en 9,5 días, lo que puede estar asociado al cese del amamantamiento y a la recuperación de las concentraciones de insulina (Quintans et al. , 2010). Concluimos que el CF con afrechillo de arroz ad libitum reduce la tasa de ganancia de peso durante el DT, y no permite aumentar los pesos al destete, mientras que el DT reduce las tasas de ganancia de peso y el peso al destete de los terneros, pero adelanta el momento de la concepción de las vacas. En estas condiciones, con vacas en condición corporal > a 4,5 unidades, es necesario evaluar el costo-beneficio de aplicar DT.

\section{BIBLIOGRAFÍA}

Bentancor, M., Bistolfi, A., Zerbino, L., Viñoles, C., 2013. Efecto del creep feeding y el destete temporario sobre el desarrollo de los terneros y la eficiencia reproductiva de vacas Hereford Primíparas, in: XLI Jornadas Uruguayas de Buiatría. Paysandú, Uruguay, p. 134.

Park, J.K., Kwon, E.G., Kim, C.H., 2013. Effects of increasing supplementation levels of rice bran on milk production and fatty acid composition of milk in Saanen dairy goats. Anim. Prod. Sci. 53, 413-418. doi:10.1071/AN12124

Quintans, G., Banchero, G., Carriquiry, M., López-Mazz, C., Baldi, F., 2010. Effect of body condition and suckling restriction with and without presence of the calf on cow and calf performance. Anim. Prod. Sci. 50, 931-938.

Viñoles, C., Jaurena, M., De Barbieri, I., Do Carmo, M., Montossi, F., 2013. Effect of creep feeding and stocking rate on the productivity of beef cattle grazing grasslands. New Zeal. J. Agric. Res. 56, 279-287. 



\title{
EFECTO DEL CREEP FEEDING CON AFRECHILLO DE ARROZY UNA SAL COMERCIAL Y EL DESTETE TEMPORARIO SOBRE PARÁMETROS PRODUCTIVOS DE LOS TERNEROS Y LA EFICIENCIA REPRODUCTIVA DE VACAS PRIMÍPARAS
}

\author{
J. P. Alvarez ${ }^{1}$, A. Da Silva ${ }^{2}$, C. Viñoles ${ }^{1}$
}

\begin{abstract}
RESUMEN
El objetivo de este trabajo fue evaluar el efecto del creep feeding con afrechillo de arroz y con una sal comercial, sobre las tasas de ganancia y peso al destete de los terneros y el impacto del destete temporario sobre la preñez de vacas de primera cría, paridas con 2 años de edad. Se utilizaron 262 vacas Hereford, Aberdeen Angus y sus cruzas con sus terneros. El diseño experimental fue completamente al azar, con un arreglo factorial de los tratamientos [Creep feeding (CF) con afrechillo de arroz (AA) y una sal comercial (SC)] y destete temporario (DT). Se formaron 6 grupos: 1) Sin CF y Sin DT (-CF-DT, $n=44) ; 2$ ) Sin CF y Con DT (-CF+DT, n=40); 3) Con CF con afrechillo de arrroz (AA) y Sin DT (+CFAA-DT, $n=42)$; 4) Con CFAA y Con DT (+CFAA+DT, $n=37)$; 5) Con CF con sal comercial y Sin DT (+CFSC-DT, $n=48) ; 6$ ) Con CFSC y Con DT (+CFSC+DT, n=51). El AA fue administrado en comederos de autoconsumo. Los animales pastorearon en forma continua sobre campo natural con una oferta de forraje promedio de $9 \pm 1 \mathrm{~kg} \mathrm{MS} / \mathrm{kg}$ PV. El CF y el DT afectaron negativamente las tasas de ganancia y los pesos al destete de los terneros (-CF-DT $=172 \pm 1,9$ $\mathrm{kg}$; $-\mathrm{CF}+\mathrm{DT}=159 \pm 1,9 \mathrm{~kg} ;+$ CFAA-DT $=159 \pm 1,6 \mathrm{~kg}$; +CFAA+DT $=147 \pm 1,6 \mathrm{~kg}$; +CFRS$\mathrm{DT}=141 \pm 2,0 \mathrm{~kg} ;+\mathrm{CFRS}+\mathrm{DT}=132 \pm 2,0 \mathrm{~kg} ; \mathrm{P}<0,001)$. La condición corporal de las vacas fue similar entre grupos, y aumentó entre el inicio $(3,84 \pm 0,04)$ y fin del experimento $(4,23 \pm 0,04$ $\mathrm{P}<0,01)$. Las vacas de los grupos +CFAA+DT y +CFAA-DT concibieron 15-20 días antes que los demás grupos $(P<0,01)$, pero no se observó diferencia en la preñez final $(74 \%)$. Concluimos que el creep feeding con AA y SC y el DT disminuye las tasas de ganancia y pesos al destete de los terneros, y que en vacas de primera cría, con adecuada condición corporal y asignación de forraje, el DT no mejora su eficiencia reproductiva pero el creep feeding con AA permite adelantar el momento de la preñez.
\end{abstract}

${ }_{1}^{1}$ INIA, Instituto Nacional de Investigación Agropecuaria.

${ }^{2}$ Estudiante de tesis de Facultad de Veterinaria. 


\section{INTRODUCCIÓN}

La eficiencia productiva de la cría vacuna depende de los kg de ternero destetado por hectárea, indicador que integra el porcentaje de destete, el peso del ternero al destete y el número de vacas por hectárea (Simeone y Beretta, 2002). El porcentaje de destete está determinado por la nutrición y el amamantamiento, habiéndose generado estrategias a nivel Nacional para levantar estas dos restricciones (Viñoles et al., 2009). El destete temporario, aplicado a hijos de vacas cuya condición corporal es > a 3,5, permite aumentar el porcentaje de preñez, pero tiene un efecto negativo en la tasa de ganancia y los pesos al destete de sus terneros (Quintans et al., 2010). El creep feeding o suplementación preferencial del ternero permite aumentar las tasas de ganancia y los pesos al destete de los terneros en $20-30 \mathrm{~kg}$, pero el impacto en la eficiencia reproductiva de la vaca no es consistente (Viñoles et al., 2013). La asociación de ambas tecnologías, permite duplicar las ganancias de peso de los terneros durante el período de aplicación de la tablilla, y eliminar el efecto negativo de la misma al destete (Bentancor et al., 2013). Sin embargo, el impacto económico del creep feeding es altamente dependiente del costo de la ración utilizada, por lo que la búsqueda de alternativas costo-efectivas es muy relevante para el productor. En este sentido, el uso de un sub-producto como el afrechillo de arroz podría ser una estrategia viable. Existen además en el mercado sales minerales diseñadas para aplicar la estrategia de creep feeding, pero no hemos encontrado información científica que respalde su uso. Por lo tanto, nos planteamos la hipótesis de que el uso del creep feeding con afrechillo de arroz y una sal comercial asociado al destete temporario aumentaría las ganancias de peso de los terneros durante el período de aplicación de la tablilla y eliminaría las diferencias de peso al destete generadas por el destete temporario, y que el destete mejoraría el porcentaje de preñez final de las vacas. El objetivo de este trabajo fue evaluar el efecto del creep feeding con afrechillo de arroz y con una sal comercial, sobre las tasas de ganancia y peso al destete de los terneros y el impacto del destete temporario sobre la preñez de vacas de primera cría, paridas con 2 años de edad.

\section{MATERIALES Y MÉTODOS}

El experimento tuvo una duración de 129 días (19 de noviembre de 2013 a 28 de marzo de 2014) y fue realizado en un predio comercial en el Departamento de Cerro Largo. Se utilizaron 262 vacas de las razas Hereford, Aberdeen Angus y sus cruzas de primera cría con 2 años y sus respectivos terneros, los cuales al inicio del experimento tenían mínimo 60 días de edad y un peso promedio de $74,56 \pm 22,07 \mathrm{~kg}$. Se utilizaron 13 toros Aberdeen Angus a los cuales se les realizó una revisación andrológica previa. El diseño experimental fue completamente al azar, con un arreglo factorial de los tratamientos [Creep feeding (CF) con afrechillo de arroz (AA) y una sal comercial (SC)] y destete temporario (DT). Se formaron 6 grupos: 1) Sin CF y Sin DT (-CF-DT, n=44); 2) Sin CF y Con DT (-CF+DT, n=40); 3) Con CF con afrechillo de $\operatorname{arrroz}(A A)$ y Sin DT (+CFAA-DT, $n=42)$; 4) Con CFAA y Con DT (+CFAA+DT, $n=37$ ); 5) Con CF con sal comercial y Sin DT (+CFSC-DT, n=48); 6) Con CFSC y Con DT (+CFSC+DT, n=51). Cada tratamiento tuvo su repetición. Los animales pastorearon en forma continua sobre campo natural con una oferta de forraje promedio de $9 \pm 1 \mathrm{~kg} \mathrm{MS} / \mathrm{kg}$ $\mathrm{PV}$. Los terneros fueron suplementados con AA con $21 \%$ de proteína cruda y 2 Mcal EM/kg MS y una sal comercial energizada que aportó $18 \%$ de proteína cruda y 2,7 Mcal EM/kg MS. La suplementación con AA se realizó en comederos de autoconsumo, realizando 2-3 recargas semanales, y la $\mathrm{RC}$ en bateas, con recargas de acuerdo al consumo de las mismas. EI DT duró 14 días, colocándose la tablilla nasal el día de inicio del entore a la mitad de los terneros de cada grupo, que pesaran al menos $70 \mathrm{~kg}$. Todos los animales fueron pesados al inicio del experimento y luego a los 28, 63, 99, y 134 días, y se evaluó la condición corporal de las vacas por apreciación visual (escala 1-8) y se realizó monitoreo de actividad cíclica y diagnóstico de gestación mediante ecografía. 
La disponibilidad de forraje se evaluó cada 45 días. Las variables continuas con medidas repetidas en el tiempo (peso vivo, condición corporal, ganancia de peso, asignación de forraje) fueron analizadas utilizando el procedimiento mixto de SAS, ajustando las diferencias por el test de Tukey-Kramer. El momento de la preñez y la preñez final fueron analizados utilizando el test de supervivencia y glimmix, respectivamente. Valores de $\mathrm{P}>0,05$ fueron considerados significativos $y$ valores de $P>0,05$ y $<$ a 0,1 tendencias.

\section{RESULTADOS}

EI DT afectó el peso al destete de los terneros. Los terneros a los que se les aplicó destete temporario fueron más livianos al destete ( $P<0,01$, Cuadro 1$)$. Se observó un efecto del creep feeding sobre el peso de los terneros, aunque no en el sentido esperado. Los terneros de los grupos control fueron más pesados que los que recibieron suplementación con afrechillo de arroz y estos últimos presentaron mayor peso respecto a los grupos que recibieron la sal comercial $(P<0,01$, Cuadro 1$)$.

Cuadro 1. Ganancia de peso diaria y peso al destete de terneros que no recibieron creep feeding (-CF) ni destete temporario (-DT) o recibieron creep feeding (+CF) con afrechillo de arroz (AA) o una sal comercial (SC) y destete temporario (+DT) mediante la aplicación de tablilla nasal por 14 días.

\begin{tabular}{|c|c|c|c|c|c|c|}
\hline & -CF-DT & -CF+DT & +CFAA-DT & +CFAA+DT & +CFRS-DT & +CFRS+DT \\
\hline Ganancia $(\mathrm{kg} / \mathrm{d})$ & $0,75 \pm 0,02^{\mathrm{a}}$ & $0,66 \pm 0,03^{b}$ & $0,65 \pm 0,02^{b}$ & $0,55 \pm 0,02^{c}$ & $0,43 \pm 0,03^{e}$ & $0,38 \pm 0,03^{d}$ \\
\hline Peso destete $(\mathrm{kg}$ & y) $172 \pm 1,9^{a}$ & $159 \pm 2,0^{b}$ & $159 \pm 1,6^{b}$ & $147 \pm 1,6^{c}$ & $141 \pm 2,0^{c}$ & $132 \pm 2,0^{d}$ \\
\hline Preñez (n) & $34 / 44$ & $28 / 40$ & $33 / 42$ & $30 / 37$ & $33 / 48$ & $36 / 51$ \\
\hline
\end{tabular}

Letras diferentes en la misma fila difieren estadísticamente

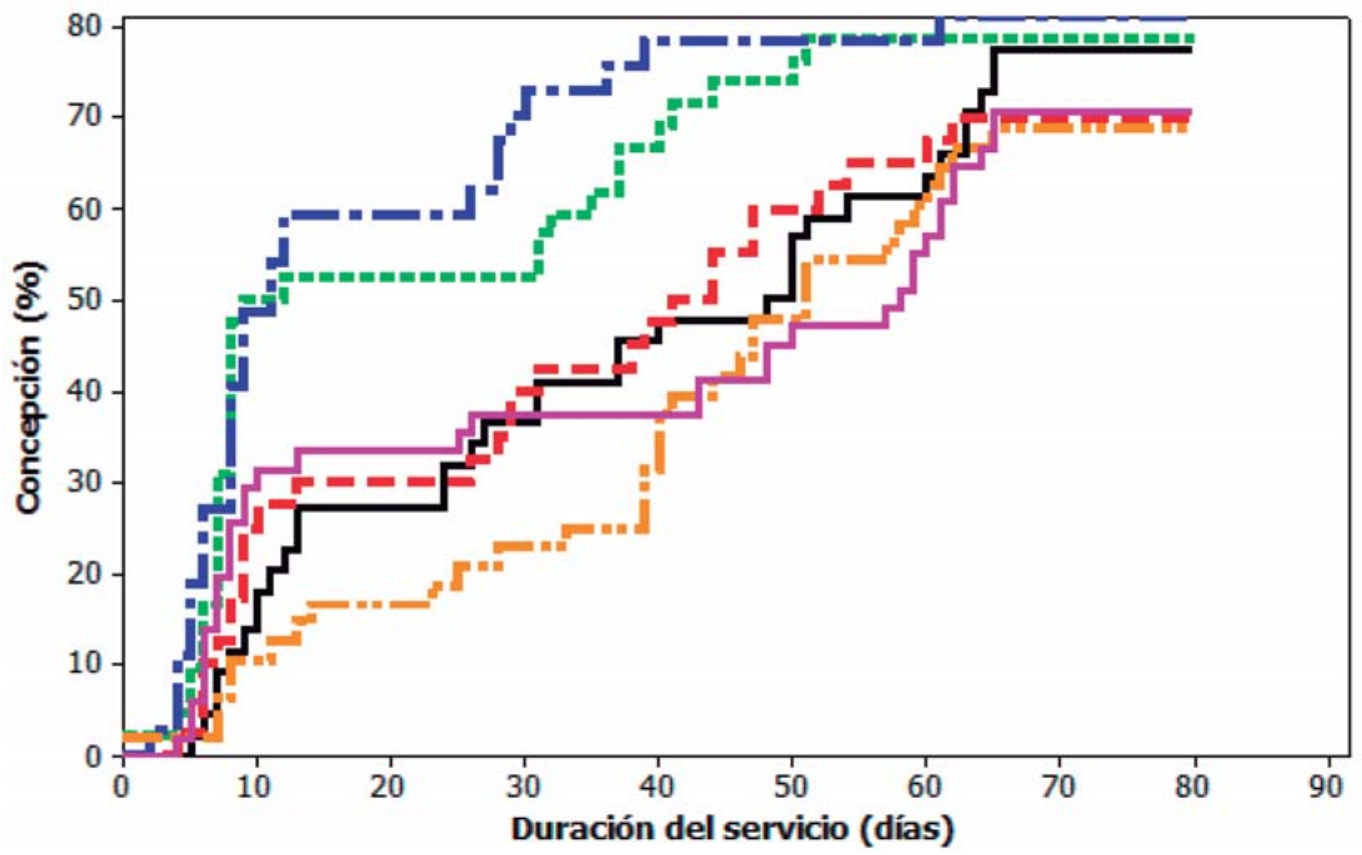

Figura 4. Días desde el inicio del servicio en que ocurre la preñez de las vacas cuyos terneros no recibieron creep feeding (-CF) ni destete temporario (-DT) o recibieron creep feeding $(+\mathrm{CF})$ con afrechillo de arroz (AA) o una sal comercial (SC) y destete temporario (+DT) mediante la aplicación de tablilla nasal por 14 días. -CF-DT= línea negra; -CF+DT= línea roja, +CFAA-DT=línea verde, +CFAA+DT=línea azul; +CFSC-DT=línea naranja; +CFSC+DT=línea fucsia. 
La condición corporal aumentó del inicio $(3,84 \pm 0,04)$ al fin del experimento $(4,23 \pm 0,04$; $\mathrm{P}<0,05)$ pero fue similar entre grupos. El creep feeding con AA adelantó el momento de la preñez de las vacas $(24,1 \pm 3,4$ días $)$ comparado con los grupos SC $(43,6 \pm 3,3$ días) y sin creep feeding (39 $\pm 3,6$ días; $P<0,01$ ), pero la preñez final fue similar entre grupos, 74 \% (Cuadro 1, Figura 4).

\section{DISCUSIÓN}

La hipótesis de que el creep feeding asociado al destete temporario aumentaría las ganancias de peso de los terneros durante el período de aplicación de la tablilla y eliminaría las diferencias de peso al destete generadas por el destete temporario y que el destete mejoraría el porcentaje de preñez final de las vacas no fue aceptada. El impacto negativo de la tablilla en el peso al destete de los terneros fue consistente con resultados anteriores (Quintans et al., 2010; Bentancor et al., 2013). Los terneros que recibieron AA y RC fueron más livianos que los que no recibieron suplemento. La pérdida de peso promovida por el creep feeding con AA fue similar a la ocasionada por el DT en el grupo control. La menor ganancia y peso al destete en el grupo creep feeding con AA podría estar asociado a la calidad del suplemento, ya que generalmente está en el límite del porcentaje de proteína recomendado para esta categoría. Sin embargo en este caso específico el resultado del análisis de laboratorio del suplemento demostró que la concentración de proteína fue de $21 \%$. Por lo tanto la explicación del menor desempeño de los terneros a los que se les administro AA podría estar explicado por el contenido de lípidos y/o la presencia en el suplemento de factores antinutricionales que afectaron el funcionamiento ruminal (Park et al., 2013). El resultado de la suplementación con SC fue aún menos estimulante que el de la suplementación con $A A$, pero no contamos con antecedentes para justificar este resultado, por lo que se requieren más estudios para evaluar las causas de la baja respuesta obtenida.
Las vacas cuyos terneros recibieron DT no tuvieron un aumento en los indicadores reproductivos, lo que podría estar asociado a la buena condición corporal de las mismas y a la alta asignación de forraje en todos los grupos. Sin embargo, el CF con AA permitió adelantar el momento de la concepción de las mismas, resultados que concuerdan con los observados previamente (Bentancor et al., 2013).

Concluimos que el creep feeding con AA y SC y el DT disminuyen las tasas de ganancia y pesos al destete de los terneros, y que en vacas de primera cría, con adecuada condición corporal y asignación de forraje, el DT no mejora su eficiencia reproductiva pero el creep feeding con AA permite adelantar el momento de la preñez.

\section{BIBLIOGRAFÍA}

Bentancor M, Bistolfi A, Zerbino L (2013) Efecto del Creep Feeding y el Destete Temporario sobre el desarrollo de los terneros y la eficiencia reproducttiva de vacas primíparas.

Park JK, Kwon EG, Kim CH (2013) Effects of increasing supplementation levels of rice bran on milk production and fatty acid composition of milk in Saanen dairy goats. Animal Production Science 53:413-418.

Quintans G et al. (2010) Effect of body condition and suckling restriction with and without presence of the calf on cow and calf performance. Animal production science VO - 50, no. 10.

Simeone A, Beretta V (2002) Destete precoz en ganado de carne. Editor. Agropecuaria Hemisferio Sur S. R. L.

Viñoles C et al. (2013) Effect of creep feeding and stocking rate on the productivity of beef cattle grazing grasslands. New Zealand Journal of Agricultural Research 56:279-287.

Viñoles C et al. (2009) Estado actual de la investigación vinculada a la Producción Animal Limpia, Verde y Ética en Uruguay. Agrociencia 13:59-79. 


\title{
EFECTO DEL CREEP FEEDING CON DDGS Y EL DESTETE TEMPORARIO SOBRE EL DESARROLLO DE LOS TERNEROS Y LA EFICIENCIA REPRODUCTIVA DE VACAS HEREFORD
}

\author{
R. Santa Cruz ${ }^{1}$, J. Armúa ${ }^{1}$, J. Alvarez $^{1}$, A. Lorenzo $^{2}$,
} P. Cuadro ${ }^{3}$, I. De Barbieri ${ }^{3}$, C. Viñoles ${ }^{3}$

\section{RESUMEN}

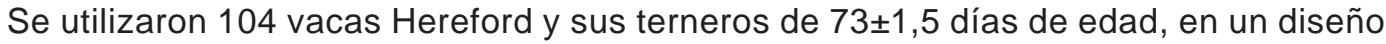
factorial que evaluó la alimentación diferencial de los terneros al pie de la madre (CF) y el destete temporario (DT). Se formaron cuatro grupos: 1) sin CF sin DT (-CF-DT; $n=26) ; 2$ ) $\sin$ CF con DT (-CF+DT; n=25); 3) con CF sin DT (+CF-DT; n=26); 4) con CF con DT (+CF+DT; $\mathrm{n}=28$ ). La suplementación se realizó durante 99 días con DDGS (granos secos de destilería con solubles) de maíz al $40 \%$ de la dieta suministrado en forma diaria. El CF (3,5 días) y DT (4,5 días) tendieron a adelantar el momento de la concepción de las vacas $(P=0,09)$. El CF $(+16,5 \mathrm{~kg})$ y DT $(-14,5 \mathrm{~kg})$ afectaron el peso de los terneros al destete $(P<0,001)$. Ambos factores afectaron la ganancia de peso de los terneros $(C F=+0,147 \mathrm{~kg} / \mathrm{d}$ y DT $=-0,139 \mathrm{~kg} / \mathrm{d}$; $P<0,001)$. La eficiencia de conversión fue 5,8 kg DDGS/kg extra de peso vivo. Concluimos que el CF con DDGS puede ser una alternativa de menor costo y con resultados similares a los obtenidos con raciones comerciales, particularmente en lo que refiere a ganancia, peso vivo al destete y eficiencia de conversión de los terneros.

\section{INTRODUCCIÓN}

La eficiencia de la cría puede medirse por los kilos de ternero destetado por superficie de pastoreo, y está afectado por el porcentaje de destete, peso al destete y la carga animal (Simeone y Beretta, 2002). El creep feeding (CF) combinado con el destete temporario (DT) permite aumentar la tasa de ganancia de peso y el peso al destete de los terneros (Bentancor et al., 2013). Explorando alternativas de bajo costo, nos plantea- mos la hipótesis de que el uso de un subproducto como el DDGS (granos secos de destilería con solubles) combinado con DT (destete temporario) tiene un impacto positivo en la tasa de ganancia de peso de los terneros y la eficiencia reproductiva de las vacas.

\section{MATERIALES Y MÉTODOS}

El experimento se llevó a cabo en la Unidad Experimental Glencoe, INIA Tacuarembó, desde el 9 de diciembre de 2015 al 18 de

${ }^{1}$ Estudiantes de tesis de Facultad de Veterinaria.

2 Pasante INIA, Universidad Autónoma de Chapingo.

${ }_{3}$ INIA, Instituto Nacional de Investigación Agropecuaria 
marzo de 2016. Se utilizaron 104 vacas Hereford, y sus terneros con $73 \pm 1,5$ días de edad, en un diseño factorial de $2 \times 2$ con dos repeticiones que evaluó la alimentación diferencial de los terneros al pie de la madre (CF, con y $\sin$ ) y el destete temporario (DT, con y sin). Se formaron cuatro grupos: 1 ) $\sin$ CF sin DT (-CF-DT; $n=26) ; 2$ ) sin CF con DT (-CF+DT; n=25); 3) con CF sin DT (+CFDT; $n=26)$; 4) con CF con DT (+CF+DT; $n=28)$. El peso vivo (PV) inicial de los terneros fue $109 \mathrm{~kg}$ y el de las vacas de 501 kg las cuales tenían 4,8 unidades de condición corporal (escala 1-8 unidades). La asignación de forraje de las vacas fue de $10 \mathrm{~kg} \mathrm{MS} / \mathrm{kg} \mathrm{PV}$ al inicio del período experimental. La carga promedio durante todo el experimento fue de 1,2 UG/ha. La suplementación de los terneros se realizó desde el comienzo del entore hasta el destete definitivo (99 días), con DDGS de maíz al $40 \%$ de la dieta en forma diaria (siendo el $100 \%$ el consumo potencial de esos terneros), ajustando la cantidad de suplemento cada 2 semanas, según el cálculo de requerimientos de AFRC. La composición química del DDGS fue de 22,6\% de PC digestible y 2,8 Mcal/kgMS EM. Se evaluó la condición corporal de las vacas y el peso vivo de vacas y terneros cada 14 días. EI DT fue realizado al día 14 de iniciado el entore por 14 días. Se realizó diagnóstico de gestación para determinar la edad embrionaria/fetal. Las variables continuas fueron analizadas utilizando el procedimiento MIXED y GLM de SAS, ajustando por el peso vivo y la condición corporal inicial. El momento de la concepción fue analizado por el test de supervivencia en Minitab. Las diferencias fueron consideradas significativas si $\mathrm{P}<0,05$.

\section{RESULTADOS}

EI DT tendió a aumentar el PV de las vacas al destete y el CF y el DT tendieron a adelantar el momento de la concepción de las vacas (Cuadro 2). El CF duplicó las ganancias diarias de peso de los terneros durante el período de DT (+CF+DT $=0,622 \pm 0,07$ vs $-C F-D T=0,310 \pm 0,07 \mathrm{~kg} / \mathrm{d} ; \mathrm{P}<0,001)$. Ambos factores afectaron la ganancia de peso y el peso al destete de los terneros durante todo el experimento (Cuadro 2). La eficiencia de conversión fue de 5,8 kg DDGS/kg extra de peso vivo.

\section{DISCUSIÓN}

El CF aumentó la tasa de ganancia y el peso al destete de los terneros. Estos resultados coinciden con los reportados por Bentancor et al. (2013) y Viñoles et al. (2013), y destacan que el nivel nutricional en nuestros sistemas criadores extensivos limita la expresión del potencial de crecimien-

Cuadro 2. Peso vivo (PV, kg), condición corporal (CC) y momento de la concepción de las vacas y ganancia diaria $(\mathrm{kg} / \mathrm{d})$ y peso vivo al destete de terneros que recibieron (+DT) o no (-DT) destete temporario asociado (+CF) o no (-CF) con creep feeding al pie de la madre (MediatEEM).

\begin{tabular}{|lcccccccc|}
\hline & -CF-DT & -CF+DT & +CF-DT & +CF+DT & EEM & CF & DT & CF*DT \\
\hline Vacas & & & & & & & & \\
PV destete (kg) & 522 & 532 & 513 & 545 & 8,5 & NS & 0,06 & NS \\
CC (unidades) & $5,04^{\mathrm{a}}$ & $5,09^{\mathrm{a}}$ & $4,87^{\mathrm{b}}$ & $5,05^{\mathrm{a}}$ & 5,01 & 0,05 & 0,02 & $\mathrm{NS}$ \\
Concepción (d) & $23^{\mathrm{a}}$ & $18^{\mathrm{ab}}$ & $19^{\mathrm{ab}}$ & $15^{\mathrm{b}}$ & 2,5 & 0,09 & 0,09 & $\mathrm{NS}$ \\
\hline Terneros & & & & & & & & \\
Ganancia (kg/d) & $0,902^{\mathrm{a}}$ & $0,770^{\mathrm{b}}$ & $1,056^{\mathrm{c}}$ & $0,907^{\mathrm{a}}$ & 0,909 & $<0,001$ & $<0,001$ & $\mathrm{NS}$ \\
PV destete (kg) & $191^{\mathrm{a}}$ & $178^{\mathrm{b}}$ & $206^{\mathrm{c}}$ & $190^{\mathrm{a}}$ & 1,6 & $<0,001$ & 0,001 & NS \\
\hline
\end{tabular}

$\mathrm{EEM}=$ error estándar de la media; $\mathrm{NS}=$ no significativo; ${ }^{\mathrm{a}} \mathrm{V} \mathrm{S}^{\mathrm{b}} \mathrm{VS} \mathrm{s}^{\mathrm{c}}=$ letras diferentes en la misma fila difieren estadísticamente. 
to de los terneros. El DT tuvo un impacto negativo en los terneros cuando no se asoció al CF, ya que los terneros sometidos únicamente a DT fueron $12 \mathrm{~kg}$ más livianos al destete respecto a terneros que recibieron DT y CF. EI DT y el CF tendieron a adelantar el momento de la preñez, lo que puede estar asociado con el efecto metabólico del destete (Quintans et al., 2010) y a cambios en el comportamiento ingestivo de los terneros. Teniendo en cuenta la importancia de buscar alternativas productivo-económicas atractivas para intensificar sosteniblemente los sistemas criadores de la ganadería extensiva del Uruguay, es que incursionamos en el estudio de la inclusión de este sub-producto en dietas de terneros en lactación. Al evaluar conjuntamente el precio de este producto con otras opciones nutricionales en el mercado (273 U\$S vs 320 U\$S la ración de 18 \% PC y 400 U\$S la ración de $21 \%$ PC) y los resultados obtenidos en términos de peso al destete, ganancia y eficiencia de conversión, concluimos que es una alternativa tecnológica que requiere de más investigación analítica y modelación en nuestros sistemas de producción.

\section{BIBLIOGRAFÍA}

Bentancor, M., Bistolfi, A., Zerbino, L., Viñoles, C., 2013. Efecto del creep feeding y el destete temporario sobre el desarrollo de los terneros y la eficiencia reproductiva de vacas Hereford Primíparas, in: XLI Jornadas Uruguayas de Buiatría. Paysandú, Uruguay, p. 134.

Quintans, G., Banchero, G., Carriquiry, M., López-Mazz, C., Baldi, F., 2010. Effect of body condition and suckling restriction with and without presence of the calf on cow and calf performance. Anim. Prod. Sci. 50, 931-938.

Simeone, A., Beretta, V., 2002. Destete precoz en ganado de carne. Editor. Agropecu. Hemisferio Sur S.R.L. Fac. Agron. 118 p.

Viñoles, C., Jaurena, M., De Barbieri, I., Do Carmo, M., Montossi, F., 2013. Effect of creep feeding and stocking rate on the productivity of beef cattle grazing grasslands. New Zeal. J. Agric. Res. 56, 279-287. 



\title{
EFECTO DE MEDIANO PLAZO DE DIFERENTES SISTEMAS DE MANEJO SOBRE EL CRECIMIENTO, PARÁMETROS ENDÓCRINOS Y PUBERTAD EN TERNERAS HEREFORD PASTOREANDO CAMPO NATURAL
}

D. Guggeri ${ }^{1}$, A. Meikle $^{2}$, M. Carriquiry ${ }^{3}$, F. Montossi ${ }^{1}$, I. De Barbieri', C. Viñoles ${ }^{1}$

\begin{abstract}
RESUMEN
Este trabajo compara diferentes sistemas de manejo aplicados a edad temprana sobre el desarrollo corporal, parámetros endócrinos y edad a la pubertad en terneras para carne pastoreando campo natural. Las terneras fueron asignadas a tres tratamientos: 1) Destete precoz (DP, $n=15)$ a los $75 \pm 1,5$ días de edad; 2) Destete tradicional (DTr, $n=14)$ a los $158 \pm 1,5$ días de edad; 3 ) Destete tradicional con creep feeding ( $D T r+C F, n=17)$. Las terne-

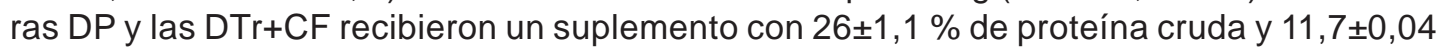
MJ de energía metabolizable/kg de materia seca desde los 75 a los 158 $\pm 1,5$ días. Las terneras DTr tuvieron una mayor ganancia de peso diario respecto a las terneras DP, asociado a mayores concentraciones de IGF-I al momento del DTr, pero la edad a la pubertad fue similar en ambos grupos. Las terneras DTr+CF $(P<0,05)$ tuvieron una mayor ganancia de peso diario, mayores concentraciones de IGF-I al destete, fueron más pesadas y altas desde el destete hasta los $539 \pm 1,5$ días $(P<0,02)$ y la pubertad ocurrió más temprano que en las DP $(P<0,05)$ y tendió a ocurrir antes que en las terneras $D \operatorname{Tr}(P=0,06)$. Concluimos que la edad al destete tiene un impacto de corto plazo sobre el crecimiento corporal y las concentraciones de IGF-I, que no tienen efecto sobre la edad a la pubertad. EI CF indujo un desarrollo corporal más rápido, relacionado a una manifestación más temprana de la pubertad.
\end{abstract}

\section{INTRODUCCIÓN}

La edad a la pubertad y al primer parto afectan la productividad de la vaca en toda su vida reproductiva (Lesmeister et al., 1973). En el ganado de carne bajas ganan- cias de peso antes del destete y bajos pesos al destete están asociados con un retraso en la edad a la pubertad (Arije y Wiltbank, 1971). En sistemas de cría extensivos la variabilidad en la cantidad y calidad de las pasturas durante el verano e invierno

${ }^{1}$ INIA, Instituto Nacional de Investigación Agropecuaria.

${ }^{2}$ Laboratorio de Endocrinología y Metabolismo Animal, Facultad de Veterinaria.

${ }^{3}$ Producción Animal y de Pasturas, Facultad de Agronomía. 
(Berretta et al., 2000), limita la cantidad de energía y proteína que consumen los terneros e impacta negativamente en su tasa de crecimiento antes y después del destete (Viñoles et al., 2009). La suplementación con concentrados de terneras al pie de la madre o destetadas en forma precoz, son dos estrategias de manejo que pueden ser utilizadas en épocas de escasez de comida para aumentar los pesos al destete (Holloway y Totusek, 1973; Neville y McCormick, 1981) y lograr una pubertad anticipada.

Las vaquillonas alcanzan la pubertad a una proporción constante de su peso adulto proyectado (Freetly et al., 2011), lo cual está asociado con las concentraciones de insulina, factor de crecimiento similar a la insulina tipo I (IGF-I), glucosa y leptina, que señalan directa o indirectamente sobre las neuronas hipotalámicas (Brito et al., 2007). Se ha encontrado que las terneras destetadas precozmente alcanzan la pubertad a la misma edad que las terneras destetadas en forma tradicional (600 días de edad; de Castro et al., 2004), pero se puede inducir una pubertad precoz (menos de 300 días) si las terneras destetadas precozmente son alimentadas con una dieta rica en concentrados (Gasser et al., 2006). A pesar de que está bien establecido que el eje somatotrófico, las hormonas metabólicas y los metabolitos están involucrados en el crecimiento de los tejidos y la maduración sexual, hay falta de información sobre el impacto de los diferentes sistemas de manejo sobre estos parámetros (Loy et al., 2002).

La hipótesis de este trabajo es que un sistema de manejo que a edad temprana estimule altas tasas de ganancia de peso, va a estimular un aumento en las concentraciones de hormonas metabólicas, acelerar el crecimiento y desarrollo corporal y adelantar la manifestación de la pubertad.

El objetivo de este trabajo fue comparar diferentes grupos de terneras que fueron destetadas precozmente con terneras que fueron destetadas en forma tradicional con o sin suplementación rica en energía/proteína, sobre el crecimiento y desarrollo corporal, parámetros endócrinos y edad a la pubertad.

\section{MATERIALES Y MÉTODOS}

El experimento fue realizado en «Glencoe» Campo Experimental del «Instituto Nacional de Investigación Agropecuaria» (INIA Tacuarembó), Paysandú, Uruguay (S31º W42 ${ }^{\circ}$ ), desde Diciembre (verano) a Mayo (otoño) de su segundo año de vida.

Se utilizaron 46 terneras Hereford (hijas de vacas multíparas) nacidas en la primave-

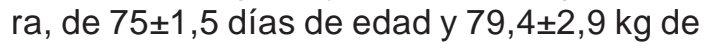
peso vivo, las que fueron distribuidas en tres grupos experimentales: 1) Destete precoz (DP; $n=15$ ); terneras destetadas a los $75 \pm 1,5$ días de edad suplementadas desde los 75 a los 158 $\pm 1,5$ días de edad (Período I) a una tasa de 1,5\% del peso vivo; 2) Destete tradicional (DTr; $n=14$; tratamiento control), terneras destetadas a los 158 $\pm 1,5$ días de edad 3) Destete tradicional con suplementación al pie de la madre ( $D T r+S, n=17)$, fueron suplementadas desde los $75 \pm 1,5$ días hasta el destete (158 días de edad) al 1,3\% del peso vivo. Los tres grupos experimentales pastorearon campo natural, la asignación de forraje y la composición química de las pasturas no difirió entre tratamientos y fue de 4,0 $\pm 0,6 \mathrm{~kg}$ de materia seca (MS)/kg peso vivo (Sollenberger et al., 2005) con un contenido de $8,7 \pm 0,3 \%$ de proteína cruda y 7,9 $\pm 0,04 \mathrm{MJ}$ de energía metabolizable (EM)/kg MS. El suplemento utilizado durante el Período I aportó $26 \pm 1,1 \%$ de proteína cruda y

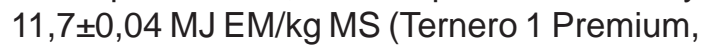
Colonia el Ombú, Río Negro, Uruguay).

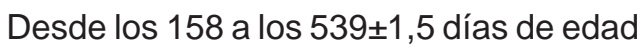
(Período II), las terneras fueron manejadas bajo las mismas condiciones nutricionales pastoreando campo natural inmediatamente después del destete tradicional (asignación de forraje: $28 \mathrm{kgMS} / \mathrm{kg}$ peso vivo) y posteriormente pastorearon campo natural mejorado con trébol blanco y lotus a una asignación de forraje de $3,9 \pm 0,8 \mathrm{~kg} \mathrm{MS} / \mathrm{kg}$ peso vivo. La composición química de las pasturas fue de 9,6 $\pm 0,4 \%$ proteína cruda y $8,6 \pm 0,13 \mathrm{MJ}$ EM / kg MS. Todas las terneras recibieron un suplemento desde los 435 a los 539 $\pm 1,5$ días de edad, a una tasa del $1 \%$ del peso vivo, el cual aportó $14,4 \pm 0,5 \%$ proteína cruda y $12,1 \pm 0,08 \mathrm{MJ}$ EM/kg MS. 
Se evaluó el peso vivo desde los 75 a los $539 \pm 1,5$ días de edad cada 14 días (balanza True-test GR $3000^{\circledR}$, True-test Corporation Limited, Montevideo, Uruguay) y se calculó el promedio de ganancia de peso diario.

La altura de anca fue medida cada 56 días desde los 158 a los 539 1 1,5 días de edad, con una regla en paralelo a los huesos de la cadera, con la ternera parada sobre una superficie nivelada. La información fue utilizada para calcular el crecimiento.

El espesor de grasa subcutánea (espesor de grasa subcutánea sobre el músculo longissimus dorsi entre la costilla 12 y la 13 , medido en $\mathrm{mm}$ ), marmoleado (porcentaje de grasa intramuscular dentro del músculo longissimus dorsi entre la costilla 12 y la 13; medido en porcentaje), área de ojo de bife (área del músculo longissimus dorsi entre la costilla 12 y la 13; medido en $\mathrm{cm}^{2}$ ) y el depósito de grasa en el anca (P8, depósito de grasa arriba de los músculos glúteos, entre las tuberosidades coxal e isquiática, medida en $\mathrm{mm}$ ), fueron estimadas por ultrasonografía, desde los 176 a 539ะ1,5 días de edad, cada 56 días por el mismo operador utilizando un ecógrafo modo $B$ en tiempo real, con un transductor lineal de 3,5 MHz (Aloka SSD 500 Echo camera, Overseas Monitor Corp. Ltd., Richmond, BC). Las imágenes logradas fueron guardadas en una computadora portátil (Houghton y Turlington, 1992) y analizadas utilizando el programa Biosoft ${ }^{\circledR}$ (Biotronics Inc., Ames, lowa, EEUU).

Se extrajeron muestras de sangre por punción de la vena yugular desde los 158 a los 539 $\pm 1,5$ días de edad cada 28 días, para determinar las concentraciones de glucosa mediante el uso de tiras reactivas (Ascensia ${ }^{\circledR}$ ENTRUST ${ }^{\circledR}$ Blood Glucose Test Strips, Bayer, Montevideo, Uruguay), y analizar concentraciones de IGF-I y leptina en el Laboratorio de Técnicas Nucleares, Facultad de Veterinaria, Montevideo, Uruguay. Las concentraciones de IGF-I fueron determinadas cada 56 días, mientras que la leptina fue determinada cada 28 días. Las concentraciones de IGF-I fueron determinadas utilizando un Radio Inmuno Análisis (RIA) con un kit comercial (IGF-I-RIACT Cis Bio International, Gifsur-Yvette, Francia) previamente validado
(Adrien et al., 2012). La sensibilidad del ensayo fue de $0,8 \mathrm{ng} / \mathrm{mL}$ y el $\mathrm{CV}$ interensayo para los controles de calidad fueron de $11,7 \%$ y $13,5 \%$, para las concentraciones bajas ( 74 $\mathrm{ng} / \mathrm{mL})$ y altas $(535 \mathrm{ng} / \mathrm{mL}$ ) respectivamente. Las concentraciones de leptina fueron determinadas por un RIA de fase líquida utilizando un kit comercial multi especies, (RIA kit, Millipore, Cat XL-85K) previamente validado para bovinos (Pinotti y Rosi, 2006). La sensibilidad del ensayo fue de $1,4 \mathrm{ng} / \mathrm{mL}$ y el CV interensayo para los controles de calidad fueron de $19,7 \%$ y $14,0 \%$, para las concentraciones bajas $(4,2 \mathrm{ng} / \mathrm{mL})$ y altas $(18,8$ $\mathrm{ng} / \mathrm{mL}$ ) respectivamente.

Los ovarios fueron examinados desde los

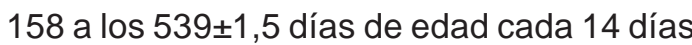
mediante ultrasonografía transrrectal, utilizando un ecógrafo en modo B en tiempo real, con un transductor de 7,5 MHz (Aloka SSD 500 Echo camera, Overseas Monitor Corp. Ltd., Richmond, BC), para determinar la presencia de un cuerpo lúteo, la cual fue interpretada como el comienzo de la pubertad (Bergfeld et al., 1994).

\section{RESULTADOS}

Durante el Período I el peso vivo y el promedio de las ganancias de peso diarias fueron superiores en las terneras $\mathrm{DTr}+\mathrm{CF}$ $(1,25 \pm 0,03 \mathrm{~kg} / \mathrm{día})$ que en las terneras DTry DP $(0,86 \pm 0,03$ kg/día, 0,75 $\pm 0,03$ kg/día, respectivamente), y mejores en las terneras $\mathrm{DTr}$ que en las terneras DP. Al destete y durante el Período II, el peso vivo y la altura de anca fueron superiores en las terneras DTr+CF que en las terneras DTr y DP (Figura 5), pero el promedio de la ganancia de peso diaria durante el Período II fue menor en las terneras $\operatorname{DTr}+\mathrm{CF}(0,39 \pm 0,01 \mathrm{~kg} /$ día $)$, que en las terneras $D \operatorname{Tr}(0,42 \pm 0,01 \mathrm{~kg} /$ día $)$ y DP $(0,41 \pm 0,01$ kg/día). No se observó diferencia entre tratamientos para crecimiento durante el período II $(0,06 \pm 0,04$ cm/día).

Las terneras DTr+CF tuvieron una mayor área de ojo de bife al destete y durante el Período II $\left(36,1 \pm 0,7 \mathrm{~cm}^{2}\right)$ que los grupos DTr $\left(31,4 \pm 0,8 \mathrm{~cm}^{2}\right)$ y DP $\left(33,7 \pm 0,8 \mathrm{~cm}^{2} ; \mathrm{P}<0,001\right)$, mientras que en las DP fue mayor que en las terneras DTr. Las terneras DTr+CF 


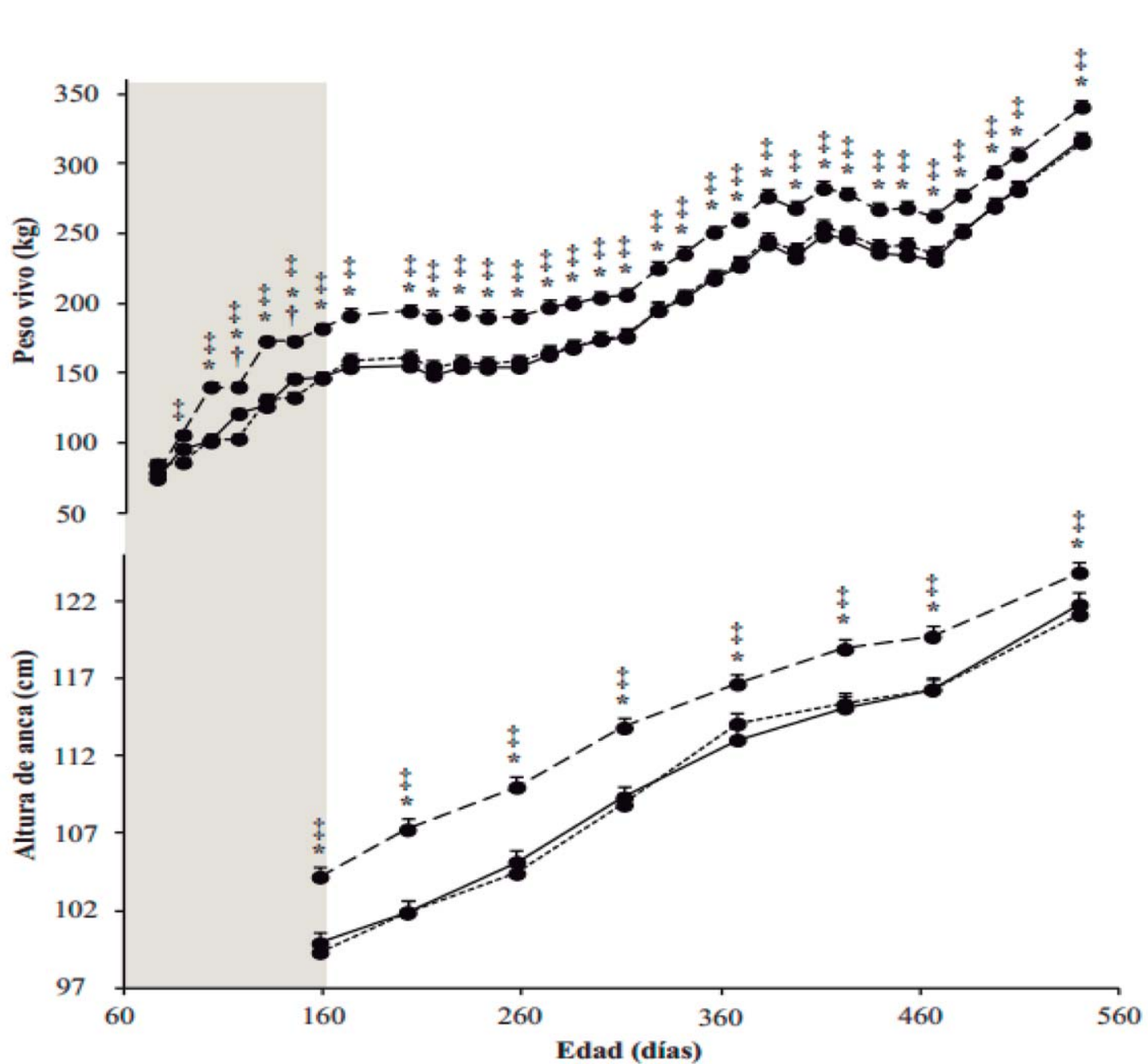

Figura 5. Peso vivo (panel superior) desde los 75 a los 158 días de edad (Período I: indicado por el área sombreada) y desde los 158 a los 539 días de edad (Período II) y cambios en la atura de anca (panel inferior) durante el Período II en terneras destetadas en forma precoz (DP, línea de punteado fino), terneras destetadas en forma tradicional (DTr, línea contínua) y terneras destetada en forma tradicional que recibieron creep feeding (DTr+CF, línea de punteado grueso). $† P<0,05$ entre DP y $D T r ;{ }^{*} P<0,05$ entre DTr y DTr+CF; ‡ P<0,05 entre DTr+CF y DP

$(2,4 \pm 0,08 \mathrm{~mm})$ tuvieron un mayor espesor de grasa subcutánea en el periodo II, que las terneras $\operatorname{DTr}(2,1 \pm 0,09 \mathrm{~mm})$ y DP $(2,2 \pm 0,08$ $\mathrm{mm} ; \mathrm{P}<0,04)$. No se observaron diferencias en marmoleado $(1,7 \pm 0,09 \%)$ ni en el espesor de grasa en el sitio P8 $(2,5 \pm 0,1 \mathrm{~mm})$ entre grupos.

Las concentraciones de IGF-I fueron mayores a los 158 y 383 días en las terneras DTr+CF que en las DP y y DTr (Figura 6). A los 158 y 509 días de edad las terneras DTr tuvieron mayores concentraciones de IGF-I que las terneras DP (Figura 6). A los 158 días de edad las concentraciones de glucosa fueron similares en todos los grupos, pero bajaron abruptamente entre los 158 y los 202 días de edad y variaron mucho durante el resto del experimento. Las concentraciones de leptina fueron similares entre grupos durante todo el período experimental.

La pubertad ocurrió antes en las terneras DTr+CF (472 $\pm 8,0$ días) que en las terneras DP $(526 \pm 7,2$ días; $P<0,01)$ y tendió $(P=0,06)$ a ocurrir antes en las terneras DTr+CF comparada con las terneras DTr (484 $\pm 3,4$ días). Una proporción similar de terneras DTr y DP 


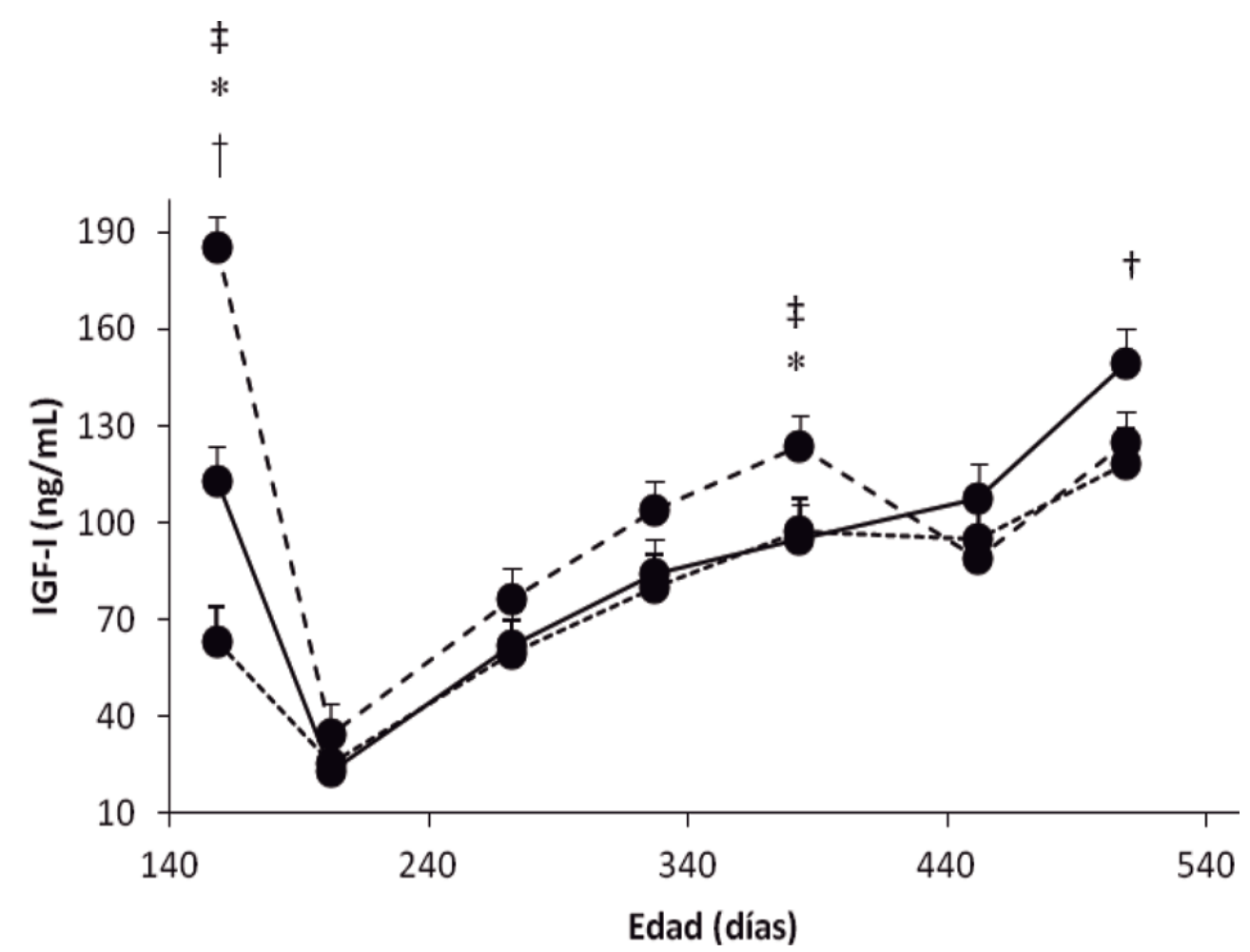

Figura 6. Concentraciones de IGF-I entre los 158 y 539 días de edad en terneras destete precoz (DP, línea de punteado fino), destetadas tradicional (DTr, línea contínua) y destete tradicional con suplementación ( $D T r+C F$, línea de punteado grueso). $\uparrow P<0,05$ entre DP y DTr; * $\mathrm{P}<0,05$ entre DTr y DTr+CF; ‡ P<0,05 entre DTr+CF y DP.

alcanzaron la pubertad al final del experimento. Las variables que mejor explicaron la variación en la edad a la pubertad, fueron la ganancia de peso diario durante el Período II (29\%) y I (23\%), el área de ojo de bife (19\%), altura de anca (15\%) y las concentraciones de IGF-I (7\%).

\section{DISCUSIÓN}

La hipótesis de que en un sistema de manejo que a edad temprana induce altas tasas de ganancia de peso, estimularía un aumento de las concentraciones de hormonas metabólicas, el crecimiento y desarrollo corporal y una pubertad más temprana fue aceptada. Las terneras DTr+CF tuvieron una mayor ganancia de peso diario (durante el Período I) y peso al destete comparadas con las terneras DTr y DP, lo cual es consistente con reportes previos (Holloway y Totusek, 1973). Esto estuvo asociado con una mayor altura de anca y una mayor área de ojo de bife y mayor espesor de grasa comparado con las terneras DTr, al momento del destete. Este resultado era esperado, ya que existe un orden en la deposición de los tejidos durante la curva de crecimiento de los animales jóvenes, donde el hueso y los músculos anteceden a la acumulación de grasas, cuyo depósito será estimulado en animales alimentados con una dieta con altos contenidos de energía y proteína (Owens et al., 1993; Davis et al., 1998). Los pesos al momento del destete tradicional fueron similares entre las terneras DTr y DP, en contraste con los resultados reportados por de Castro et al. (2004) en terneras sometidas a condiciones similares de pastoreo. Las contradicciones pueden atribuirse a la duración del período de tiempo que las terneras recibieron el suplemento y a la cantidad del mismo. El mayor promedio de ganancia de peso diario durante el Período I de las terneras $\mathrm{DTr}+\mathrm{CF}$ comparadas con las terneras DP y 
DTr y de estas últimas comparadas con las terneras DP estuvo asociado a mayores concentraciones de IGF-I, aunque al destete las concentraciones de glucosa y leptina fueron similares. El IGF-I, que juega un rol esencial en la regulación del crecimiento y desarrollo (Laron 2001), aumenta en animales que son alimentados con dietas no restrictivas (Armstrong et al., 1993). La finalización de la suplementación en las terneras de los tratamientos DTr+CF y DP, la finalización del amamantamiento de las terneras de los tratamientos DTr y DTr+CF y el descenso en la asignación de forraje que ocurrió a mediados de otoño, determinaron un período de subnutrición típico de terneras que se alimentan sobre campo natural (Gutiérrez et al., 2013). Durante éste período todos los grupos de terneras movilizaron músculo y depósitos de grasas, lo que estuvo asociado con una disminución en las concentraciones de glucosa e IGF-I. A pesar de que la glucosa decreció de manera similar en todos los grupos, la disminución en los niveles de IGFI fue más pronunciado en las terneras DTr+CF y DTr que en las terneras DP, sugiriendo una respuesta metabólica diferente dependiendo del sistema de manejo que recibieron entre los dos y los cinco meses de edad.

La superioridad de las terneras DTr+CF en peso vivo, altura de anca y área de ojo de bife comparada con las terneras DTr y DP, duró hasta el final del experimento, aunque la magnitud de esta diferencia fue decreciendo hacia el final del mismo. Se ha reportado que terneras nutricionalmente restringidas a una edad de siete meses, requieren de 14 a 18 meses para compensar su retraso en el crecimiento (Berge, 1991), lo que concuerda con nuestros resultados. Se ha descrito que terneras alimentadas con un alto plano nutricional a edad temprana, mantuvieron la diferencia en tamaño corporal hasta los 1,5 años de edad (Holloway y Totusek, 1973). De cualquier manera, las terneras DTr y DP tuvieron un mayor promedio de ganancia de peso diario durante el Período II comparadas con las terneras DTr+CF. A pesar de que las terneras DP y DTr, tenían un peso vivo y altura de anca similar, las terneras DP mantuvieron una mayor área de ojo de bife hasta el final del experimento. Las diferencias pueden ser explicadas por la administración de concentrados en la dieta de las terneras DP comparada con la dieta exclusivamente a base de campo natural de las terneras DTr, como ha sido demostrado en novillos de carne alimentados en base a concentrados comparado con aquellos alimentados a base de pasturas (Realini et al., 2004). El aumento en los parámetros que estiman la composición corporal, asociados con el aumento en las concentraciones de IGF-I que ocurrió en todos los grupos de terneras hacia el final del experimento, pueden ser indicativos de la presencia de un crecimiento compensatorio (Hornick et al., 2000), ya que aumentaron los niveles de comida por administración del suplemento que recibieron todos los grupos al final del período experimental. Estos hallazgos refuerzan el concepto de que el plano nutricional que las terneras reciben antes y después del destete, determinan la trayectoria de crecimiento de las mismas y el momento que alcanzan la pubertad (Hall et al., 1995; Gasser et al., 2006).

Las terneras DTr+CF alcanzaron antes la pubertad que las terneras DP y tendieron a alcanzarla antes comparadas con las terneras DTr, siendo similar entre las terneras DP y DTr. Las terneras que tuvieron tasas de crecimiento mayores antes del destete, alcanzaron la pubertad a edades más tempranas comparadas con sus contemporáneas que crecieron más lento (Wiltbank et al., 1966; Arije y Wiltbank, 1971). En este experimento las variables que mejor explicaron la edad a la pubertad estuvieron relacionadas con el crecimiento, desarrollo corporal y concentraciones de IGF-I, de acuerdo con hallazgos previos (Chelikani et al., 2003).

Concluimos que aumentando el plano nutricional de terneras al pie de la madre sobre campo natural en suelos de Basalto, tiene un efecto de corto plazo en la productividad del rodeo, aumentando los pesos vivos al destete de las terneras y un efecto a mediano plazo relacionado con una pubertad más temprana en las vaquillonas de reemplazo, potencialmente reduciendo la edad al 
primer servicio y al primer parto. En este estudio a pesar de que la edad al destete tuvo un impacto de corto plazo en el crecimiento corporal y las concentraciones de IGF-I, no tuvo un efecto negativo de mediano plazo sobre el crecimiento y desarrollo corporal, concentraciones de hormonas metabólicas y edad a la pubertad.

\section{BIBLIOGRAFIA}

Arije GF, Wiltbank JN (1971) U . S . Department of Agriculture, Nebraska Agriculture Experiment Station/ ; Journal of Animal Science 33:401-406.

Armstrong JD et al. (1993) Effect of feed restriction on serum somatotropin, insulin-like growth factor-I-(IGF-I) and IGF binding proteins in cyclic heifers actively inmunized against growth hormone releasing factor. Domestic Animal Endocrinology 10:315-324.

Berge P (1991) Long - term effects of feeding during calfhood on subsequent performance in beef cattle. Livestock Production Science 28:179-201.

Berretta EJ et al. (2000) Campos in Uruguay. In: Grassland Ecophisiology and Grazing Ecology. Lemaire, G, Hodgson, J, De Moraes, A, Nabinger, C, \& Carvalho, PC d F, editors. CAB International, New York, USA pp. 377-394.

Brito LFC et al. (2007) Effect of improved nutrition during calfhood on serum metabolic hormones, gonadotropins, and testosterone concentrations, and on testicular development in bulls. Domestic Animal Endocrinology 33:460469.

de Castro T et al. (2004) 15th International Congress of Animal Reproduction. In: Does early weaning influence age at puberty in beef heifers?,. p. 21

Chelikani PK, Ambrose JD, Kennelly JJ (2003) Effect of dietary energy and protein density on body composition, attainment of puberty, and ovarian follicular dynamics in dairy heifers. Theriogenology 60:707-725.

Davis TA et al. (1998) Roles of Insulin and Amino Acids in the Regulation of Protein
Synthesis in the Neonate. The Journal of nutrition 128:347S-350S.

Freetly HC, Kuehn LA, Cundiff L V (2011) Growth curves of crossbred cows sired by $\mathrm{He}$ reford, Angus, Belgian Blue, Brahman, Boran, and Tuli bulls, and the fraction of mature body weight and height at puberty. Journal of Animal Science 89:2373-2379.

Gasser CL et al. (2006) Effect of timing of feeding a high-concentrate diet on growth and attainment of puberty in earlyweaned heifers. Journal of Animal Science 84:3118-3122.

Gutiérrez V et al. (2013) Calf Foetal And Early Life Nutrition On Grazing Conditions: Metabolic And Endocrine Profiles And Body Composition During The Growing Phase. Journal of Animal Physiology and Animal Nutrition 97:720-731.

Hall JB et al. (1995) Body composition and metabolic profiles associated with puberty in beef heifers. Journal of animal science 73:3409-3420.

Holloway JW, Totusek R (1973) Relationship between Preweaning Nutritional Management and Subsequent Performance of Angus and Hereford Females through Three Calf Crops. Journal of Animal Science 37:807-812.

Hornick JL et al. (2000) Mechanisms of reduced and compensatory growth. Domestic Animal Endocrinology 19:121-132.

Laron Z (2001) Insulin-like growth factor 1 (IGF1): a growth hormone. Mol Pathol 54:311-316.

Lesmeister JL, Burfening PJ, Blackwell RL (1973) Date of first calving in beef cows and subsequent calf production. Journal of Animal Science 36:1-6.

Loy TW et al. (2002) Effects of supplementation on intake and growth of nursing calves grazing native range in southeastern North Dakota The online version of this article, along with updated information and services, is located on the World Wide Web at/ : Effects of supplem. Journal of Animal Science 80:27172725.

Neville WE, McCormick WC (1981) PERFORMANCE OF EARLY- AND NORMALWEANED AND THEIR DAMS. Journal of Animal Science 52. 
Owens FN, Dubeski P, Hansont CF (1993) Factors that Alter the Growth and Development of Ruminants1f2 ABSTRACT/ : Journal of Animal Science 71:3138-3150.

Realini CE et al. (2004) Effect of pasture vs. concentrate feeding with or without antioxidants on carcass characteristics, fatty acid composition, and quality of Uruguayan beef. Meat Science 66:567577.
Viñoles C et al. (2009) Estado actual de la investigación vinculada a la Producción Animal Limpia, Verde y Etica en Uruguay. Agrociencia XIII:59-79.

Wiltbank JN et al. (1966) Effects of Heterosis on Age and Weight at Puberty in Beef Heifers. Animal Science 25:744-751. 


\title{
EFECTO DE MEDIANO PLAZO DE LA NUTRICIÓN SOBRE PARÁMETROS ENDÓCRINOS Y LA EXPRESIÓN DE GENES DEL EJE SOMATOTRÓFICO EN ENDOMETRIO E HÍGADO EN VAQUILLONAS HEREFORD
}

D. Guggeri ${ }^{1}$, A. Meikle ${ }^{2}$, M. Carriquiry ${ }^{3}$, F. Montossi ${ }^{1}$, I. De Barbieri ${ }^{1}$, C. Viñoles ${ }^{1}$

\begin{abstract}
RESUMEN
Se evaluó el efecto de mediano plazo de distintos manejos aplicados a edad temprana sobre parámetros endocrinos y expresión de genes del eje somatotrófico en hígado y endometrio en vaquillonas Hereford pastoreando campo natural. Las vaquillonas recibieron tres tratamientos: 1 ) destete precoz ( $n=8)$ a los $75 \pm 1,5$ días de edad (DP), 2) destete tradicional a los $158 \pm 1,5$ días de edad (DTr) y 3 ) destete tradicional con creep feeding (CF) desde los $75 \pm 1,5$ a 158 $\pm 1,5$ días de edad (DTr+CF). A los 709 $\pm 1,5$ días (edad del primer servicio) las vaquillonas fueron sincronizadas con prostaglandina con un intervalo de 11 días, se detectó celo (Día 0), y se siguió el primer ciclo estral hasta el día 16, momento en el que se resincronizaron y se siguieron hasta el día 7 del segundo ciclo estral. Se realizó sangrado diario durante ambos ciclos estrales y biopsias hepáticas y uterinas los días 7 y 16 . Al día 7 las vaquillonas del grupo $D T r+C F$ expresaron más receptores para hormona de crecimiento en hígado que las del grupo $\operatorname{DTr}(P=0,05)$ y mayores concentraciones de transcripto de la proteína de unión 3 de IGF (IGFBP-3), que las de los grupos DTr y DP $(P<0,05)$. El endometrio de las vaquillonas del grupo $D T r+C F$ tendió $(P=0,1)$ a tener una mayor expresión del transcripto de IGF-I en el día 7 comparado con las del grupo de DP, y en el día 16 se encontraron mayores concentraciones del transcripto de IGF-II en las vaquillonas del grupo $D T r+C F$ comparado con las de los grupos DTr y DP $(P<0,05)$. Las concentraciones de leptina e IGF-I fueron similares entre grupos, pero las concentraciones de progesterona fueron mayores $(P<0,02)$ los días 15 y 16 del ciclo estral en las vaquillonas del grupo $\mathrm{DTr}+\mathrm{CF}$ respecto a las de los grupos DP y DTr. Concluimos que el CF en terneras pastoreando campo natural, tiene un efecto a mediano plazo en el funcionamiento del eje somatotrófico en hígado y endometrio, con un potencial de efecto positivo en la eficiencia reproductiva del rodeo.
\end{abstract}

${ }^{1}$ INIA, Instituto Nacional de Investigación Agropecuaria.

${ }^{2}$ Laboratorio de Endocrinología y Metabolismo Animal, Facultad de Veterinaria.

${ }^{3}$ Producción Animal y de Pasturas, Facultad de Agronomía. 


\section{INTRODUCCIÓN}

Un incremento en el plano nutricional a temprana edad está asociado positivamente con un estado metabólico que estimula el crecimiento (Hopper et al., 1993; Hall et al., 1995) y adelanta la edad a la pubertad (Wiltbank et al., 1966). El creep feeding y el destete precoz con dietas altas en energía son estrategias de manejo que permiten lograr estos objetivos (Gasser, 2013; Guggeri et al., 2014). Corderas alimentadas en un alto plano nutricional antes del destete producen más corderos en su edad adulta comparadas con corderas alimentadas con dietas restrictivas (Rhind et al.,1998), resultado que está probablemente asociado a un mayor sobrevivencia embrionaria (Gunn et al., 1995). Por este motivo, sería importante estudiar el efecto residual de diferentes manejos aplicados a edad temprana sobre el ambiente uterino de las vaquillonas al primer servicio.

El crecimiento y la reproducción están altamente regulados por el eje somatotrófi$\mathrm{co}$, integrado por la hormona del crecimiento $(\mathrm{GH})$ y su receptor (GHR), los factores de crecimiento similares a la insulina tipos I y II (IGF-I, IGF-II), y sus receptores y proteínas de unión (IGFBP1-6) (Laron, 2001). Un alto plano nutricional durante la lactancia está asociado con un aumento en las concentraciones plasmáticas de IGF-I al destete (Guggeri et al., 2014), con potenciales efectos en la eficiencia reproductiva de las vacas. Sin embargo, se desconoce si los cambios nutricionales aplicados a edad temprana tienen un impacto de mediano plazo en el funcionamiento del eje somatotrófico.

Por lo tanto, nos planteamos la hipótesis de que las altas ganancias de peso vivo a edad temprana tienen un efecto de mediano plazo en el funcionamiento de eje somatotrófico, que podría favorecer el desempeño reproductivo de las vaquillonas al primer servicio. El objetivo de este trabajo fue evaluar el impacto de diferentes sistemas de manejo impuestos entre los 75 a 158 días de edad, en la concentración de hormonas reproductivas y metabólicas y en la expresión génica en hígado y endometrio de miembros del eje somatotrófico al momento del primer servicio en vaquillonas Hereford.

\section{MATERIALES Y MÉTODOS}

El experimento se llevó a cabo en la Estación Experimental Glencoe de INIA. Los animales provenían de un experimento anterior, en el cual se utilizaron 46 terneras Hereford, hijas de vacas multíparas de $75 \pm 1,5$ días de edad y 79,4 $\pm 2,9 \mathrm{~kg}$ de peso vivo, las que fueron asignadas al azar a 3 grupos con 2 repeticiones y se sometieron a tres medidas de manejo: destete precoz a los $75 \pm 1,5$ días de edad (DP), destete tradicional a los $158 \pm 1,5$ días de edad (DTr) y destete tradicional con creep feeding (CF) desde los $75 \pm 1,5$ a 158 $\pm 1,5$ días de edad (DTr+CF). A los 709 1,5 días (edad del primer servicio), un grupo de 22 vaquillonas con al menos dos fases luteales consecutivas fueron seleccionadas para éste experimento, conformado por 8 vaquiIlonas del grupo DP $(380 \pm 10,9 \mathrm{~kg}$ y $2,4 \pm 0,5$ fases luteales), 7 vaquillonas del grupo DTr (375 $\pm 11,7 \mathrm{~kg}$ y $2,7 \pm 0,5$ fases luteales) y 7 vaquillonas del grupo DTr+CF $(3,4 \pm 0,6 \mathrm{fa}-$ ses luteales). Se realizó sincronización de celos con dos dosis de prostaglandina $(0,0015 \mathrm{mg}$ intramuscular) con un intervalo de 11 días y detección de celos para determinar el inicio del primer ciclo estral (día $0=$ celo), se administró una tercera dosis de prostaglandina el día 16, y se volvió a detectar celo y realizar el seguimiento hasta el día 7 del siguiente ciclo estral. Las biopsias de hígado y endometrio se tomaron coincidiendo aproximadamente con el momento de la eclosión embrionaria (día 7) y del reconocimiento materno de la preñez (día 16). Se colectaron muestras de sangre diariamente por venopunción yugular para la determinación de progesterona y de IGF-I y leptina los días 7 y 16 del ciclo. Las variables continuas con medidas repetidas en el tiempo fueron analizadas utilizando el procedimiento mixto de SAS, ajustando las diferencias por el test de Tukey-Kramer. Se calculó el área debajo de la curva para las concentraciones de progesterona, que fue utilizada como covariable para analizar su efecto en la expresión génica uterina. La frecuencia de vaquillonas en cada grupo que habían iniciado la luteólisis el día 16 
fue analizada por glimmix. Valores de $\mathrm{P}>0,05$ fueron considerados significativos $y$ tendencia los valores de $P$ entre 0,05 0,1 .

\section{Resultados}

\section{Concentraciones plasmáticas de hormonas}

El número de vaquillonas que comenzaron la luteolisis el dia 16 del ciclo tendió a ser mayor en los grupos DP (6/8) y DTr (5/7) comparado con el DTr+CF (1/7) $(P=0,07)$. Las vaquillonas del grupo $\mathrm{DTr}+\mathrm{CF}$ presentaron una mayor concentración de progesterona en los días 15 y 16 que las de los demás grupos ( $P<0,02$; Figura 7 ).

Las concentraciones de IGF-I fueron similares entre grupos y días $(P>0,05$; $D P=$ $243,3 \pm 25,0 \mathrm{ng} / \mathrm{mL}, \mathrm{DTr}=224,4 \pm 29,1 \mathrm{ng} / \mathrm{mL}$ y $\mathrm{DTr}+\mathrm{CF}=260,7 \pm 29,7 \mathrm{ng} / \mathrm{mL}$; Día $7=$ $252,6 \pm 20,5 \mathrm{ng} / \mathrm{mL}$ y Día $16=232,9 \pm 18,3 \mathrm{ng} /$ $\mathrm{mL}$ ). No se observaron diferencias en la con- centración de leptina entre grupos y días $(\mathrm{P}>$ 0,$05 ; \mathrm{DP}=6,0 \pm 1,7 \mathrm{ng} / \mathrm{mL}, \mathrm{DTr}=10,2 \pm 2,0 \mathrm{ng} /$ $\mathrm{mL}$ and $\mathrm{DTr}+\mathrm{CF}=6,7 \pm 1,8 \mathrm{ng} / \mathrm{mL}$; Día $7=$ $7,9 \pm 1,1 \mathrm{ng} / \mathrm{mL}$ and Día $16=7,5 \pm 1,1 \mathrm{ng} / \mathrm{mL}$ ).

\section{Expresión génica en hígado}

Al día 7, las vaquillonas del grupo $D T r+C F$ expresaron más transcripto para GHR que las del grupo $D \operatorname{Tr}(P=0,05)$, siendo intermedios los valores para las del grupo DP (Figura 8). La expresión del transcripto de GHR en los grupos DP y DTr fue menor al día 7 que al dia $16(P<0,05)$, no observándose diferencias entre días para el tratamiento DTr+CF (Figura 8). El test de Tukey-Kramer mostró que la expresión del transcripto para IGFBP-3 fue mayor en las vaquillonas del grupo DTr+CF comparadas con las de los grupos DP $(P=0,007)$ y $D \operatorname{Tr}(P=0,03)$ en el día 7 (Figura 8). La expresión de IGFBP-3 se redujo del día 7 al 16 en el grupo $D T r+C F$, pero se mantuvo constante en los grupos DP y DTr (Figura 8).

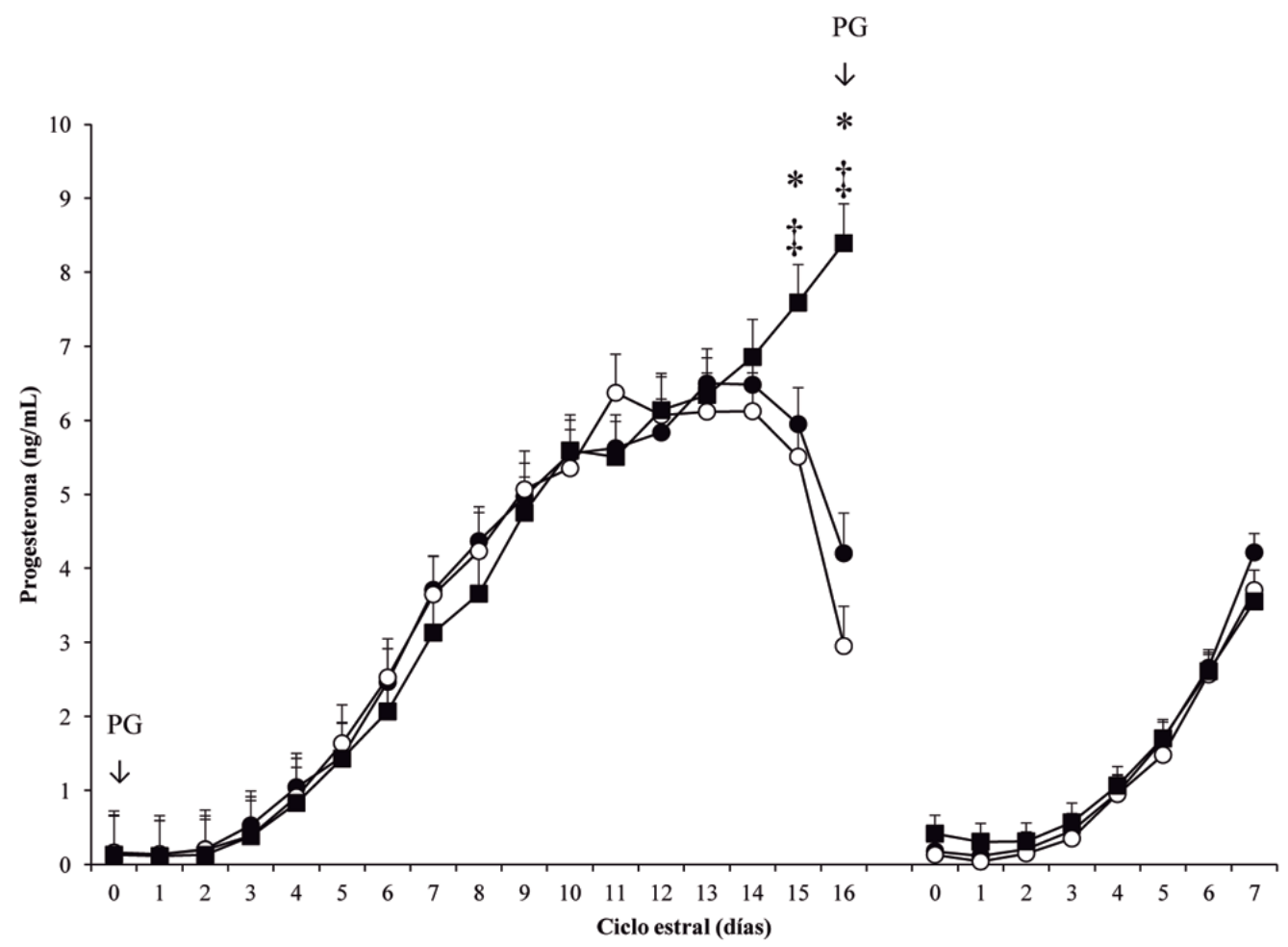

Figura 7. Concentraciones de progesterona circulante durante el ciclo estral, hasta el día 16 y 7 , cuando se tomaron biopsias de endometrio e hígado y se inyectó prostaglandina (PG), en vaquillonas de destete precoz $(\mathbf{O})$, destete tradicional $(O)$ y destete tradicional con creep feeding $(\square) . P G=$ inyección de prostaglandina * $P<0,05$ entre $D T r$ y $D T r+C F$; $\ddagger \mathrm{P}<0,05$ entre DTr+CF y DP. 


\section{Expresión génica en endometrio}

En el día 7 se observó una tendencia a mayor expresión de ARNm para IGF-I $(P=0,1)$, y al día 16 fue mayor para el grupo DTr+CF que para los grupos DP y DTr (Figura 8). Respecto a las expresión de ARNm para IGFII, se encontraron mayores concentraciones del transcripto en las vaquillonas del grupo $\mathrm{DTr}+\mathrm{CF}$ que en las de los grupos DP y DTr $(P=0,04$; Figura 8).

\section{DISCUSIÓN}

Este es el primer estudio que describe el efecto de mediano plazo de diferentes sistemas de manejo aplicados a edades tempranas sobre la expresión de genes de miembros del eje somatotrófico en útero e hígado en vaquillonas. La expresión diferencial de los mismos ocurrió aun cuando habían desaparecido las diferencias en peso vivo inducidos por los diferentes tratamientos a los que fueron sometidas.

Un alto plano nutricional y balance energético positivo están asociados con un in-

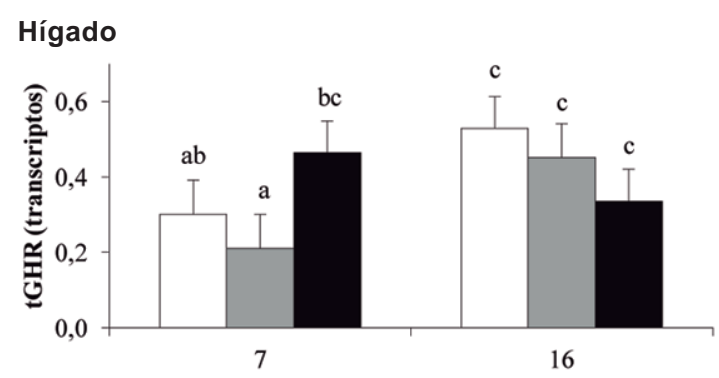

Endometrio
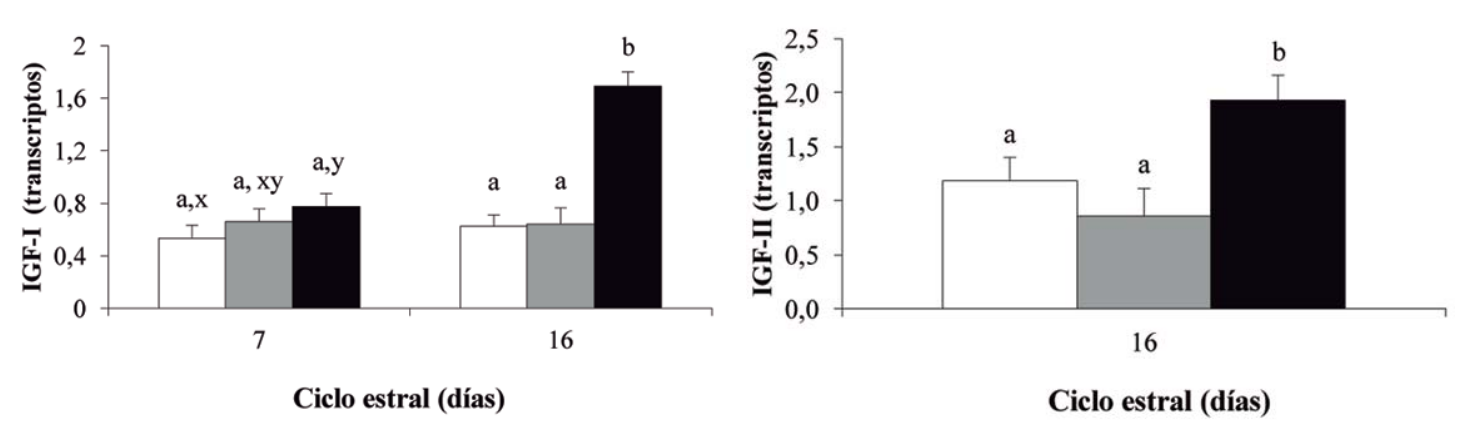

Figura 8. Expresión hepática y endometrial de tGHR, IGFBP-3 e IGF-I al día 7 y 16 y expresión cremento en la concentración de hormonas metabólicas (Chelikani et al., 2009) en la expresión de transcripto de GHR en hígado (Jiang y Lucy, 2001; Rajaram et al., 1997) y con la fertilidad (Rhoads et al., 2008). La ausencia de diferencias en las concentraciones de IGF-I y leptina entre grupos puede explicarse porque no existían diferencias de peso y a que se analizó solamente en los días 7 y 16 del ciclo. Una mayor expresión hepática del transcripto de GHR determina un aumento en las concentraciones séricas de IGF-I e IGFBP-3 y disminución de IGFBP2 (Rajaram et al., 1997). En este estudio la expresión hepática del transcripto de IGFBP3 al día 7 fue mayor en las vaquillonas del grupo DTr+CF que en los grupos DP y DTr. Este resultado es relevante ya que estas proteínas de unión estimulan el desarrollo embrionario temprano en respuesta a señales del propio embrión (Liu et al., 1995). Además el IGFBP-3 ayuda en el transporte de IGF-I sistémico a su tejido blanco (Jones y Clemmons, 1995), creando así un mejor ambiente para el desarrollo embrionario. El efecto de las ganancias diarias diferenciales fue

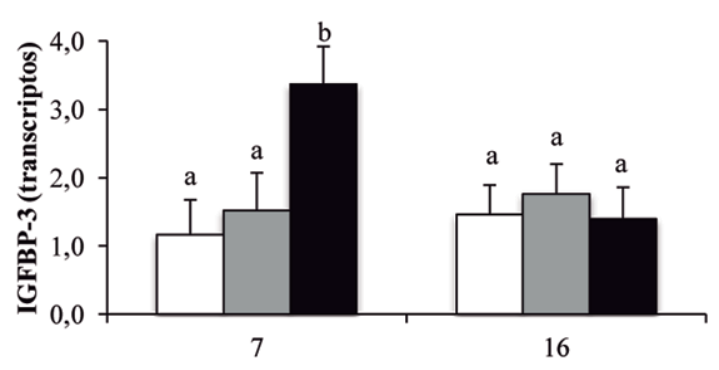

Ciclo estral (días)

\footnotetext{
endometrial de IGF-II al día 16 del ciclo estral en vaquillonas de grupo destete precoz
(blanco), destete tradicional (gris) y destete tradicional con creep feeding (negro).

endometrial de IGF-II al día 16 del ciclo estral en vaquillonas de grupo destete precoz
(blanco), destete tradicional (gris) y destete tradicional con creep feeding (negro). $a$ vs $b$ vs $c P<0,05 ; x$ vs $y, P=0,1$.
} 
evidente aun después de terminados los tratamientos (Guggeri et al., 2014), sugiriendo que el plano nutricional aplicado a edades tempranas puede programar la sensibilidad del hígado a la acción de la $\mathrm{GH}$, aumentando el IGFBP-3 hepático y potenciando la fertilidad al primer servicio.

Las mayores concentraciones de progesterona los días 15 y 16 del ciclo estral en las vaquillonas del grupo DTr+CF, podrían explicarse por la cantidad de ciclos estrales previos (Guggeri et al., 2014). Este resultado sería muy relevante ya que la fertilidad al celo puberal es menor que la que ocurre al tercer celo (Byerley et al., 1987), debido a la existencia de fases luteales cortas con baja secreción de progesterona después de la primera ovulación (Gasser 2013). Sin embargo, las vaquillonas de todos los grupos seleccionadas para este experimento presentaban al menos 2 fases luteales previas, motivo por el cual las diferencias encontradas en las concentraciones de progesterona estarían explicadas por un mayor soporte luteotrófico brindado por factores de crecimiento sistémicos u hormonas metabólicas (Spicer y Echternkamp, 1995).

En este trabajo, el grupo DTr+CF tuvo una mayor expresión endometrial del transcripto de IGF-I al día 7 y 16 y de IGF-II al día 16 comparados con los otros grupos. La mayor expresión endometrial de IGF-I e IGF-II en el grupo DTr+CF en nuestro estudio, es compatible con un mayor tamaño embrionario, como fue descrito anteriormente en ovinos (Sequeira et al., 2016). Las vaquillonas del grupo DTr+CF también presentaron mayores concentraciones de progesterona los días 15 y 16 del ciclo estral comparados con las de DP y DTr. Algunos estudios evidencian que las concentraciones de progesterona en la fase luteal temprana cambian el transcriptoma endometrial, favoreciendo el ambiente uterino y su capacidad de promover un adecuado desarrollo embrionario (Spencer et al., 2017). Por este motivo, el área debajo de la curva de progesterona fue utilizada como covariable en el modelo estadístico, demostrando que el IGF-II, pero no el IGF-I, fue afectado por esta hormona. Por lo tanto, las diferencias en expresión génica de IGF-I en en- dometrio serían parte del efecto de mediano plazo de altos planos nutricionales aplicados a edades tempranas.

Concluimos que la mejora en el plano nutricional de terneras lactantes pastoreando en campo natural, tiene un efecto de mediano plazo en la expresión de genes de miembros del eje somatotrófico en hígado y útero. Estos efectos podrían reducir las pérdidas embrionarias a través del incremento en la sensibilidad del hígado a la GH, mayor expresión endometrial de IGF-I e IGF-II y promoción del desarrollo embrionario asociado a mayores concentraciones de progesterona en el período crítico del reconocimiento materno de la preñez.

\section{BIBLIOGRAFÍA}

Byerley DJ et al. (1987) Pregnancy rates of beef heifers bred either on pubertal or third estrus. Journal of Animal Science 65:645-650.

Chelikani PK et al. (2009) Effects of dietary energy and protein density on plasma concentrations of leptin and metabolic hormones in dairy heifers. Journal of dairy science 92:1430-1441.

Gasser CL (2013) Beef species syposium, considerations on puberty in replacement beef heifers. Journal of Animal Science 1336-1340.

Guggeri D et al. (2014) Effect of different management systems on growth, endocrine parameters and puberty in Hereford female calves grazing Campos grassland. Livestock Science 167:455462.

Gunn RG, Sim DA, Hunter EA (1995) Effects of nutrition in utero and in early life on the subsequent lifetime reproductive performance of Scottish Blackface ewes in two management systems. Animal Science 60:223-230.

Hall JB et al. (1995) Body composition and metabolic profiles associated with puberty in beef heifers. Journal of animal science 73:3409-3420.

Hopper HW et al. (1993) Effect of prepubertal body weight gain and breed on carcass composition at puberty in beef heifers. Journal of animal science 71:1104-1111. 
Jiang H, Lucy MC (2001) Variants of the 5'untranslated region of the bovine growth hormone receptor mRNA: Isolation, expression and effects on translational efficiency. Gene 265:45-53.

Jones JI, Clemmons DR (1995) Insulin-Like Growth Factors and Their Binding Proteins: Biological Actions. Endocrine Reviews 16.

Laron Z (2001) Insulin-like growth factor 1 (IGF1): a growth hormone. Mol Pathol 54:311-316.

Liu HC et al. (1995) Production of insulin-like growth factor binding proteins (IGFBPS) by human endometrial stromal cell is stimulated by the presence of embryos. Journal of assisted reproduction and genetics 12:78-87.

Rajaram S et al. (1997) Insulin-Like Growth Factor-Binding Proteins in Serum and Other Biological Fluids/: Regulation and Functions *. Endocrine Reviews 18:801831.

Rhind S. et al. (1998) Effects of restriction of growth and development of Brecon Cheviot ewe lambs on subsequent lifetime reproductive performance. Small Ruminant Research 30:121-126.
Rhoads ML et al. (2008) Uterine and Hepatic Gene Expression in Relation to Days Postpartum, Estrus, and Pregnancy in Postpartum Dairy Cows. Journal of Dairy Science 91:140-150.

Sequeira M et al. (2016) Gestation-related gene expression and protein localization in endometrial tissue of Suffolk and Cheviot ewes at gestation Day 19, after transfer of Suffolk or Cheviot embryos. Theriogenology 86:1557-1565.

Spencer TE et al. (2017) Insights into conceptus elongation and establishment of pregnancy in ruminants. Reproduction, Fertility and Development 29:84-100.

Spicer LJ, Echternkamp SE (1995) The ovarian insulin and insulin-like growth factor system with an emphasis on domestic animals. Domest Anim Endocrinol 12:223-245.

Wiltbank JN et al. (1966) Effects of Heterosis on Age and Weight at Puberty in Beef Heifers. Animal Science 25:744-751. 


\title{
IMPACTO DE LARGO PLAZO DE DISTINTOS SISTEMAS DE MANEJO APLICADOS A TEMPRANA EDAD SOBRE LAS DIMENSIONES DE LOS TERNEROS Y LA PRODUCCIÓN DE LECHE EN LA PRIMERA LACTANCIA DE VACAS HEREFORD
}

D. Guggeri ${ }^{1}$, R. Méndez ${ }^{2}$, P. Cuadro ${ }^{1}$, A. Martin ${ }^{1}$, M. Ferrón ${ }^{1}$, L. Velóz ${ }^{3}$, C. Viñoles ${ }^{1}$

\begin{abstract}
RESUMEN
El objetivo de este experimento fue comparar el peso y dimensiones al nacimiento, asistencias al parto y producción de leche de vacas de primera cría paridas con 2 años de edad, que fueron sometidas a diferentes manejos nutricionales entre los 2 y 5 meses de vida. Se utilizaron 76 vacas Hereford de primera cría, que fueron sometidas a diferentes sistemas de manejo entre los dos y los cinco meses de edad (destetadas precozmente a los 2 meses de edad (DP) y destetadas en forma tradicional con 5 meses (DTr) que fueron suplementadas $(\mathrm{DTr}+\mathrm{CF})$ o no (DTr-CF) al pie de la madre. Se evalúo el peso vivo y las dimensiones de los terneros y las asistencias al parto. Se midió la producción de leche en forma mecánica a los 30, 60 y 90 días posparto. Las vacas DTr+CF parieron terneros más livianos y de menores dimensiones que las DTr-CF, sin diferenciarse de las DP. Sin embargo, no hubo diferencias en la proporción de vacas asistidas al parto. Las vacas DTr+CF tendieron a producir menos leche, por lo que sus terneros tuvieron menos ganancias y fueron más livianos hasta los 90 días de edad. Concluimos que el manejo aplicado a terneras entre los 2 y 5 meses de edad, tiene efectos de largo plazo en su primer ternero, que tiene menor peso y dimensiones al nacimiento y menor ganancia y peso en los primeros 90 días de vida asociados a una menor producción de leche.
\end{abstract}

\section{INTRODUCCIÓN}

La edad al primer parto afecta la productividad de la vaca en el rodeo de cría (Lesmeister et al., 1973). Para entorar vaquillonas con 13-15 meses es importante partir de terneras de $200 \mathrm{~kg}$ al destete (Smeaton et al., 2009). En nuestros siste- mas de cría pastoriles, el período crítico de crecimiento de la ternera que determina el peso al destete ocurre durante el verano, estación donde el crecimiento del forraje (Berreta, 1998) limita la producción de leche de las vacas. A partir de los 2 meses de edad, la ternera no logra cubrir sus requerimientos en base a la leche materna (Ever-

${ }^{1}$ INIA, Instituto Nacional de Investigación Agropecuaria.

${ }^{2}$ Estudiante IGAP.

${ }^{3}$ Estudiante iniciación beca ANII 
sole, 2001), y la alta variabilidad en la productividad del campo natural impide que expresen su potencial de crecimiento. Es aquí donde la nutrición focalizada con concentrados (CF) y/o pasturas pueden ser estratégicamente utilizados (Pigurina et al., 2000). Un alto plano nutricional a temprana edad, influiría positivamente sobre la edad a la cual las terneras alcanzan la pubertad (Wiltbank et al., 1966), pero se ha descrito una correlación negativa entre la tasa de crecimiento antes del destete y la futura habilidad materna de las terneras (Herd et al., 1998). Dado que de los tres a los 10 meses de edad, la glándula mamaria tiene una tasa de desarrollo más rápida que el resto de los tejidos (crecimiento alométrico), se postula que la deposición de grasa en la ubre durante este período, impediría el correcto desarrollo del tejido mamario (Martin et al., 1981). Otro aspecto importante es la facilidad de parto de esas vacas que paren con 2 años de edad, ya que se ha descrito que vacas sometidas a CF cuando eran terneras, paren terneros más pesados, lo que podría aumentar las dificultades de parto (Holloway y Totusek, 1973). Por lo tanto, nos planteamos la hipótesis de que altos planos nutricionales, asociados a altas tasas de ganancia de peso pre-destete, estarían asociados a un mayor tamaño del ternero al nacimiento y a una menor producción de leche en la primera lactancia. El objetivo de este trabajo fue evaluar el impacto de distintos sistemas de manejo entre los 2 y 5 meses de edad, sobre el tamaño y dimensiones del ternero al nacimiento y la producción láctea en los tres primeros meses de lactancia de vacas paridas con 2 años de edad.

\section{MATERIALES Y MÉTODOS}

El experimento se realizó en la Estación Experimental Glencoe, INIA Tacuarembó, Paysandú, Uruguay, en dos años consecutivos. Se utilizaron 106 terneras Hereford nacidas en primavera 2008 (Año 1) y 2009 (Año 2), que fueron sometidas a tres tratamientos entre los dos y cinco meses de edad. Los tratamientos utilizados fueron destete precoz a los 2 meses de edad (DP; $n=18$ y $n=19$ ) y destete tradicional (DTr $=5$ meses de edad) con creep feeding (DTr+CF; $n=18$ y $n=17$ ) o sin CF (DTr-CF; n=18 y n=16) (ración con > $18 \%$ de proteína). El peso vivo al momento del destete tradicional fue mayor en las terneras DTr+CF $(176 \pm 5,1 \mathrm{~kg}$ y $195 \pm 5,9 \mathrm{~kg})$ que en las DTr-CF $(156 \pm 5,1 \mathrm{~kg}$ y $184 \pm 5,7 \mathrm{~kg})$ y las DP $(136 \pm 5,1 \mathrm{~kg}$ y $124 \pm 5,7 \mathrm{~kg})$ en los años 1 y 2 , respectivamente. La tasa de ganancia de peso fue superior en las terneras DTr+CF $(0,808 \pm 0,02$ y 0,934 $\pm 0,04 \mathrm{~kg} / \mathrm{d})$ que en las DTr-CF $(0,632 \pm 0,02$ y 0,781 \pm $0,04 \mathrm{~kg} / \mathrm{d})$ y las DP $(0,496 \pm 0,02$ y $0,310 \pm$ $0,04 \mathrm{~kg} / \mathrm{d}$ ), y mayores en las DTr-CF que en las DP en ambos años. La base nutricional hasta el destete definitivo fue campo natural. A partir del destete definitivo, todas las terneras fueron sometidas al mismo plano nutricional: mejoramiento de campo natural con suplementación estratégica (sequía año 2009) o pastoreo de avena con suplementación de afrechillo de trigo $1 \%$ del peso vivo, y a partir del entore con 14 meses de edad todas las vacas estuvieron sobre campo natural. Al inicio del servicio las vaquillonas $\mathrm{DTr}+\mathrm{CF}$ pesaban $348 \pm 6,8 \mathrm{~kg}$, las DTr-CF $334 \pm 6,6 \mathrm{~kg}$ y las DP $310 \pm 6,7 \mathrm{~kg}$ promedio para ambos años. Las vaquillonas DTr+CF concibieron antes $(21,6 \pm 3$ días) que las DTrCF $(37,0 \pm 3$ días $)$ y las DP $(39,5 \pm 3$ días $)$ y el porcentaje de preñez al final del servicio fue mayor en las DTr+CF (94\%) que en las DTrCF (58\%) y las DP (47\%) en el año 2. Un total de 76 vacas parieron en 2010 y 2011 con 2 años de edad. Al parto, se registró el peso vivo y dimensiones de los terneros (largo del cuerpo y tronco y altura a las cruces y anca), y se evaluó la dificultad de parto usando una escala de $1=$ sin dificultad a $5=$ cesárea. Se registró el peso vivo de los terneros desde el nacimiento hasta los 3 meses de edad. Una muestra de las vacas (7 por grupo en 2010 y 5 por grupo en 2011) fueron ordeñadas en forma mecánica en tres oportunidades a los 30, 60 y 90 días de paridas, determinándose la producción de leche y los porcentajes de proteína, grasa y lactosa. Las variables se analizaron utilizando un modelo lineal mixto en SAS considerándose el efecto grupo, año y su interacción en el modelo estadístico. El padre de los terneros y el día que nacieron desde que comenzó la parición (Día 0) fueron usados como covariable en el modelo. Se conside- 
raron significativos valores de $\mathrm{P}<0,05$ y tendencias para valores de $\mathrm{P}>0,05 \mathrm{y}<0,1$.

\section{RESULTADOS}

Los terneros nacidos de vacas $\mathrm{DTr}+\mathrm{CF}$ fueron más livianos y de menores dimensiones que los nacidos de vacas DTr-CF, pero similares a los de las vacas DP (Cuadro 3). Sin embargo, el porcentaje de asistencias fue similar entre grupos (Cuadro 3). Los terneros hijos de vacas DTr+CF tuvieron una menor tasa de ganancia diaria de peso y llegaron a los 90 días siendo más livianos que los de vacas DTr-CF, pero similares a los de los hijos de las vacas DP (Cuadro 3).

Las vacas DTr+CF tendieron a producir $(P=0,1)$ menos leche $(4,9 \pm 0,4 \mathrm{~kg})$ que las DTr-CF $(6,0 \pm 0,4 \mathrm{~kg})$ y DP $(5,9 \pm 0,4 \mathrm{~kg})$. La concentración de grasa $(3,5 \pm 0,1 \%)$, proteína $(3,04 \pm 0,04 \%)$, y lactosa $(5,2 \pm 0,02 \%)$ fue similar entre grupos.

\section{DISCUSIÓN}

La hipótesis de que altos planos nutricionales asociados a altas tasas de ganancia de peso pre-destete, estarían asociados a un mayor tamaño del ternero al nacimiento y a una menor producción de leche en la primera lactancia, fue parcialmente aceptada. Las vacas DTr+CF parieron terneros más livianos y pequeños que las DTr-CF, sin diferenciarse de las DP. Estos resultados son opuestos a los reportados anteriormente, donde se describen mayores pesos de los terneros al nacimiento (Holloway y Totusek, 1973), lo que podría deberse al momento en que fueron aplicados los tratamientos (a partir de los 140 días (Holloway y Totusek, 1973) y de los 75 a los 158 días en este trabajo). Las diferencias en peso y dimensiones de los terneros hijos de vacas mejor alimentadas puede asociarse a una programación periconcepción, ya que hembras jóvenes sobrenutridas durante el período pre-servicio o concepción temprana, pueden dar origen a fetos más chicos, asociados a un acortamiento de la gestación y partos prematuros (Wallace et al., 2001). En este experimento, no estaba pre-definido evaluar el largo de gestación, que requiere de conocer en forma exacta el momento de concepción, pero el peso al nacimiento de los terneros hijos de vacas Dtr+CF no estaría asociado al nacimiento de terneros prematuros. A pesar de las diferencias en peso y tamaño, la incidencia de asistencias fue similar entre grupos de vacas, hipótesis que debería testarse con

Cuadro 3. Peso vivo (PV), dimensiones (largo del cuerpo (LC), largo del tronco (LT), altura a las cruces (AC), altura de anca (AA), asistencias (As), ganancia diaria (GDP) y peso a los 90 días (P90) de terneros nacidos de vacas que fueron destetadas en forma precoz (DP) o tradicional y recibieron (DTr+CF) o no (DTr-CF) creep feeding cuando eran terneras y que parieron con dos años de edad.

\begin{tabular}{|lcccccc|}
\hline Grupo & $\begin{array}{c}\text { DP } \\
(\mathbf{n}=26)\end{array}$ & $\begin{array}{c}\text { DTr-CF } \\
(\mathbf{n}=21)\end{array}$ & $\begin{array}{c}\text { DTr+CF } \\
(\mathbf{n}=29)\end{array}$ & Grupo & Año & Grupo*año \\
\hline PV (kg) & $32,5 \pm 0,9^{\mathrm{ab}}$ & $34,5 \pm 0,8^{\mathrm{a}}$ & $31,3 \pm 0,8^{\mathrm{b}}$ & 0,02 & $\mathrm{~ns}$ & $\mathrm{~ns}$ \\
LC (cm) & $80,5 \pm 1,1^{\mathrm{ab}}$ & $82,4 \pm 0,9^{\mathrm{a}}$ & $78,3 \pm 0,9^{\mathrm{b}}$ & 0,01 & $\mathrm{~ns}$ & $\mathrm{~ns}$ \\
LT (cm) & $58,2 \pm 1,1^{\mathrm{ab}}$ & $59,9 \pm 1,0^{\mathrm{a}}$ & $55,7 \pm 1,0^{\mathrm{b}}$ & 0,05 & 0,03 & $\mathrm{~ns}$ \\
AC (cm) & $68,9 \pm 0,8^{\mathrm{ab}}$ & $69,3 \pm 0,7^{\mathrm{a}}$ & $67,2 \pm 0,7^{\mathrm{b}}$ & 0,08 & 0,01 & $\mathrm{~ns}$ \\
AA (cm) & $73,3 \pm 1,0^{\mathrm{a}}$ & $73,2 \pm 0,9^{\mathrm{a}}$ & $70,5 \pm 0,8^{\mathrm{b}}$ & 0,05 & 0,06 & $\mathrm{~ns}$ \\
As (n) & $5 / 26$ & $8 / 21$ & $6 / 29$ & $\mathrm{~ns}$ & $\mathrm{~ns}$ & $\mathrm{~ns}$ \\
GDP $(\mathrm{g} / \mathrm{d})$ & $0,667 \pm 0,03^{\mathrm{ab}}$ & $0,738 \pm 0,03^{\mathrm{a}}$ & $0,625 \pm 0,03^{\mathrm{b}}$ & 0,01 & 0,01 & $\mathrm{~ns}$ \\
P90 (kg) & $95,8 \pm 2,6^{\mathrm{ab}}$ & $103 \pm 2,2^{\mathrm{a}}$ & $89,7 \pm 2,4^{\mathrm{b}}$ & 0,02 & $\mathrm{~ns}$ & $\mathrm{~ns}$ \\
\hline
\end{tabular}

Letras diferentes en la misma fila indican diferencias para el valor de $\mathrm{P}$ indicado en la columna de efecto grupo- ns= no significativo. 
un mayor número de vacas. Las vacas DTr+CF tendieron a producir menos leche, lo que se vio reflejado en menores tasas de ganancia de peso y peso de los terneros a los 90 días de edad. Las diferencias en producción de leche no fueron significativas, probablemente asociado a que solamente se ordeñaron 12 vacas de cada tratamiento en ambos años. Estos resultados coinciden con los publicados previamente, y sugieren que altas tasas de ganancia de peso a edades tempranas $(>0,8 \mathrm{~kg} / \mathrm{d}$ ) promueven un engrasamiento de la ubre en vacas para carne, tal como ocurre en vaquillonas lecheras (Holloway y Totusek, 1973; Martin et al., 1981; Herd et al., 1998). Por lo tanto, en nuestros sistemas de cría tradicionales sobre suelos superficiales, donde el crecimiento de la ternera se ve restringido durante el verano, el aumento en las tasas de ganancia de peso podría tener efectos de largo plazo en la progenie, lo que debería de ser analizado económicamente considerando ventajas y desventajas en todo el ciclo productico (peso al destete propio y de su primer ternero, pubertad, momento de la concepción y preñez al primer servicio).

\section{BIBLIOGRAFÍA}

Berreta EJ (1998) Principales características climáticas y edaficas de la region de basalto en Uruguay. Seminario de actualizacion en tecnologías para basalto. Serie técnica 102 INIA.

Herd DB, Wikse SE, Carstens G (1998) The role of creep feeding in beef cattle production.

Holloway JW, Totusek R (1973) Relationship between Preweaning Nutritional Management and Subsequent Performance of Angus and Hereford Females through Three Calf Crops. Journal of Animal Science 37:807-812.

Lesmeister JL, Burfening PJ, Blackwell RL (1973) Date of first calving in beef cows and subsequent calf production. Journal of Animal Science 36:1-6.

Martin TG et al. (1981) Creep Feed as a Factor Influencing Performance of Cows and Calves. Journal of animal science 53:33-39.

Smeaton D et al. (2009) Profitable Farming of Beef Cows. In: MEAT \& WOOL NZ. Morris, $S$ \& Smeaton, D, editors. Palmerston North, New Zeland pp. $42-68$.

Wallace J et al. (2001) Nutrient partitioning during adolescent pregnancy. Reproduction 122:347-357. 


\section{CONSIDERACIONES FINALES}

Los resultados de 9 años de trabajo en creep feeding, demuestran que esta tecnología permite aumentar entre 15 y $36 \mathrm{~kg}$ el peso de los terneros al destete, con muy buenas eficiencias de conversión (3,6 a 6,1, Cuadro 4) siempre que el suplemento utilizado tenga un contenido de proteína superior al $18 \%$ y que sea administrada en forma diaria (Figura 9). Los resultados sugieren que los terneros no sustituyen la leche materna por el suplemento, sino que reducen el tiempo dedicado al pastoreo y en situaciones en que la asignación de forraje es muy limitante (3 kg MS/kg PV) el creep feeding permite reducir el consumo de leche (Figura 9). No se observó un efecto consistente del creep feeding en la condición corporal ni en la preñez de las vacas. En las oportunidades en que fue positivo, se observó un adelanto en el momento de la concepción de las vacas de 4 a 20 días y un aumento en el porcentaje de preñez del 20\% (Figura 9). La mejora en la eficiencia reproductiva de mayor impacto ocurrió cuando se utilizaron vacas de primera cría, en condición corporal sub-óptima (3,8$4,1)$ y con una asignación de forraje que no fue limitante (6-9 kg MS/kg PV). Confirmamos también que el destete temporario reduce las tasas de ganancia de los terneros durante el período de aplicación de la tablilla

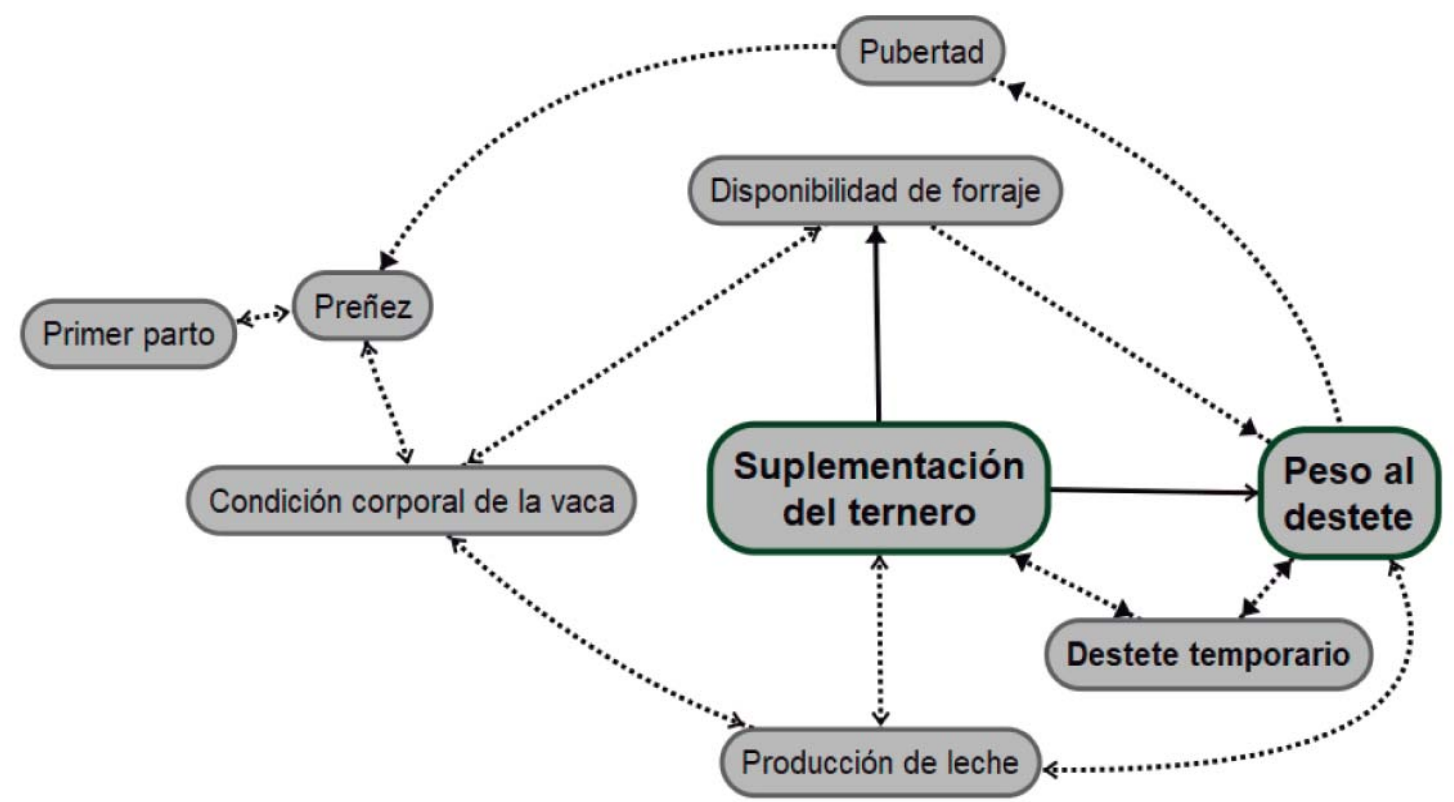

Figura 9. Impacto de la suplementación del ternero sobre su peso al destete, y los efectos de mediano plazo sobre la pubertad y preñez en la vaquillona de reemplazo y de largo plazo sobre la progenie al primer parto, y las interacciones con otras variables del sistema (disponibilidad de forraje y condición corporal de las vacas) que determinan el impacto en la producción de leche de las vacas y en la preñez de las madres. La asociación de la suplementación del ternero con el destete temporario podría permitir levantar algunas restricciones que implica el uso de esta técnica. 


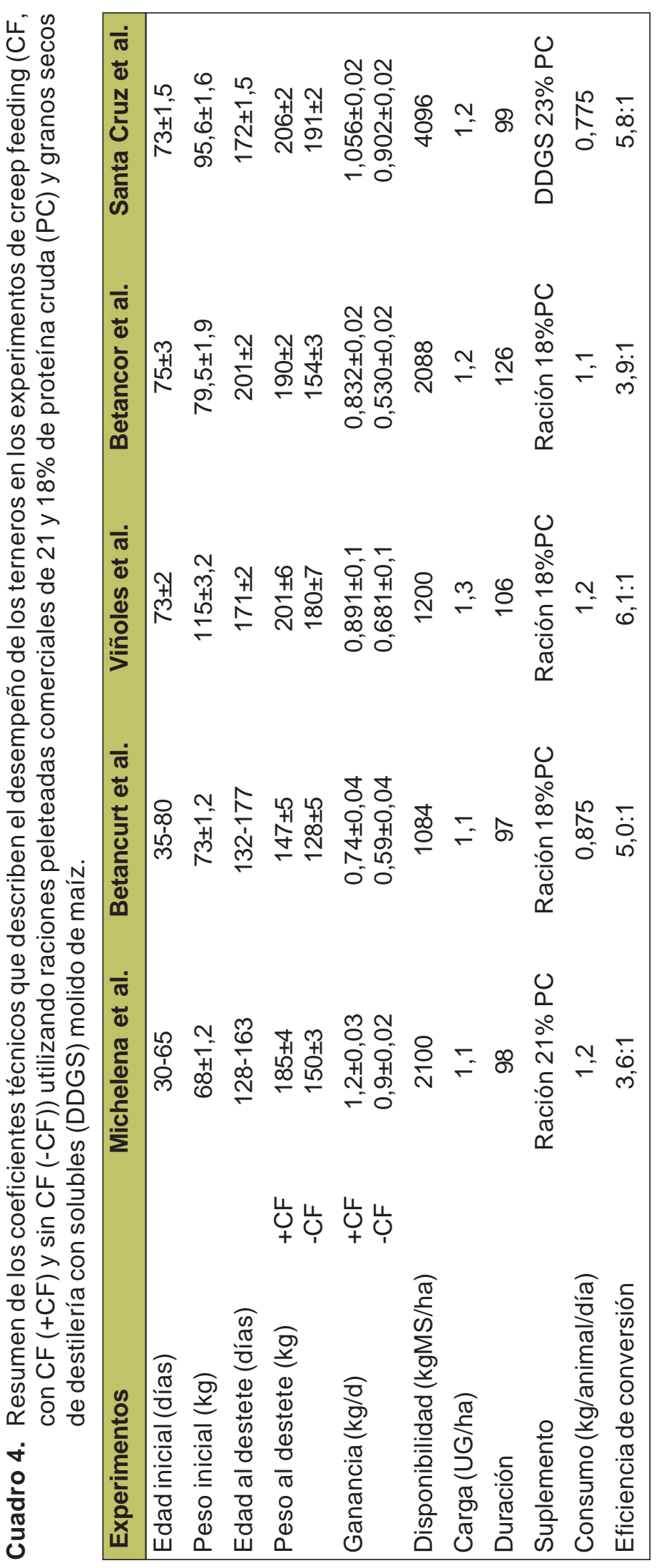


a 200-300 g/día, y que el creep feeding con un suplemento de calidad adecuada y administrado diariamente permite duplicar esas ganancias (200-300 g; Figura 9). El destete temporario con tablilla nasal por 14 días, redujo en forma consistente el peso al destete de los terneros (3 a 18 kg). En nuestros experimentos, utilizando vacas en condición corporal $>$ a 3,8 unidades y con una buena asignación de forraje en campo natural, el destete temporario no aumentó el porcentaje final de preñez, sino que tuvo un impacto en adelantar el momento de la concepción en 4 a 11 días. Uno de los mejores resultados de aplicación del creep feeding se obtuvieron utilizando DDGS de maíz, con un $22,6 \%$ de proteína cruda digestible, en término de ganancia y peso final de los terneros, en que se superaron los $200 \mathrm{~kg}$. En los experimentos presentados en esta serie técnica, la suplementación de los terneros duró 98 a 126 días. Considerando que el creep feeding duplica la tasa de ganancia de peso de los terneros durante el período de aplicación de la tablilla nasal, queda abierta la oportunidad de explorar su efecto por un menor período de tiempo, antes y durante el período de destete temporario. Otro aspecto que resulta muy relevante es el impacto de mediano y largo plazo del creep feeding en las vaquillonas de reemplazo. Observamos que las vaquillonas que recibieron creep feeding tienen un crecimiento y desarrollo más acelerado compatible con una pubertad 12 a 54 días más temprana, y esto se asocia con una concepción más temprana (15-18 días) y un mayor porcentaje de preñez (30 \% superior) en vaquillonas entoradas con 13 -15 meses (Figura 9). Esta mayor eficiencia reproductiva se explica por mayores concentraciones de hormonas metabólicas, que tienen un impacto positivo en el funcionamiento del eje somatotrófico y en conjunto generan un ambiente uterino más propicio para el desarrollo embrionario temprano y el reconocimiento materno de la preñez. El efecto del creep feeding se visualiza todavía en la progenie de la vaca de primera cría con 2 años de edad. La vaca sometida a creep feeding cuando tenía 2 a 5 meses de edad, pare terneros más livianos y de menores dimensiones, aspecto que podría ser positivo para reducir el porcentaje de distocias (Figura 9). Sin embargo, el aspecto negativo es que producen menos leche y por lo tanto la tasa de ganancia de peso de sus terneros hasta los 90 días de edad se ve reducida, lo que se refleja en menores pesos vivos. Por lo tanto, el impacto económico del creep feeding en el sistema deberá evaluarse considerando los aspectos positivos y negativos de esta herramienta durante al menos los primeros 3 años de vida de la vaca. 



\title{
RECOMENDACIONES PRÁCTICAS PARA LA APLICACIÓN DE LA TÉCNICA DE CREE FEEDING
}

\author{
P. Cuadro ${ }^{1}$, V, Porcile ${ }^{1}$, C. Viñoles ${ }^{1}$
}

\section{ELECCIÓN Y PREPARACIÓN DEL POTRERO}

Según la experiencia de 9 años de investigación en la Unidad Experimental INIA Glencoe, se puede afirmar que la elección y preparación del potrero debe comenzar antes de la parición del rodeo. Esto permite realizar los movimientos de ganado pertinentes para poder reservar los potreros unos 45 días antes del inicio de la aplicación del creep feeding. El objetivo es comenzar con un acúmulo de forraje disponible cercano a los 2000 kg de materia seca por hectárea, manejándose en una altura promedio de 8 a $10 \mathrm{~cm}$. La asignación de forraje del par vaca-ternero no debe ser limitante y para ello debe superar los $6 \mathrm{~kg} \mathrm{MS} / \mathrm{kg}$ de peso vivo.

\section{ELECCIÓN DEL LUGAR DENTRO DEL POTRERO}

El lugar a elegir dentro del potrero debe ser de buen drenaje, seco y firme, en lo posible cerca del agua y con buena sombra, pero a la vez de fácil acceso para poder llegar en un vehículo para suministrar la ración y la sal a los animales. La estructura debe ser fácilmente identificable para que los animales visiten el área de suplementación, y contar con suficiente cantidad de luz. Es conveniente observar los hábitos del ganado para evitar ciertos lugares como paraderos y tener en cuenta zonas donde permanecen más tiempo o frecuentan más (zona cercana a abrevaderos, zonas de pastoreo y sombra).

\section{PREPARACIÓN DE LA INFRAESTRUCTURA}

Para armar el «corral» al cual acceden solamente los terneros se pueden utilizar diferentes materiales: hierro, madera o hasta un varejón atravesado en la portera de un corral. Las dimensiones del corral dependen de la cantidad de animales a suplementar y los puntos de acceso para los terneros deben ser por los 4 lados del área a utilizar. En los experimentos realizados en INIA, la altura de los travesaños fue entre 80 y $95 \mathrm{~cm}$ desde el nivel del suelo, los lados del corral fueron de 6,6 m, permitiendo así que los terneros pudieran entrar y salir fácilmente hasta alcanzar el tamaño del destete (Figura 10).

Se pueden utilizar comederos construidos con tarrinas plásticas, ubicados a lo largo, con un total de 6 metros, con acceso por ambos lados y elevados a unos $0,30 \mathrm{~m}$ del piso para evitar que pisoteen la ración, siendo conveniente que estén bajo un techo (Figura 10). Para asegurarnos que todos los terneros accedan al comedero y así minimizar el comportamiento de dominancia, se recomienda un espacio de 0,50-0,60 m por ternero, generando así una capacidad para unos 10 a 12 animales por cada lado del comedero.

Otra alternativa son los comederos de «autoconsumo» con la precaución de elegir raciones que se deslicen en forma correcta, sin que se atasquen al absorber humedad, y teniendo en cuenta que a esta edad los terneros son muy susceptibles a los olores y

${ }^{1}$ INIA, Instituto Nacional de Investigación Agropecuaria. 


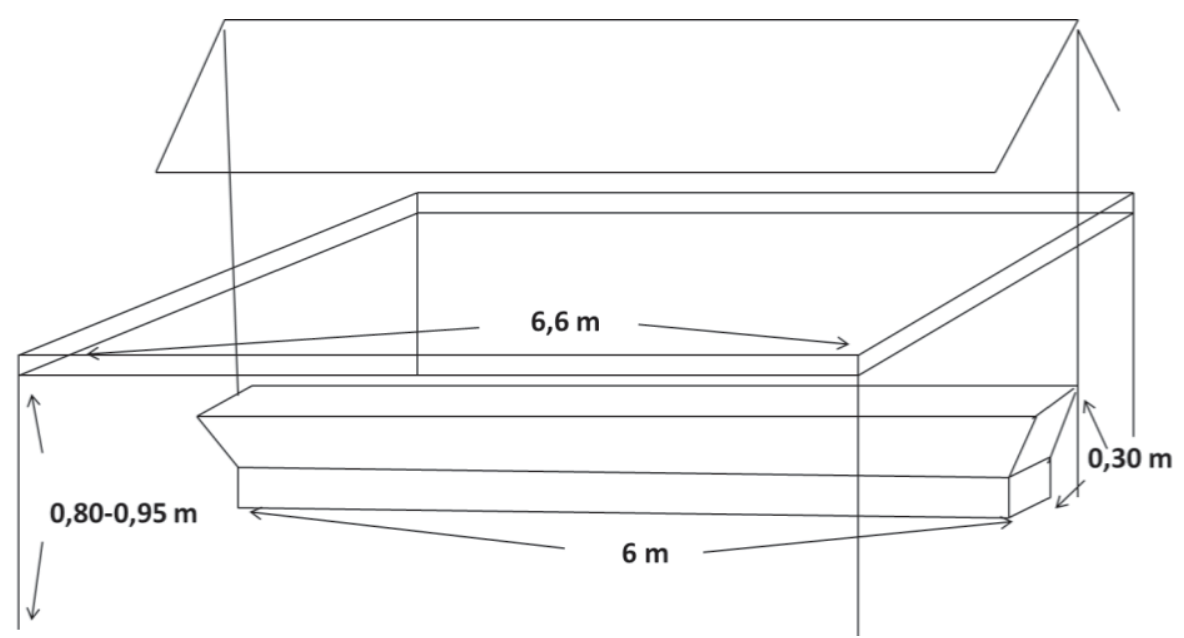

Figura 10. Representación esquemática del modelo del área de creep feeding utilizada en la unidad experimental Glencoe.

al sabor del suplemento. Basados en nuestra experiencia, no se recomienda el uso de afrechillo de arroz en terneros lactantes. Deben usarse raciones de buena calidad y palatabilidad, con un contenido proteico no menor a $18 \%$. El comedero donde se coloca la sal para las vacas debe estar a un lado del corral al que acceden los terneros, y debe de ser de 0,80 a 1,00 m de altura para que los terneros no tengan acceso a la mezcla mineral (Figura 11).

\section{LOTEO DE ANIMALES}

El loteo se puede hacer de varias formas según el objetivo productivo de cada establecimiento: por fecha de parición, por sexo, por categoría de madres (primíparas y multíparas). Es recomendable comenzar con terneros de aproximadamente 2 meses edad, porque a partir de esta edad la producción de leche de la vaca no alcanza para cubrir los requerimientos de los terneros, y comienza a disminuir su ganancia diaria de peso, lo que limita el peso al destete.

\section{SANIDAD}

Es necesario seguir un plan sanitario acorde a esta categoría animal, con el aval de un veterinario, para que no se vea afectado el desempeño productivo de los animales. En los experimentos llevados a cabo por INIA, antes del inicio de la alimentación preferencial se realizaron:

a) Vacunas contra Clostridiosis.

b) Antiparasitarios.

c) Vacunas contra Queratoconjuntivitis.

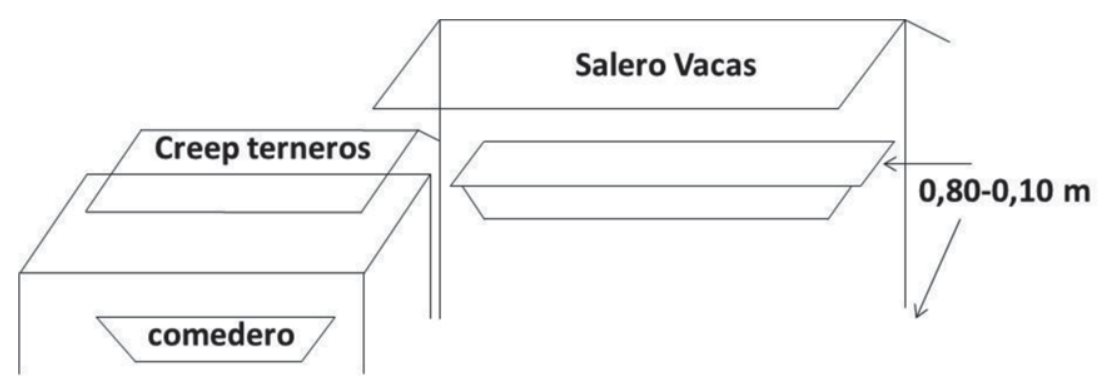

Figura 11. Representación esquemática del salero disponible para las vacas a un lado del área de creep feeding de los terneros. 


\section{APRENDIZAJE Y ACOSTUMBRAMIENTO}

El aprendizaje de los terneros a comer el suplemento es la clave del éxito de la aplicación de esta tecnología. Para ello se los puede pasar por las mangas y ponerles un puñado de ración en la boca y pasarles el suplemento por la nariz, para que puedan saborearlo y olerlo. La mejor forma de enseñar a comer a los terneros es junto a sus madres (que deben estar habituadas a comer suplemento), ya que por curiosidad y por imitación, acuden al comedero. Para lograr este objetivo, sin aumentar excesivamente los costos, se puede apartar un pequeño grupo de vacas de primera cría y/o pobre condición corporal, y ofrecerles el suplemento en comederos de una altura que permita el acceso de los terneros. Una vez que los terneros coman el suplemento (consumo que puede estimularse con el espolvoreo de la ración con melaza), se los puede distribuir junto a sus madres en los grupos de mayores dimensiones que se quieren suplementar en forma preferencial, para que enseñen a los demás terneros a comer. El acostumbramiento de la flora y fauna ruminal al suplemento debe ser gradual, durante un período de 7 a 10 días, comenzando en el primer día con una cantidad de ración al 0,2\% del peso vivo y aumentando gradualmente hasta llegar al $1 \%$ (o a la cantidad predefinida) del peso vivo promedio de los terneros en el día 10. Durante los primeros 10-15 días a un mes es conveniente arrimar a los animales hacia el área de creep feeding para que se habitúen a la misma, ya que una vez creado el hábito lo harán solos.

\section{MONITOREO Y MANEJO DE LOS ANIMALES}

Es importante chequear la ración remanente en los comederos con frecuencia y cada vez que se suministra, para evitar restos con mal olor y sabor. Es importante observar diariamente a los animales para detectar miasis, presencia de animales con diarrea por problemas de acidosis temporales, conjuntivitis, entre otros aspectos sanitarios. Es recomendable pesar a los animales quincenal o mensualmente para monitorear su evolución de peso y ajustar la cantidad de suplemento ofrecido.

\section{FIN DEL PERÍODO DE SUPLEMENTACIÓN}

La finalización del período de suplementación dependerá del objetivo de cada productor. No se recomienda realizar cambios abruptos en la cantidad y calidad de la dieta, ya que los mismos implican la adaptación de la flora y fauna ruminal y en la eficiencia del uso del alimento. Si el objetivo es aumentar el peso al destete para realizar una recría más rápida, no debería de disminuirse el plano nutricional ofrecido a los animales. Si se definiera suspender la suplementación con concentrados es conveniente comenzar 10 días antes, e ir reduciendo en forma gradual la cantidad de suplemento ofrecido desde el máximo (por ejemplo $1 \%$ del peso vivo) hasta retirarla en su totalidad, en un período de 7 a 10 días. 
Impreso en Editorial Hemisferio Sur S.R.L.

Buenos Aires 335

Montevideo - Uruguay

Depósito Legal 372.660/17 
INIA Dirección Nacional

Andes 1365, P. 12

Montevideo

Tel.: 59829020550

Fax: 59829023633

iniadn@dn.inia.org.uy

INIA La Estanzuela Ruta 50, Km 11

Colonia

Tel.: 59845748000

Fax: 59845748012

iniale@le.inia.org.uy

INIA Las Brujas

Ruta 48, Km 10

Canelones

Tel.: 59823677641

Fax: 59823677609

inia_lb@lb.inia.org.uy

INIA Salto Grande

Camino al Terrible

Salto

Tel.: 59847335156

Fax: 59847329624

inia_sg@sg.inia.org.uy

INIA Tacuarembó

Ruta 5, Km 386

Tacuarembó

Tel.: 59846322407

Fax: 59846323969

iniatbo@tb.inia.org.uy

INIA Treinta y Tres Ruta 8, Km 281

Treinta y Tres

Tel.: 59844522023

Fax: 59844525701 iniatt@tyt.inia.org.uy

www.inia.uy 